\author{
UNIVERSIDADE DE SÃO PAULO \\ ESCOLA DE ENGENHARIA DE SÃO CARLOS \\ DEPARTAMENTO DE ENGENHARIA DE ESTRUTURAS \\ MESTRADO EM ENGENHARIA DE ESTRUTURAS
}

CAMILA ALEXANDRINO MOURA

\title{
Aplicação de formulação baseada no Método dos Elementos Finitos Posicional na análise bidimensional elástica de compósitos particulados
}

SÃO CARLOS 

CAMILA ALEXANDRINO MOURA

\title{
Aplicação de formulação baseada no Método dos Elementos Finitos Posicional na análise bidimensional elástica de compósitos particulados
}

\begin{abstract}
VERSÃO CORRIGIDA
A versão original encontra-se na Escola de Engenharia de São Carlos

Dissertação apresentada ao Departamento de Engenharia de Estruturas da Escola de Engenharia de São Carlos, Universidade de São Paulo, como parte dos requisitos para obtenção do título de Mestre em Engenharia de Estruturas.
\end{abstract}

Orientador: Prof. Dr. Rodrigo Ribeiro Paccola

São Carlos

2015 
AUTORIZO A REPRODUÇÃO TOTAL OU PARCIAL DESTE TRABALHO, POR QUALQUER MEIO COONVENCIONAL OU ELETRÔNICO, PARA FINS DE ESTUDO E PESQUISA, DESDE QUE CITADA A FONTE.

Moura, Camila Alexandrino

M929a Aplicação de formulação baseada no Método dos Elementos Finitos Posicional na análise bidimensional elástica de compósitos particulados / Camila Alexandrino Moura; orientador Rodrigo Ribeiro Paccola. São Carlos, 2015.

Dissertação (Mestrado) - Programa de Pós-Graduação em Engenharia de Estruturas -- Escola de Engenharia de São Carlos da Universidade de São Paulo, 2015.

1. Compósitos Particulados. 2. Influência das Partículas. 3. Método dos Elementos Finitos Posicional. 4. Análise Não-Linear Geométrica. 5. Sólidos Bidimensionais. 6. Concreto. I. Título. 


\section{FOLHA DE JULGAMENTO}

Candidata: Engenheira CAMILA ALEXANDRINO MOURA

Título da dissertação: "Aplicação de formulação baseada no método dos elementos finitos posicional na análise bidimensional elástica de compósitos particulados."

Data da defesa: 05/05/2015

\section{Comissão Julgadora:}

Prof. Dr. Rodrigo Ribeiro Paccola (Orientador)

(Escola de Engenharia de São Carlos/EESC)

Prof. Titular Humberto Breves Coda

(Escola de Engenharia de São Carlos/EESC

Prof. Dr. Leandro Vanalli

(Universidade Estadual de Maringá/UEM)
Resultado:

ApROVADA

Aprovards

$\frac{\text { APROVASA }}{\text { (VTAEO OCNAEREACIA) }}$

Coordenadora do Programa de Pós-Graduação em Engenharia Civil (Engenharia de Estruturas):

Prof. Titular Humberto Breves Coda

Presidente da Comissão de Pós-Graduação:

Prof. Associado Paulo César Lima Segantine 

Para meus pais Moura e Lázara, por tudo o que fizeram e ainda fazem por mim.

Para meus irmãos Luiz e Carol, pela amizade e carinho. 



\section{AGRADECIMENTOS}

Ao professor Rodrigo Ribeiro Paccola pela orientação, solicitude, generosidade e apoio durante toda a realização do mestrado.

Aos professores Coda e Wladimir, e aos amigos de departamento Hugo, Socorro, Aref e Ketson pelas discussões e contribuições a esta dissertação.

Aos funcionários da biblioteca e do departamento de Pós-Graduação em Engenharia de Estruturas EESC-USP e ao suporte físico e técnico disponível em ambos.

Aos professores de engenharia civil da FACENS Milito e Usuda e aos demais professores que estiveram em alguma etapa da minha vida acadêmica, pelos ensinamentos.

A CNPQ e a CAPES, pela bolsa de estudos concedida.

Aos meus amados avós (in memorian), a D.Hilda (in memorian), e a todos os familiares e amigos que não citei, mas que de alguma forma, sempre estarão em minha memória.

A Deus, por esta conquista. 

"Que os vossos esforços desafiem as impossibilidades; lembrai-vos de que as grandes coisas do homem foram conquistadas do que parecia impossível."

Charles Chaplin 



\section{RESUMO}

MOURA, C. A. Aplicação de formulação baseada no Método dos Elementos Finitos Posicional na análise bidimensional elástica de compósitos particulados. Dissertação (Mestrado em Engenharia de Estruturas) - Departamento de Engenharia de Estruturas, Escola de Engenharia de São Carlos, Universidade de São Paulo, São Carlos, 2015.

A utilização de materiais compósitos tornou-se uma alternativa importante em muitas aplicações dentro de diversas áreas da engenharia, pois seus constituintes podem agregar propriedades mecânicas, térmicas e acústicas ao compósito, garantindo eficiência e baixo custo. Com isso, faz-se necessário um maior conhecimento do comportamento mecânico desses materiais diante das solicitações, principalmente no que diz respeito aos campos de deslocamento, deformações e tensões. O presente trabalho tem por finalidade a análise, em nível macroscópico, de estruturas bidimensionais elásticas constituídas de materiais compósitos particulados, utilizando formulação desenvolvida no contexto do Grupo de Mecânica Computacional (GMEC), do Departamento de Engenharia de Estruturas (SET), da Escola de Engenharia de São Carlos (EESC), da Universidade de São Paulo (USP), no qual se insere a presente pesquisa. A formulação utilizada baseia-se no Método dos Elementos Finitos Posicional (MEFP) e foi desenvolvida em nível mesoscópico por tratar da interação entre matriz e partículas. Tal formulação possibilita a consideração da interação partícula-matriz sem a necessidade de coincidência entre as malhas da matriz e das partículas e sem o aumento do número de graus de liberdade dos problemas, admitindo-se aderência perfeita entre as fases. A formulação considera material isotrópico e comportamento não-linear geométrico das fases. A aplicação da formulação foi aqui proposta com o intuito de avaliar a influência da geometria, tamanho, fração volumétrica, distribuição e propriedades mecânicas das partículas adotadas, no comportamento global da estrutura em nível macroscópico. Foram desenvolvidos e apresentados exemplos de aplicação, com comparação dos resultados numéricos das análises com resultados de ensaios experimentais encontrados na literatura, bem como com resultados de modelos matemáticos de homogeneização e modelos numéricos propostos por outros 
autores, que utilizaram o método dos elementos finitos e técnicas de homogeneização assintótica.

Palavras-chave: Compósitos Particulados, Influência das Partículas, Método dos Elementos Finitos Posicional, Análise Não-Linear Geométrica, Sólidos Bidimensionais, Concreto. 


\section{ABSTRACT}

\section{MOURA, C. A. Application of a Positional Finite Element Method based}

formulation on the elastic two-dimensional analysis of particulate composites. Dissertação (Mestrado em Engenharia de Estruturas) - Departamento de Engenharia de Estruturas, Escola de Engenharia de São Carlos, Universidade de São Paulo, São Carlos, 2015.

The use of composite materials has become an important alternative in many applications in different areas of engineering, because their constituents can add mechanical, thermal and acoustic properties to the composite, ensuring efficiency and low cost. Thus, it is necessary a better understanding of the mechanical behavior of these materials, mainly regarding displacement, stress and strain fields. This study aims to analyze, in macroscopic scale, two-dimensional elastic structures made of particulate composite materials, using formulation developed in the context of the Grupo de Mecânica Computacional (GMEC), of Departamento de Engenharia de Estruturas (SET), of Escola de Engenharia de São Carlos (EESC), of Universidade de São Paulo (USP). The formulation is based on the Positional Finite Element Method and was developed in mesoscopic level, considering the matrix-particles interaction and neglecting the interface, by means of kinematic relations used to ensure adherence of the particles to the matrix without introducing new degrees of freedom in the problem. The formulation considers isotropic material and geometric non-linear behavior of the composite phases. The application of the formulation was proposed in this work in order to evaluate the influence of geometry, size, volume fraction, distribution and mechanical properties of the particles adopted in the global behavior of the structure in macroscopic level. Numerical examples were developed and presented in order to compare the numerical results of the analysis with results obtained in experimental studies found in the literature, as well as results of mathematical models and numerical models using finite element method and the asymptotic homogenization technique.

Keywords: Particle Composite Materials, Influence of Particles, Positional Finite Element Method, Geometric Nonlinear Analysis, Two-Dimensional Solids, Concrete. 



\section{SUMÁRIO}

1. Introdução 19

1.1. Contextualização e justificativas $\quad 19$

1.2. Objetivo 23

1.3. Objetivos específicos e metodologia $\quad 24$

2. Revisão Bibliográfica $\quad 27$

2.1.Considerações Iniciais $\quad 27$

2.2.Homogeneização: Estudos analíticos e numéricos 32

2.3.Estudos experimentais 33

2.3.1. Concreto Natural 34

2.3.2. Concreto Leve 35

2.3.3. Concreto de alto desempenho 37

2.4.Estudos numéricos 39

3. Análise Bidimensional Elástica de Compósitos Particulados via MEFP 45

3.1.Relações cinemáticas - acoplamento partícula-matriz 45

3.2.Energia de Deformação 48

3.3.Equações de Equilíbrio: Método de Newton-Raphson 50

4. Exemplos 53

4.1. Exemplo 01: Avaliação do módulo de elasticidade de concretos com agregados leves $\quad 54$

4.2. Exemplo 02: Módulo de elasticidade de concretos de alto $\begin{array}{ll}\text { desempenho } & 60\end{array}$

4.3. Exemplo 03: Sólido bidimensional com geometria trapezoidal 65

4.4. Exemplo 04: Sólido bidimensional com inclusão de vazio 71

5. Considerações Finais 75

5.1. Propostas de Trabalhos Futuros 76

6. Referências Bibliográficas $\quad 77$ 



\title{
1. INTRODUÇÃO
}

Neste capítulo apresentam-se os aspectos gerais sobre os temas que norteiam os estudos relacionados à formulação utilizada na modelagem numérica do comportamento dos compósitos particulados. Com este propósito, são discutidos a natureza, o ambiente e a importância dos materiais compósitos, do método dos elementos finitos (MEF) e da não-linearidade geométrica nas análises realizadas, buscando localizar o trabalho no contexto geral dos temas envolvidos, apresentando-se ainda os objetivos e justificativas do presente trabalho.

\subsection{Contextualização e Justificativas}

\begin{abstract}
"Mais importante do que qualquer nova aplicação é o próprio conceito dos novos 'materiais'. Ele marca uma mudança da preocupação com substâncias à preocupação com estruturas, uma mudança de artesão a cientista como inventor do homem, uma mudança de química para a física como a disciplina básica, e uma mudança, sobretudo, a partir da experiência concreta da oficina de abstrair matemática, uma mudança começando com o que a natureza oferece para o que o homem quer realizar" (DRUCKER ${ }^{1}, 1969$ apud HERAKOVICH, 2012).
\end{abstract}

Materiais compósitos são estruturas constituídas em escala macroscópica por no mínimo dois componentes ou fases, com propriedades físicas e químicas nitidamente distintas em sua composição. Os materiais constituintes de cada fase mantém suas características individuais, porém, quando combinados, formam um composto com propriedades difíceis de obter usando apenas um dos componentes, Mendonça (2005). A grande versatilidade de fabricação e manipulação aliada à capacidade mecânica em aplicações estruturais levam os materiais compósitos às mais diferentes aplicações de engenharia, Guimarães (2006).

Em busca de melhores características físicas e químicas, aliando o design ao elevado desempenho mecânico, nota-se a crescente utilização de materiais compósitos, nas mais diversas áreas da engenharia, podendo-se citar aplicações em transportes aéreos e navais, habitações civis, comunicação, recreação,

\footnotetext{
${ }^{1}$ DRUCKER, P.F. The age of discontinuity. $1^{\text {a }}$ edição. New York, Harper \& Row, 1969
} 
automobilismo, biomecânica, esportes e demais segmentos que requerem alto desempenho mecânico e estabilidade estrutural, Callister (2001). O autor destaca ainda que a capacidade do ser humano de produzir e manipular os materiais que atendam às suas necessidades está intimamente ligada ao desenvolvimento e ao avanço das sociedades.

A área dos materiais compósitos pode ser considerada de abrangência multidisciplinar, uma vez que não se restringe a um único profissional; são químicos, cientistas de materiais, engenheiros químicos, engenheiros mecânicos e engenheiros estruturais que estão envolvidos com o desenvolvimento e aplicações dos compósitos, aumentado cada vez mais em número e qualidade (REDDY, 2004). O potencial dos materiais compósitos, como comentado, pode ser constatado na sua ampla aplicabilidade: são indispensáveis às indústrias aeroespacial, marítima, de transporte, de infraestruturas civis, bem como em aplicações de próteses médicas, placas de circuitos eletrônicos e equipamentos esportivos (CALLISTER, 2001; BARBERO, 2008; VASILIEV e MOROZOV, 2001; HERAKOVICH, 1998; REDDY, 2004). Sendo que é importante para a aplicabilidade dos materiais compósitos, conhecer as propriedades de cada constituinte e a relação entre elas, a fim de obter maior controle sobre as propriedades do material compósito resultante (MEHTA e MONTEIRO, 2008; CALLISTER, 2001).

Os materiais compósitos estão presentes desde o início dos tempos (HERAKOVICH, 2012), seja no corpo humano, nas plantas ou nos animais, despertando interesse de alguns nomes ilustres da ciência que estiveram envolvidos no estudo desses materiais, como JC Maxwell ${ }^{2}$ (1873), Lord Rayleigh ${ }^{3}$ (1892) e Albert Einstein ${ }^{4}$ (1906) apud Hashin (1983). E mesmo sendo um assunto de notoriedade há bastante tempo, os compósitos podem ser considerados novos materiais, uma vez que só a partir do início da década de 1960 os engenheiros e

\footnotetext{
${ }^{2}$ MAXWELL, J.C. Treatise on Electricity and Magnetism. 1를 edição. Oxford, Clarendon Press, 1973, p. 365.

${ }^{3}$ LORD RAYLEIGH. On the influence of obstacles arranged in rectangular order upon the properties of a medium. Philosophical Magazine, vol 34, p. 1270-1275, 1892.

${ }^{4}$ EINSTEIN, A. Eine Neue Bestimmung der Moleküldimensionen, in Annalen der Physik, vol.19, 1906, p. 289-306, vol. 34, 1911, p. 591-592 (errata). English translation in Investigations on the Theory of Brownian Motion, Dover, 1956, p. 36-62.
} 
cientistas começaram a explorar o potencial dos materiais compósitos com maior rigor (HASHIN, 1983; HERAKOVICH, 1998).

A simulação do comportamento mecânico dos materiais compósitos não é simples. Para aplicação desses materiais com segurança nos projetos de engenharia, faz-se necessária a realização de estudos com relação ao comportamento mecânico desses materiais diante das solicitações, a fim de prever de forma adequada as distribuições de tensões a que o material ou elementos estruturais constituídos por sua aplicação possam estar submetidos durante sua utilização.

Com a utilização e desenvolvimento de modelos numéricos mais precisos e representativos dos materiais e estruturas é possível estimar, de forma mais próxima do real, o comportamento da estrutura durante sua vida útil, quantificando a deterioração dos componentes estruturais e determinando os carregamentos limite e em serviço para serem usados em projetos.

Com o objetivo de buscar a representação do comportamento mecânico desses materiais, vários modelos numéricos vêm sendo propostos ao longo dos anos (ZIENKIEWICZ et. al., 2013). Na maioria das vezes esses modelos numéricos, ou formulações, baseiam seus desenvolvimentos em métodos de energia, com aplicação direta do Método dos Elementos Finitos (MEF) (LI e LIU, 2002; TOULEMOND et. al. 2008; WANG et. al. 1999b). A aplicação do MEF, atrelada a técnicas de armazenagem de dados de problemas esparsos, apresenta vantagens para o tratamento de problemas com consideração de matérias compósitos com inclusões, sejam de fibras ou de partículas, devido ao grande número de informações geradas e necessárias à obtenção de resultados.

Voltando um pouco à origem do método dos elementos finitos, que não está associado a uma época ou apenas a um único autor, é possível afirmar que foi com a rápida evolução e expansão da ciência da computação que o método dos elementos finitos passou a ser mais difundido e aplicado em diversas áreas (ASSAN, 2003; ZIENKIEWICZ et. al., 2013).

$\mathrm{Na}$ modelagem numérica de meios contínuos, em alguns casos mais específicos, é desejável que se considerem os efeitos das não-linearidades física e geométrica nas análises. A não-linearidade física está associada ao comportamento não-linear da lei constitutiva adotada para representação da relação tensão $\mathrm{x}$ deformação envolvida nos modelos, já a não-linearidade geométrica está associada 
à importância que a mudança da geometria terá na configuração equilibrada deslocada do corpo, não sendo conveniente adotar a configuração indeformada como configuração para determinação do equilíbrio do problema (BONET e WOOD, 1997). Em geral, os códigos baseados no método dos elementos finitos, usados na modelagem de estruturas esbeltas e com grandes deslocamentos e deformações, utilizam as referidas não-linearidades em suas formulações (SORIANO, 2003).

Voltando aos compósitos, na maioria das vezes esses materiais se apresentam na forma de matrizes reforçadas por fibras ou partículas, bem como na forma de laminados, reforçados ou não por fibras e/ou partículas, podendo ser constituídos por camadas de diferentes materiais e com propriedades mecânicas distintas, proporcionando características específicas ao conjunto.

O presente trabalho se destina à análise do comportamento, em nível macroscópico, de matérias compósitos particulados, com ênfase ao concreto, utilizando para tanto uma formulação baseada no método dos elementos finitos posicional para meios elásticos bidimensionais. A formulação utilizada foi desenvolvida no contexto do Grupo de Mecânica Computacional (GMEC), do Departamento de Engenharia de Estruturas (SET), da Escola de Engenharia de São Carlos (EESC), da Universidade de São Paulo (USP), no qual se insere a presente pesquisa.

Por se tratar de formulação baseada no método dos elementos finitos posicional, a não-linearidade geométrica é considerada naturalmente na formulação, porém, não serão considerados os efeitos da não-linearidade física nas análises, limitando-se as aplicações ao regime elástico. A formulação utilizada, que pode ser considerada como desenvolvida em nível mesoscópico por tratar da interação entre matriz e partículas, segue a mesma ideia dos trabalhos desenvolvidos por Vanalli (2004), Baiocco et. al. (2013) e Sampaio (2014), onde compósitos reforçados com fibras são analisados, sem necessidade de coincidência entre as malhas da matriz e das partículas e sem o aumento do número de graus de liberdade dos problemas, sendo estas consideradas vantagens para a abordagem numérica de compósitos reforçados.

Por seguir a mesma estratégia dos trabalhos citados, uma terceira fase do compósito particulado, que é a interface entre a matriz e as partículas, é desconsiderada e a aderência perfeita entre as duas fases é assumida. 
Nos capítulos seguintes apresentam-se a revisão bibliográfica e as formulações do elemento bidimensional utilizado na modelagem tanto da matriz como das partículas, bem como a parcela da formulação responsável pelo acoplamento entre as duas fases sem o acréscimo dos graus de liberdade. Essas formulações são apresentadas resumidamente, sendo que os detalhes podem ser consultados diretamente nos trabalhos de Vanalli (2004), Baiocco et. al. (2013) e Sampaio (2014). São apresentados também os exemplos de aplicação da referida formulação, com as comparações dos resultados numéricos das análises com resultados de programas experimentais encontrados na literatura, bem como com resultados de modelos matemáticos de homogeneização e modelos numéricos propostos por outros autores, inclusive utilizando o método dos elementos finitos e técnicas de homogeneização assintótica.

O objetivo da presente proposta, que consiste ainda em validar a metodologia desenvolvida no GMEC/SET/EESC/USP para consideração de compósitos particulados, desperta interesse para engenharia de estruturas, uma vez que se apresenta mais econômica, no que se refere ao custo computacional, que as metodologias tradicionais para tratamento desses materiais, justificando assim 0 desenvolvimento de pesquisas e contribuições nesta área.

\subsection{Objetivo}

O objetivo principal desta pesquisa consiste em modelar estruturas bidimensionais elásticas constituídas de materiais compósitos particulados, avaliando, entre outras coisas, a influência da geometria, tamanho, fração volumétrica, distribuição e propriedades mecânicas das partículas adotadas, no comportamento da estrutura em nível macroscópico. Serão realizadas tais verificações tanto em análises com células periódicas, para obtenção de propriedades físicas homogeneizadas, quanto em análises de problemas com dimensões reais, que simulam estruturas compostas de partículas dispersas aleatoriamente para obtenção dos campos de deslocamentos.

Como dito anteriormente, será utilizada formulação desenvolvida e implementada no contexto do GMEC/SET/EESC/USP para tais aplicações. A 
formulação se baseia no método dos elementos finitos posicional, sem aumento dos graus de liberdade do sistema.

\subsection{Metodologia}

A metodologia adotada para atingir o objetivo principal da presente pesquisa pode ser dividida nas seguintes etapas:

a. Levantamento bibliográfico sobre os assuntos relacionados ao tema da dissertação;

b. Familiarização com a formulação desenvolvida e implementada no GMEC/SET/EESC/USP, inclusive com o código resultante das referidas implementações, permitindo sua utilização nas análises desejadas;

c. Desenvolvimento de gerador de partículas, possibilitando a distribuição destas de forma aleatória ou estruturada em domínios bidimensionais. Nesta etapa também foi incorporada no gerador a possibilidade de geração de partículas com geometrias pré-definidas ou aleatórias. Vale lembrar que as representações das partículas são sempre compostas por elementos finitos triangulares com ordem de aproximação qualquer para as posições nodais;

d. Estudo da estratégia utilizada para identificação das posições de inserção da malha das partículas na malha da matriz. Neste ponto vale lembrar que o acoplamento matriz-partículas, com aderência perfeita, para se simular o compósito foi obtido ao se inserir o elemento de chapa (que simula a partícula) dentro de outro elemento de chapa (que simula a matriz). O Método adotado nesta etapa consiste em escrever as posições nodais da partícula em função das posições nodais dos nós dos elementos finitos de chapa no meio onde estão imersas, processo análogo ao adotado em Vanalli (2004); Sampaio et. al. 
(2011); Baiocco et. al. (2013); Sampaio (2014) e Nogueira et. al. (2014), onde as fibras foram inseridas em uma posição qualquer do domínio sem aumentar o número de graus de liberdade do sistema e sem necessidade de coincidência das malhas.

e. Familiarização com os programas de apoio, desenvolvidos no SET/EESC/USP, sendo um deles o AcadMesh2D, que consiste em CAD acoplado a um gerador de malhas que considera as informações do domínio bidimensional sólido modelado e as condições de contorno, possibilitando a geração de arquivos de entrada de modelos de elementos finitos; e o outro AcadView, que consiste em programa para pós-processamento de resultados em elementos finitos;

f. Familiarização com o programa comercial Ansys ${ }^{\circledR}$, para geração das malhas necessárias para as simulações numéricas;

g. Escolha dos exemplos a serem modelados, de tal forma que a validação da metodologia adotada tenha como referência outros modelos numéricos, experimentais e teóricos, seguida da montagem dos arquivos de entradas de dados para o programa desenvolvido no GMEC/SET/EESC/USP;

h. Simulação numérica dos exemplos escolhidos, considerando diferentes tipos de concretos, discutindo-se a influencia da geometria, do tamanho, da porcentagem e das propriedades mecânicas das partículas inseridas no domínio, no que se refere ao comportamento macroscópico dos modelos, tanto para obtenção de módulos de elasticidade longitudinal do material homogeneizado, quanto para análise do comportamento global em deslocamento da estrutura; 


\section{REVISÃO BIBLIOGRÁFICA}

Neste capítulo apresentam-se a definição e classificação de materiais compósitos, identificando os compósitos particulados em especial, bem como a escala de análise adotada na presente pesquisa. Apresentam-se ainda os levantamentos bibliográficos mais diretamente relacionados aos estudos teóricos, numéricos e experimentais de materiais compósitos, com destaque aos particulados, bem como aos estudos que apresentam formulações que são relacionadas à formulação utilizada na modelagem dos exemplos.

\subsection{Considerações Iniciais}

Os compósitos, que são uma subdivisão dos materiais dentro da Engenharia dos Materiais, consistem na combinação, em escala macroscópica, de dois ou mais materiais diferentes. Um material composto é concebido para apresentar propriedades melhores do que as encontradas isoladamente em cada material que 0 constitui (CALLISTER, 2001).

Evitando que todo material técnico seja considerado um compósito, a definição foi estendida, segundo Callister (2001) e Rosler (2007), como um material multifásico que exibe uma proporção significativa das propriedades de ambas as fases constituintes, em que o material é feito artificialmente e as fases constituintes são quimicamente diferentes e separadas por uma interface distinta. Além disso, a maioria dos compostos foi criada para melhorar as combinações de características mecânicas, tais como a rigidez, a dureza e a resistência ao ambiente e a altas temperaturas (CALLISTER, 2001).

Diversas classificações dos materiais compósitos são encontradas na literatura. Uma das que melhor distribui os diferentes tipos de compósitos é a apresentada na Figura 2.1.

$\mathrm{Na}$ literatura é possível encontrar estudos que tratam dos materiais compósitos como laminados, fibrosos, particulados e também como painéis 'sanduiche' (Barbosa et. al., 2012). Quanto aos laminados, algumas teorias e modelos associados a elementos finitos de estruturas compostas são discutidas em Reddy (2004), onde placas e cascas são analisadas. 


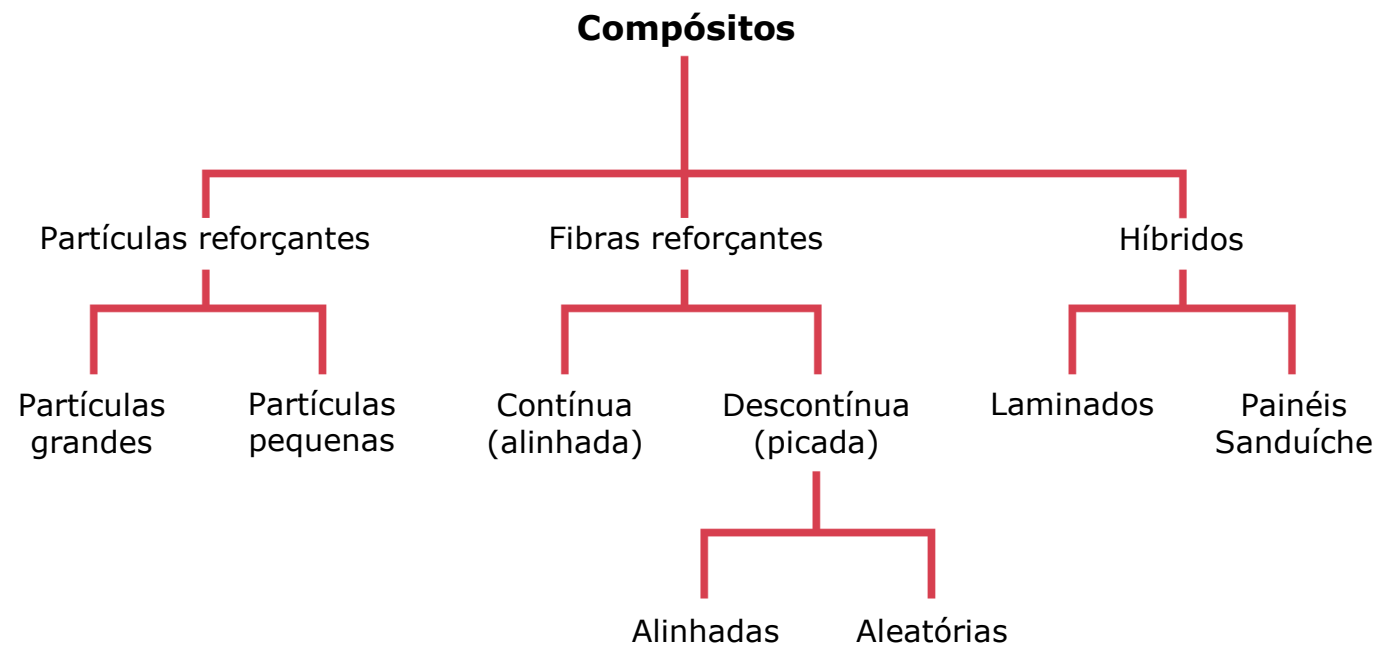

Figura 2.1 - Classificação de materiais compósitos.

FONTE: adaptado de Callister (2001)

No que diz respeito às análises linear e não-linear geométrica de estruturas laminadas, Zhang e Yang (2006) apresentaram uma formulação para placas compostas, utilizando elementos finitos planos quadrilaterais e triangulares, que consistem na combinação entre membrana e comportamento à flexão. Os autores utilizaram uma abordagem Lagrangiana Total, baseando-se diretamente na teoria de primeira ordem de deformação de cisalhamento para placas de compósitos laminados. Como método de obter elementos de placa laminado compósito, empregaram as funções de viga de Timoshenko, cujas funções de deslocamento podem ser aplicadas às placas grossas e finas.

Por outro lado, a versão não-linear da teoria generalizada laminada de Reddy (2004) é apresentada com a utilização de elemento de placa em Barbero e Reddy (1990) e Petyt el. al. (1994) e com a utilização de elemento de casca em Han el. al. (2008).

Callister (2001) subdivide os compósitos de partículas de reforço em partículas pequenas e partículas grandes, que serão abordadas neste estudo. Lembrando ainda, que o termo "grande", ou particulado, indica que as interações de partículas na matriz não podem ser tratadas como atômica ou de nível molecular, como acontece com as partículas "pequenas". Na maioria dos compostos de partículas grandes, a fase de partículas é mais dura e mais rígida do que o da matriz, mas nem sempre isso ocorre. Essas partículas reforçantes tendem a restringir o movimento da fase de matriz na vizinhança de cada partícula. 
Além disso, o grau de reforço ou melhoria do comportamento mecânico depende da ligação forte na interface matriz - partícula. Na Figura 2.2, é possível notar a diferença entre fibras e partículas reforçantes.

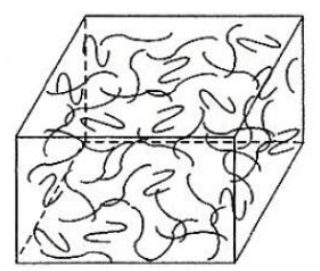

(a)

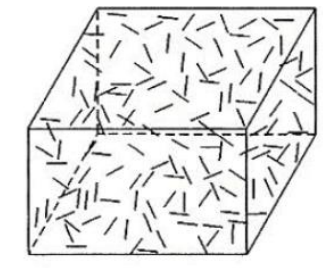

(b)

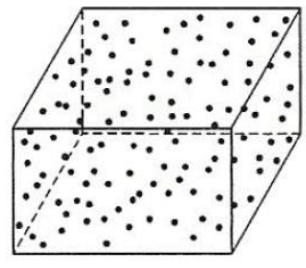

(c)

Figura 2.2 - (a) Fibras longas, (b) fibras curtas e (c) compósitos particulados.

(Fonte: KOLLÀR, 2003)

O concreto é um dos materiais compósitos mais populares (YANG et al., 1995; CALLISTER, 2001; Tu; Lu, 2011a), sendo o material mais largamente usado na construção civil. O consumo do concreto corresponde a dez vezes o consumo do aço em muitos países e nenhum outro material é consumido em tal quantidade, a não ser a água (MEHTA e MONTEIRO, 2008). Composto de cimento, agregado miúdo, agregado graúdo e água, ele é fácil de moldar em qualquer forma, e altamente resistente a ambientes marinhos (YANG et al., 1995). Quanto ao agregado, ele não serve só para, moderadamente, aumentar a rigidez e resistência à fratura; mas, tem a adicional vantagem de agir como um material de enchimento. Dessa forma, ocorre a redução do custo global do concreto, ao contrário do cimento que é relativamente caro (ROSLER, 2007; CALLISTER, 2001). Este é um exemplo que a estrutura interna de um material deve ser levada em consideração, tanto no concreto, nas ligas metálicas ou ainda em outros compósitos.

A maioria dos modelos clássicos é baseada no pressuposto de que o material pode ser representado como contínuo homogêneo, em que o comportamento é descrito independente da estrutura do material. Nesse caso, os únicos componentes geométricos são formados pelo tamanho e forma da estrutura considerada (VAN MIER, 1997). Mas, apesar da composição do concreto muitas vezes não ser considerada, o concreto é um material de multiescala. Segundo Van Mier (1997); Zaitsev e Wittmann (1981), o concreto apresenta o nível nano, micro, meso e macro de observação. Um diagrama é apresentado na Figura 2.3, em que há três escalas principais, que são destacadas para a investigação do concreto. 


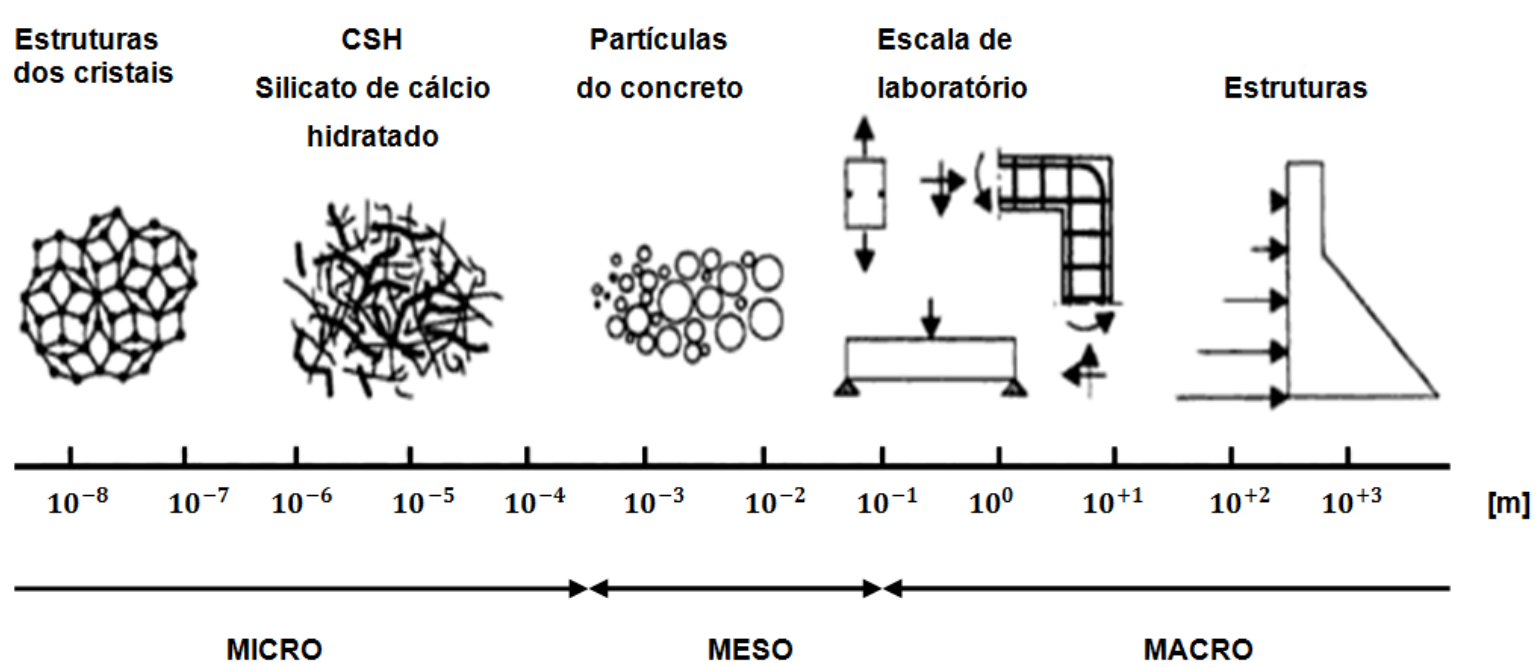

Figura 2.3 - As diversas escalas de observação que devem ser consideradas, quando se estuda materiais e estruturas (Fonte: Van Mier, 1997)

Os três níveis de observação novamente são mostrados na Figura 2.4, distinguindo as características estruturais que são importantes em cada nível, de acordo com Van Mier (1997). No nível micro, a estrutura interna de cimento e pasta de cimento endurecido é a característica estrutural mais importante. No nível meso, analogamente como ocorre no presente estudo, a estrutura da partícula é mais importante, e a heterogeneidade do material é o motivo do aparecimento de concentrações de tensão locais. No macro, nível em que os engenheiros estruturais trabalham, em geral, a estrutura do material interno não é reconhecida, desconsiderando-se os efeitos de interface entre as fases.

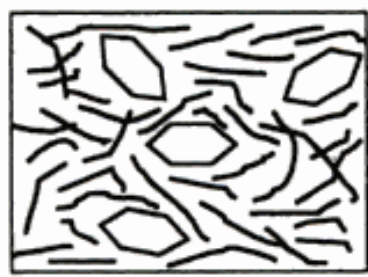

(a)

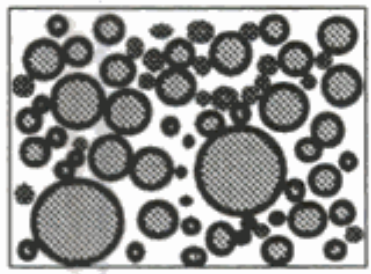

(b)

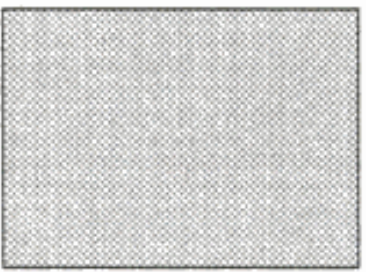

(c)

Figura 2.4 - Definição da escala de cimento e concreto (a) micro (b) meso e (c) macro (Fonte: Van Mier, 1997)

Assim, igualmente ao que foi adotado no presente estudo, o concreto pode ser considerado bifásico (MEHTA e MONTEIRO, 2008). As duas fases, compostas da matriz de cimento e de partículas de agregado, podem ser facilmente distinguidas 
numa seção polida de um 'corpo-de-prova' de concreto, conforme Figura 2.5, desprezando-se a influência da interface matriz-partícula, considerando tal ligação como de aderência perfeita.

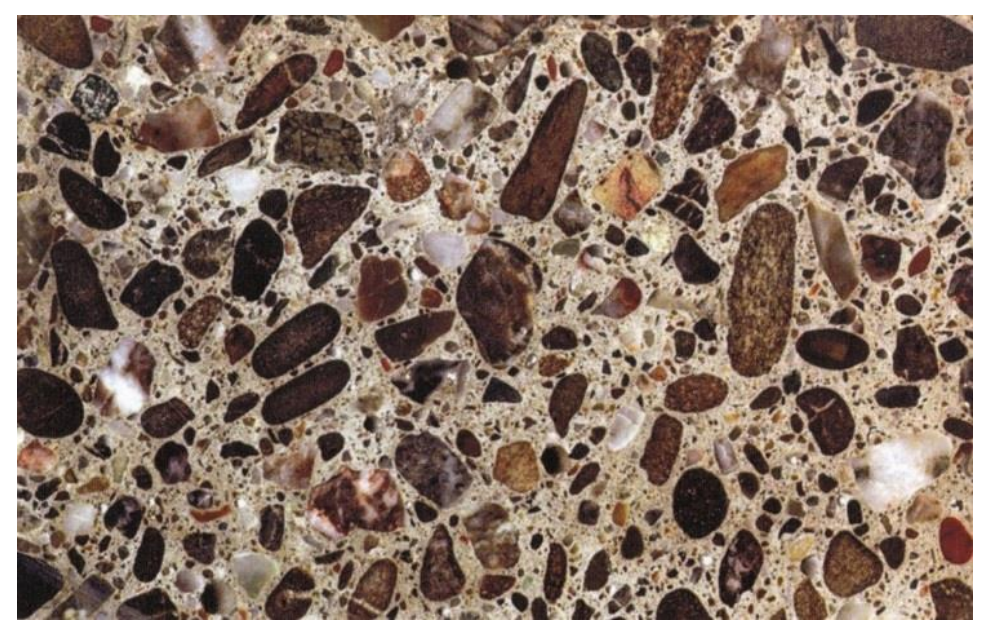

Figura 2.5 - Partículas de agregado de tamanho e forma variados dispersas, aleatoriamente, no meio ligante de pasta endurecida. Fonte: Mehta e Monteiro (2008)

Segundo Allen (2001), as perdas de precisão na análise do dano, podem não ser significativas quando as escalas de análise são significativamente diferentes. Zaitsev e Wittmann (1981), apontam como principal defeito de uma estrutura, as rachaduras advindas do vínculo entre inclusões e matriz, situações causadas por sedimentação e secagem de encolhimento. Em virtude disso, esses autores propõem, como ideal, os parâmetros de análises na escala de comprimento anterior ao nível que se objetiva explicar (WANG et. al. 1999a; ALLEN, 2001; ZAITSEV e WITTMANN, 1981; VAN MIER, 1997, TU e LU, 2011a). Sob o mesmo ponto de vista, o presente estudo considera os parâmetros de análise do nível meso para se explicar o comportamento da estrutura no nível macro.

No que segue, apresentam-se no item 2.2 estudos teóricos e numéricos que adotam a técnica de homogeneização em materiais compósitos como estratégia para abordagem dos problemas. No item 2.3 apresentam-se estudos experimentais sobre o concreto 'natural', o concreto leve, o concreto permeável e o concreto de alta resistência. No item 2.4 apresentam-se estudos numéricos sobre a influência da partícula no concreto e nas ligas metálicas, bem como estudos numéricos que abordam formulações relevantes para a presente proposta. 


\subsection{Homogeneização: Estudos Analíticos e Numéricos}

Os processos de homogeneização tomam como referência a modelagem das estruturas em escalas menores que a macroscópica e são usados para avaliar as propriedades elásticas homogeneizadas do material compósito considerando as propriedades elásticas dos constituintes de cada fase, ou seja, matriz e reforços (Barbero, 2008).

As técnicas de homogeneização são divididas por Milton (2004) em homogeneização do ponto de vista intuitivo, homogeneização periódica, homogeneização em mídia aleatória e homogeneização baseada em diferentes estratégias de convergência, sendo esta divisão promovida em virtude dos diversos trabalhos com diferentes abordagens encontrados na literatura e apresentados pelo autor.

De acordo com o trabalho de Willis ${ }^{5}$ (1983) apud Prado (2013), os diferentes métodos propostos para estudo do comportamento mecânico dos compósitos estão divididos em quatro grandes categorias, a saber: métodos assintóticos, autoconsistentes, variacionais e métodos de modelagem, sendo que os detalhes de cada uma dessas abordagens podem ser encontrados nos referidos trabalhos.

Estudos analíticos de homogeneização foram realizados por Eshelby (1957); Eshelby (1959) e Hashin; Shtrikman (1963); Hill (1965); Mori e Tanaka (1973); Hashin (1983); Allaire (1992), sendo que os limites elásticos médios para materiais compósitos foram obtidos em Voigt $\left(\mathrm{VOIGT}^{6}, 1889\right.$ apud YANG et. al., 1995) para o limite superior e Reuss (REUSS ${ }^{7}, 1929$ apud YANG et. al., 1995) para o limite inferior. Entre esses autores, Yang e Huang (1996) realizaram um trabalho teórico de homogeneização de compósitos particulados fundamentado por Eshelby (1957) e Mori e Tanaka (1973), no qual um modelo teórico para estudar o comportamento elástico do concreto, ao considerar um composto de três fases distintas (dupla inclusão), foi apresentado. Além disso, os resultados obtidos das propriedades elásticas foram amplamente comparados com os resultados experimentais.

\footnotetext{
${ }^{5}$ Willis, J.R. The overall elastic response of composite materials. J. Appl. Mech.,v. 50, n. 4b, p. 1202-1209, 1983.

${ }^{6}$ W. Voigt, Ueber die Beziehung zwischen den beiden Elasticitätsconstanten isotroper Körper, Wied. Ann. 38 (1889) 573-587.
}

7 A, Reuss Berechnung der Fließgrenze von Mischkristallen auf Grund der Plastizitätsbedingun für Einkristalle, Z. Angew. Math. Mech.9 (1929) 49-58 
Dentre os estudos numéricos de homogeneização (MICHEL at. al., 1999; ALLEN, 2001), o modelo de homogeneização de meios aleatórios, utilizando métodos variacionais foi realizado por Toulemond et al. (2008), que utilizou o método dos elementos finitos com diferentes tamanhos de malhas de célula unitária dos elementos de inclusão com geometria esférica. Os autores também apresentaram os resultados das relações entre as propriedades elásticas de matriz e inclusões, que representam a argamassa e os agregados.

Farage et. al. (2009) realizaram análise numérica via método dos elementos finitos e homogeneização de expansão assintótica $(\mathrm{AEH})$, que consiste numa técnica multiescala que é aplicada à meios periódicos para estimar as propriedades mecânicas dos compósitos, no caso concretos, cuja formulação de problemas de elasticidade linear foi implementada em programa de manipulação simbólica, com a adoção de elementos planos bidimensionais. Este estudo numérico considera concretos leves, homogeneizado num meio bifásico, fabricados com a mesma argamassa (matriz) composta de cinco tipos de agregados leves de argila expandida, com frações volumétricas variadas, que correspondem a 12,5\%, 25,0\%, $37,5 \%$ e $45,0 \%$. A fim de verificar a influência da geometria da inclusão no resultado homogeneizado, foram adotadas no referido estudo três formas geométricas simples para modelar a inclusão nas células periódicas. Ao comparar os resultados obtidos, de problemas simples, com estudos experimentais, os autores constataram potencialidade na técnica empregada para a simulação do módulo de elasticidade homogeneizado de concretos e resistência à compressão. Segundo os autores, mais estudos precisam ser feitos para verificar a influencia da geometria das partículas no concreto, visto que as três geometrias diferentes parecem ter sido mais influenciadas por aspectos relacionados à malha de elementos finitos adota nas análises.

\subsection{Estudos Experimentais}

O módulo de elasticidade pode descrever o comportamento mecânico do concreto (ABDELGADER, 2003) e também de outros compósitos. No projeto de concreto armado e protendido, os módulos elásticos de materiais estruturais são parâmetros muito importantes, particularmente no que se refere aos níveis de 
deslocamentos (KLISZCZEWICZ e AJDUKIEWICZ, 2002) e na concepção de elementos estruturais com base na rigidez Yang et. al. (1995). Como resultado, muitos estudos experimentais foram desenvolvidos com o propósito de se analisar o módulo de elasticidade, equivalente ou homogeneizado, do compósito a partir das propriedades elásticas dos constituintes da matriz e das partículas para diferentes tipos de concretos.

\subsubsection{Concreto "Natural"}

Yang et. al. (1995) realiza um ensaio experimental e compara através de previsões teóricas o efeito do agregado no módulo de elasticidade de materiais compósitos a base de cimento. O autor utilizou diferentes tipos e formas de agregados, isto é, aço esférico, vidro esférico, cascalho arredondado, pedra britada angular, para mostrar que os diferentes tipos e as frações de volume, que variam em $10 \%, 20 \%$ e $30 \%$, afetam significativamente o módulo de elasticidade dos materiais compósitos de concreto e os resultados experimentais se aproximam muito das previsões teóricas, onde o módulo de elasticidade foi calculado baseado nos limites de Hashin-Shtrikman (HASHIN E SHTRIKMAN, 1963) e na micromecânica clássica. Os módulos de elasticidade e coeficientes de poisson diminuem à medida que a relação água/cimento aumenta. Os resultados dos testes mostram ainda que quando o módulo de elasticidade e a fração de volume do agregado aumentam, o módulo de elasticidade do compósito melhora.

Palmquist et. al. (2001) estudaram como as diferentes frações de volume, $15 \%$, 33\% e 50\%, de agregados de solo vitrificados afetam o desempenho mecânico do concreto em relação ao concreto feito com agregado graúdo natural. Os resultados experimentais mostraram que para grandes frações de volume a forma irregular do agregado vitrificado (alongada com extremidade afiada) e sua textura lisa tornam, consequentemente, o concreto rígido e a ligação entre as fases pobre, o que diminui a resistência à compressão. Por outro lado, o solo vitrificado, por possuir módulo de elasticidade elevado, pode aumentar consideravelmente o módulo de elasticidade do concreto. Enquanto que para o concreto de agregados naturais, com o aumento da fração de volume de $0 \%$ a $50 \%$, não existe qualquer alteração perceptível no módulo de elasticidade. 
Abdelgader (2003) realizou ensaios experimentais com três tipos de agregados graúdos, sendo: arredondado, achatado e misto; e três proporções de misturas diferentes de argamassa para a análise da relação tensão-deformação, módulo de elasticidade e resistência à compressão do concreto intitulado 'dois estágios'. A análise revelou que curvas de tensão deformação obtidas para este concreto, onde os agregados graúdos (maior proporção) são colocados numa forma e posteriormente é injetada argamassa para preencher os espaços vazios entre os agregados, são afetados principalmente pelas propriedades físicas do agregado graúdo. É possível supor que a carga aplicada é distribuída principalmente através do 'esqueleto total', o que impossibilita considerar este concreto como isotrópico. As observações de ensaio e análise mostram que a parte linear da curva de tensãodeformação pode atingir tanto $40 \%$ quanto $60 \%$ da resistência à compressão das amostras.

\subsubsection{Concreto Leve}

Crouch et. al. (2007) investigaram os efeitos que a gradação, a quantidade e o tamanho do agregado graúdo exercem sobre o módulo de elasticidade estático do concreto permeável de cimento portland (PCC), considerando quatro tipos de misturas diferentes. Através dos ensaios experimentais, os autores constataram que para este concreto, composto de cimento portland, água, agregado graúdo, e, em alguns casos, aditivos químicos ou materiais complementares de cimentação, o aumento do valor de agregado resultou em uma diminuição estatisticamente significativa na força de compressão e módulos de elasticidade estático devido à consequente diminuição da quantidade de pasta cimentícia. Entretanto, não houve diferença significativa entre o módulo elástico estático do concreto quando foram utilizados diferentes tamanhos de agregados, enquanto que para as misturas com agregados de tamanho menor as forças de compressão foram superiores.

CUI et. al. (2012) realizaram um estudo experimental para verificar a influência da fração de volume, que varia entre $30 \%, 40 \%$ e 50\%, e as propriedades do agregado leve nas propriedades mecânicas e fragilidade do concreto. Para isso cinco diferentes tipos de agregados graúdos com diferentes densidades e origens foram considerados nos ensaios, isto é, dois tipos de agregados de argila expandida 
de forma esférica, com dimensões diferentes, também foram considerados um tipo de argila expandida de forma alongada, um agregado de xisto expandido e por último um agregado que consiste na mistura de xisto e cinza de combustível pulverizado. Os resultados desta proposta de ensaio foram avaliados e os autores observaram que o formato dos agregados propostos exerce grande influência sobre as propriedades mecânicas do concreto leve resultante da mistura. A influência que o volume, a densidade e a tensão de esmagamento das partículas de agregados graúdos leves geram no pico de tensão, na deformação e no módulo de elasticidade do concreto de agregados leves são avaliados. Conforme sugere a literatura, com o aumento do volume de agregados leves ocorre, em geral, uma diminuição do pico de tensão e do módulo de elasticidade longitudinal.

KE et. al. (2009) investigaram, através de um estudo experimental, a influência que o volume e as características dos agregados leves, de diferentes locais de fabricação, exercem sobre as propriedades mecânicas do concreto, tal como resistência à compressão e módulo de elasticidade. O estudo considera seis tipos agregados de argila e o xisto expandidos, considerando variadas frações de volume e qualidade dos agregados. Aspectos como a densidade, a geometria, a espessura da casca, a porcentagem de poros dilatados e grãos quebrados destes agregados também são considerados. Os agregados de argila chegam a ser nodulares a quase esféricos, já os agregados de xisto são mais irregulares e constituídos por vários tipos de grãos correspondentes a diferentes graus de extensão. A rigidez do agregado leve é 3,5 a 4 vezes menor do que a matriz de cimento, assim, o módulo de elasticidade do concreto de agregado leve diminui com o aumento da fração em volume de agregados leves, onde os valores são ainda menores para o agregado de xisto. $O$ módulo de elasticidade e a resistência do concreto são efetivamente influenciados pela densidade do agregado. Para os agregados de densidade inferior a $1000 \mathrm{~kg} / \mathrm{m}^{3}$ o módulo de elasticidade e a resistência à compressão do concreto leve são fortemente afetados pela fração de volume de agregado. Por outro lado, os agregados com densidades de, respectivamente, $1430 \mathrm{~kg} / \mathrm{m}^{3}$ e $1570 \mathrm{~kg} / \mathrm{m}^{3}$, o aumento da fração em volume diminui o módulo de elasticidade de concretos, mas não ocorre a redução da resistência à compressão. 


\subsubsection{Concreto de Alto Desempenho}

Zhou et.al. (1995) realizam um estudo experimental para verificar o efeito que o agregado graúdo gera no módulo de elasticidade e na resistência a compressão de concretos de alto desempenho. Para isso, os autores utilizaram seis tipos de materiais diferentes, a saber: Argila Expandida, Cinza Volante, Calcário, Cascalho, Vidro e Aço; bem como empregaram uma porcentagem de volume fixa para argamassa, e agregados de $42,5 \%$. Os autores realizaram ensaios experimentais para concluindo que o agregado graúdo reflete no módulo de elasticidade do concreto e que aos 28 dias este concreto já apresentava 95\% do seu valor de módulo de elasticidade e teve pouca alteração nas idades posteriores. Com exceção de agregados de rigidez muito alta e muito baixa, os valores do módulo de elasticidade foram bem previstos pelos modelos teóricos apresentados no referido trabalho para comparação, sendo que os resultados experimentais se aproximaram mais dos obtidos no Modelo Teórico de Couto (ZHOU et.al., 1995).

Baalbaki et. al. (1991) realizaram um estudo experimental para verificar a Influência do agregado graúdo nas propriedades elásticas do concreto de alto desempenho. Três diferentes tipos de agregados graúdos foram usados, isto é: calcário dolomítico, quartzito e arenito. Dois tipos diferentes de cada agregado graúdo citado foram usados, fato que foi desprezado nas análises finais devido à semelhança de resultados que o mesmo tipo de agregado gerou no concreto. $O$ módulo de elasticidade do concreto de alto desempenho é fortemente influenciado pelas propriedades elásticas dos agregados graúdos. A influência do agregado graúdo na curva tensão-deformação para o concreto é manifestada pela semelhança das curvas dos concretos e dos seus respectivos agregados graúdos. Assim, as curvas quase paralelas para o calcário e quartzito produzem valores idênticos ao módulo de elasticidade dos seus respectivos concretos, enquanto o concreto de arenito possui módulo de elasticidade menor.

Beshr et. al. (2003), através de ensaios experimentais, avaliaram o efeito de quatro agregados graúdos diferentes, isto é, calcário (mais fraco que o dolomite), dolomite, quartzíticos (baixa capacidade de carga) e escória de aço, na resistência à compressão e à tração e módulo de elasticidade do concreto de alta resistência. Os resultados obtidos nos ensaios mostraram que as resistências à compressão mais alta e mais baixa foram obtidas nas amostras de concreto preparadas com escória 
de aço e agregados de calcário, respectivamente; e a resistência à ruptura foi mais alta nos concretos de agregados de escória de aço, seguido pelo dolomite e quartzíticos. A menor resistência à ruptura foi observada no concreto de calcário. $\mathrm{O}$ tipo de agregado graúdo influencia no módulo de elasticidade do concreto, pois ao contrário dos agregados resistentes, os agregados mais fracos tendem a produzir um concreto mais dúctil. Os resultados evidenciaram que, no concreto de alta resistência, isto é, no concreto preparado usando uma baixa relação de águacimento e elevado teor de cimento, a resistência à compressão é dependente da qualidade do agregado.

Kliszczewicz e Ajdukiewicz (2002) realizaram ensaios experimentais utilizando três diferentes tipos de agregados graúdos para avaliar a influência que o agregado graúdo exerce nas propriedades básicas do concreto de alta performance e alta resistência. Os agregados graúdos usados na elaboração dos corpos de prova cilíndricos foram o basalto, granito, e cascalho natural (pedregulho). Com posse nos resultados, os autores concluíram, ao analisar as características tensão-deformação, que para cada concreto com diferente tipo de agregado graúdo há tensões máximas diferentes e que a deformação de compressão foi a maior para o granito. Também concluíram que o agregado graúdo tem um efeito significativo no módulo de elasticidade, pois em comparação às recomendações do Eurocode 2, os valores são, na realidade, para o cascalho arredondado natural 3\% maior, 13\% maior para o agregado basalto, enquanto para agregados de granito são menores cerca de $21 \%$. O coeficiente de poisson também apresentou resultados diferentes para o concreto com agregados diferentes. $O$ autor ainda ressaltou a necessidade de se obter dados mais reais dos concretos elaborados a partir do agregado graúdo disponível em cada região e que a norma apresenta valores grosseiros, quando particularmente comparado ao concreto de alta performance.

Wu et. al. (2001) realizaram um estudo experimental para verificar o efeito que o agregado graúdo gera nas propriedades mecânicas, isto é, resistência à compressão, resistência diametral, energia de fratura, comprimento característico e módulo de elasticidade, do concreto de alto desempenho. Para isso, quatro tipos diferentes de agregado graúdo foram usados: partículas achatadas de quartzo e granito, partículas de calcário e partículas ásperas de mármore. Os autores concluíram que um agregado graúdo com uma força mais elevada e menor fragilidade, textura e adequadas características mineralógicas podem melhorar as 
propriedades mecânicas do concreto. Como a relação água-cimento é reduzida para concreto de alta resistência, a resistência do concreto é aumentada com o aumento da resistência de agregado graúdo. Entretanto, para o concreto de resistência normal, o efeito do tipo de agregado graúdo não é significativo na resistência à compressão. Devido à rigidez inerente e grande fração de volume que ele ocupa no concreto, o agregado exerce a maior influência sobre o módulo de elasticidade do mesmo. Não apenas a rigidez global, mas também o tipo de agregado, afeta o módulo de elasticidade.

\subsection{Estudos Numéricos}

De maneira simples, o método dos elementos finitos (MEF) consiste na divisão do domínio em um número finito de pequenas regiões denominadas de 'elementos finitos'. Conforme o tamanho dos elementos finitos, a malha é alterada, como pode ser visto na Figura 2.6 (ASSAN, 2003).

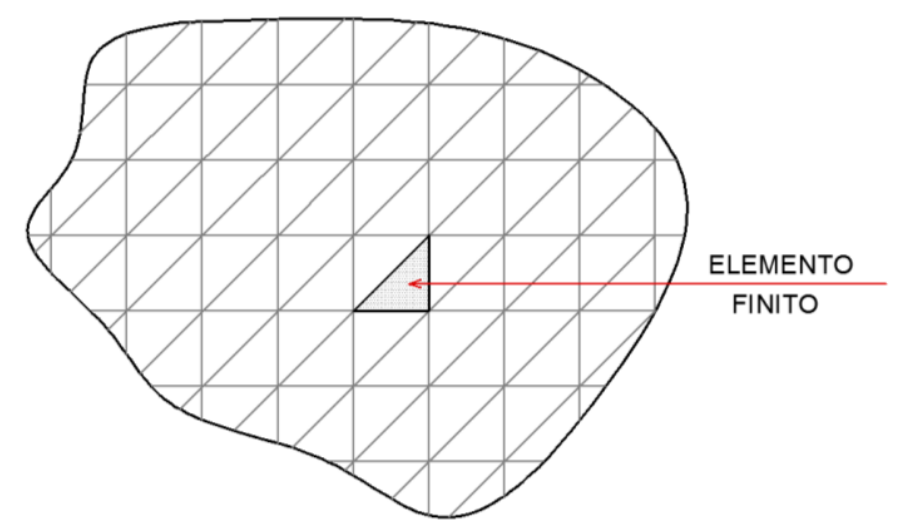

Figura 2.6 - Rede de elementos finitos (Adaptado de (Assan 2003))

O método dos elementos finitos é utilizado em vários pacotes comerciais para a modelagem de uma infinidade de problemas da engenharia. Além disso, elementos de reforço podem ser encontrados nas bibliotecas desses pacotes, em diferentes abordagens numéricas.

O pacote comercial ANSYS ${ }^{\circledR}$ apresenta três elementos de reforço que podem ser avaliados de forma não linear, conforme apresentado na Figura 2.7. O elemento (a) possui configuração tridimensional e permite que fibras possam ser inseridas 
com orientação arbitrária no contexto deste elemento. Os elementos (b) e (c) utilizam um método que é adequado para modelar grupos de reforço de fibras que aparecem em camadas ou na forma de lâminas, sendo que o elemento (b) é usado para modelos bidimensionais ; enquanto que o elemento (c) usado para modelos tridimensionais

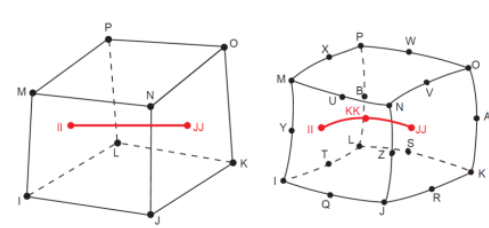

(a)

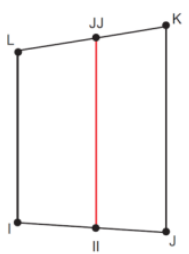

(b)

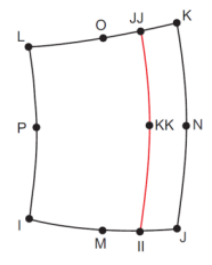

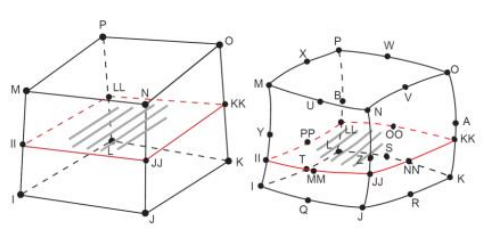

(c)

Figura 2.7 - Elementos de Reforço (a) Primeiro tipo 3D com 8 e 20 nós (b)Segundo tipo 2D com 4 e 8 nós (c) Terceiro tipo 3D com 8 e 20 nós (Fonte: Ansys ${ }^{\circledR}$ )

Nos elementos apresentados na Figura 2.7, admite-se que as fibras de reforço estão rigidamente ligadas ao elemento de base. Assim, os graus de liberdade dos nós da camada interna (II, JJ, KK, LL, etc) podem ser expressos em função dos graus de liberdade dos nós dos elementos externos (I, J, K, L, etc.). A diferença entre a opção disponibilizada pelo pacote e a formulação utilizada na presente pesquisa é que os reforços não podem atravessar os elementos que discretizam o contínuo.

Apesar do método dos elementos finitos ser bem difundido nas modelagens numéricas, outros métodos também são usados para inclusões nos domínios. A combinação do método dos elementos de contorno e do método dos elementos finitos (ZIENKIEWICZ et. al. 1977; BREBBIA e GEORGIOU, 1979; BEER e WATSON, 2002), empregada em Venturini e Leite (2005) é usualmente utilizada para tratar os casos em que as propriedades elásticas do corpo são modificadas pelas inclusões.

Vanalli (2004) desenvolveu formulação que possibilita a análise estática de meios contínuos anisotrópicos viscoplásticos reforçados ou não por fibras. Suas aplicações englobam o método dos elementos finitos (MEF) e o método dos elementos de contorno (MEC). Na modelagem do domínio são adotados elementos finitos triangulares com aproximação cúbica e quadrática para os deslocamentos; e 
na modelagem do reforço de fibras elementos finitos de barras simples são empregados.

Nos trabalhos de Vanalli (2004), Baiocco et. al. (2013), Sampaio (2014), Paccola et. al. (2008) e Radtke et. al. (2011), os autores apresentam uma técnica na qual as fibras são introduzidas por meio de relações cinemáticas simples que garantem sua aderência à matriz, sem a introdução de novos graus de liberdade no sistema de equações resultante e sem a necessidade de coincidência de nós na discretização das fibras e da matriz.

A análise não-linear geométrica de sólidos elásticos bidimensionais reforçados com fibras, via método dos elementos finitos posicional, em que nenhum grau de liberdade adicional é introduzido no sistema de elemento finito, foi apresentada por Sampaio et. al. (2011). O trabalho aborda o comportamento geometricamente não-linear, com formulação Lagrangiana total. Os elementos finitos de chapa utilizados para discretizar o sólido bidimensional apresentam ordem de aproximação qualquer e as fibras (curtas e longas) são discretizadas através de barras simples.

Com relação à formulação posicional, Coda (2003) e Coda e Greco (2004) apresentaram uma formulação simples em situações de não linearidade geométrica, utilizando o método do elemento finito posicional (MEFP) para resolução de pórticos planos. Ambos os trabalhos apresentam a análise de problemas em estruturas bidimensionais estáticas, através de uma formulação classificada como Lagrangiana total com cinemática exata, ou seja, os parâmetros de posição se referem a um sistema de coordenadas fixas durante toda a análise. Também utilizam um espaço não dimensional e o comprimento das barras é calculado (no referencial e na situação deformada) para obtenção da energia de deformação. Esses estudos propõem uma formulação baseada no princípio da minimização da energia potencial total (TAUCHERT, 1974).

Diversos trabalhos desenvolvidos no contexto do GMEC/SET/EESC/USP seguiram o enfoque da formulação posicional de Coda (2003) e Coda e Greco (2004). Marques (2006) realizou um estudo e desenvolvimento de código computacional baseado no MEFP para análise dinâmica não-linear geométrica de sólidos bidimensionais. Maciel (2008) realizou uma análise não-linear de pórticos planos e sólidos tridimensionais via MEFP. Em ambos, os desenvolvimentos a formulação posicional é Lagrangiana total baseada no potencial de energia total. 
Marques (2006) e Maciel (2008) utilizaram um algoritmo de integração temporal baseado na família de integradores temporais de Newmark. Na implementação do código computacional, o elemento finito adotado é o triangular com aproximação cúbica QST em Marques (2006) e elementos finitos tretraédricos de 20 nós com aproximação cúbica em Maciel (2008).

Além disso, Coda e Paccola (2008) realizaram uma análise não-linear geométrica de cascas, via MEFP, onde se incorpora a taxa de variação da espessura diretamente na cinemática que descreve o problema. O tensor de PiolaKirchhof de Segunda Espécie e a deformação de Green são utilizados na formulação.

Pascon (2008) implementou modelos constitutivos hiperelásticos não-lineares em um código computacional que faz uma análise não-linear geométrica de casca. Tal programa, também baseado no MEFP, usa a formulação Lagrangiana total, o Princípio dos Trabalhos Virtuais e o método iterativo de Newton-Raphson.

O método de Newton Raphson, que é uma forma de resolver as equações não-lineares de equilíbrio que ocorrem em análise não-linear, além de ser utilizado nos trabalhos citados, pode ser visto em Luenberger (1989); Cook et. al. (1989); Bonet e Wood (1997) e Crisfield (2000). Em Ogden (1984); Holzapfel (2004) os autores apresentam formulações relacionadas à análise de meios com consideração de grandes deslocamentos e grandes deformações.

No que se refere aos estudos numéricos relacionados à influência das partículas no concreto, Wang et. al. (1999a), trataram o concreto como um compósito trifásico em uma análise em nível mesoscópico, utilizando a geração de uma estrutura de agregados aleatória (RAS- random aggregate structure), em que a forma (esférica, cúbica e poligonal), tamanho e distribuição das partículas de agregado podem se parecer com a encontrada no concreto real. Cada fase, que é constituída por agregados graúdos, matriz de argamassa e zona interfacial entre o agregado e a matriz, recebeu uma malha independente de elementos finitos triangulares. Estes são combinados à não linearidade do material, cuja metodologia e os resultados são apresentados em Wang et. al. (1999b).

O mesmo procedimento proposto em Wang et. al. (1999a), em que os agregados podem ser gerados com forma e tamanhos aleatórios, localizados de forma aleatória dentro no concreto, foi adotado no trabalho de Tu e Lu (2011a). Os autores assumiram ainda que deve existir um espaço mínimo entre agregados, 
evitando sobreposições e intersecções entre dois agregados, seguindo o princípio de amostragem aleatória de Monte Carlo. Tu e Lu (2011a) apresentam o desenvolvimento e a implementação de um modelo computacional bidimensional, para realizar uma análise estática e dinâmica da modelagem em mesoescala do concreto, considerando a não-linearidade do material. Este estudo considera a estrutura composta de três componentes distintas (fases), ou seja, agregado graúdo, matriz de argamassa e zona de transição interfacial, sendo considerados, no processo para a produção da malha de elementos finitos, dois esquemas alternativos para a zona de transição de interface. A geração de uma estrutura geométrica bidimensional mesoscópica é realizada em programa de manipulação simbólica. As informações geométricas sobre os agregados (forma, tamanho, localização) e áreas de argamassa obtidas no referido programa são gravadas em arquivo de comando macro, que é então importado pelo pacote comercial ANSYS ${ }^{\circledR}$ para a geração de malha de elementos finitos. Já a análise não-linear numérica é realizada utilizando o pacote comercial LS-DYNA ${ }^{\circledR}$. Este estudo traz uma breve descrição das teorias e considerações computacionais pertinentes à análise de compósitos, enquanto que em Tu e Lu (2011b) estas investigações numéricas utilizando o modelo de mesoescala sobre o comportamento estático e dinâmico do concreto são apresentados. Os autores, após investigar o comportamento do concreto sob condições quase estáticas e dinâmicas de tensão, concluíram que a distribuição não homogênea das propriedades dos materiais no nível submesoescala, ou seja, dentro da argamassa e zona de transição, não parece afetar o comportamento dos corpos de prova de concreto de uma forma significativa. A aleatoriedade na distribuição de agregados, no entanto, tem um efeito considerável sobre o comportamento do concreto, apresentando uma variação da resistência do concreto em termos de coeficiente de variação em torno de 1,0\%. Quanto à zona de transição, esta desempenha um papel significativo na determinação da resistência do concreto. Com uma camada equivalente de elementos mais fracos para a zona de transição, o modelo de mesoescala razoavelmente reproduz a resistência do concreto; por outro lado, negligenciar a zona de transição pode levar a uma superavaliação da força em mais do que $10 \%$.

As ligas metálicas também são discutidas em estudos numéricos de compósitos particulados. Nakasone et. al. (2000) apresentam um código computacional, com formulação para o caso bidimensional, via método dos 
elementos finitos para análise elástica de distribuição de tensões dentro das inclusões, em forma de elipse, círculo, triângulo e retângulo, e na vizinhança da interface matriz-inclusão. $\mathrm{O}$ aço foi escolhido como o material de matriz e o SiC e Ti$6 \mathrm{Al}-4 \mathrm{~V}$ foram escolhidos como os materiais de inclusão, a fim de examinar os efeitos do material da matriz e material de inclusão. Os resultados obtidos pelo método proposto pelos autores foram comparados e mostraram boa concordância com os resultados teóricos e numéricos obtidos por análises do MEF, exceto para os pontos de canto afiadas das inclusões triangulares.

Por outro lado, Chen et. al. (2000) utilizam o método dos elementos finitos para analisar os efeitos da morfologia das partículas sobre a resposta mecânica local e global do compósito, empregando três modelos de compósitos com 15\% de volume de partículas de $\mathrm{SiC}$ não homogeneamente distribuídos numa matriz elastoplástica de Al-6061. No modelo $A$ as partículas adotados foram angulares com cantos afiados, no modelo $B$ as partículas angulares tiveram os cantos afiados suprimidos e no modelo $C$ as partículas foram adotadas com formato circular. Assim, o tamanho das 13 partículas usadas em cada modelo é ajustado de modo que a fração de volume seja a mesma para os três tipos de geometria de partículas. As análises foram realizadas assumindo estado plano de tensão e deformação e utilizam o elemento plano de 8 nós do pacote comercial software $\mathrm{ANSYS}^{\circledR}$. Os resultados numéricos mostram que nos modelos $B$ e $C$ a redução da curva tensãodeformação global é pequena, ao contrário da grande redução de tensões locais que sofrem, quando comparados ao modelo A. Também mostram que a morfologia das partículas tem efeitos importantes sobre a carga transportada pelas partículas. Se a dimensão mais longa da partícula angular é ao longo do eixo de carga, a partícula angular vai transportar mais carga do que a partícula circular. Enquanto que a exclusão dos cantos das partículas pode, efetivamente, reduzir a possibilidade de fratura das partículas.

A presente pesquisa, como dito anteriormente, utiliza formulação que segue a mesma ideia dos trabalhos desenvolvidos por Vanalli (2004), Baiocco et. al. (2013) e Sampaio (2014), onde compósitos reforçados com fibras são analisados, sem necessidade de coincidência entre as malhas da matriz e das partículas e sem o aumento do número de graus de liberdade dos problemas, sendo estas consideradas vantagens para a abordagem numérica de compósitos reforçados. 


\section{ANÁLISE BIDIMENSIONAL ELÁSTICA DE COMPÓSITOS PARTICULAS VIA MEFP}

Este capítulo se destina à apresentação da formulação baseada no Método dos Elementos Finitos Posicional para análise de sólidos elásticos bidimensionais reforçados com partículas, possibilitando análises tanto em grandes deslocamentos quanto em pequenos deslocamentos, sem o acréscimo de graus de liberdade ao problema por considerar aderência perfeita entre as fases, partículas e matriz. As partículas são espalhadas no domínio sem a necessidade de coincidência dos nós com os nós da malha do domínio (matriz).

A formulação, aqui descrita resumidamente, é utilizada no presente trabalho para realização das simulações numéricas apresentadas no Capítulo 4. Tal formulação foi desenvolvida e implementada no contexto do GMEC/SET/EESC/USP com base nos trabalhos de Vanalli (2004), Baiocco et. al. (2013), Sampaio et. al. (2011), Nogueira et. al. (2014) e Sampaio (2014), que tratam da análise de sólidos elásticos bidimensionais reforçados com fibras. Os detalhes das formulações que deram origem à formulação aqui aplicada podem ser consultados diretamente nessas referências citadas.

\subsection{Relações cinemáticas - acoplamento partícula-matriz}

Para obtenção de uma formulação para análise não linear geométrica de sólidos elásticos bidimensionais reforçados com partículas, sem a necessidade de coincidência dos nós das partículas com os nós da malha do domínio (matriz), faz-se necessária a determinação das coordenadas adimensionais dos nós das partículas em relação aos elementos bidimensionais que representam a matriz.

Com as coordenadas adimensionais, é possível relacionar as grandezas atribuídas às partículas com as grandezas pertencentes à matriz, compatibilizandose assim os diferentes elementos, Figura 3.1.

Para determinação das coordenadas adimensionais $\left(\xi_{1}^{p}, \xi_{2}^{p}\right)$, Figura. 3.2, recai-se em um sistema de equações que, a depender do grau de aproximação das variáveis nodais dos elementos finitos da matriz, podem ser não lineares. 


$$
X_{i}^{P}=\phi_{l}\left(\xi_{1}^{P}, \xi_{2}^{P}\right) X_{i}^{l}
$$

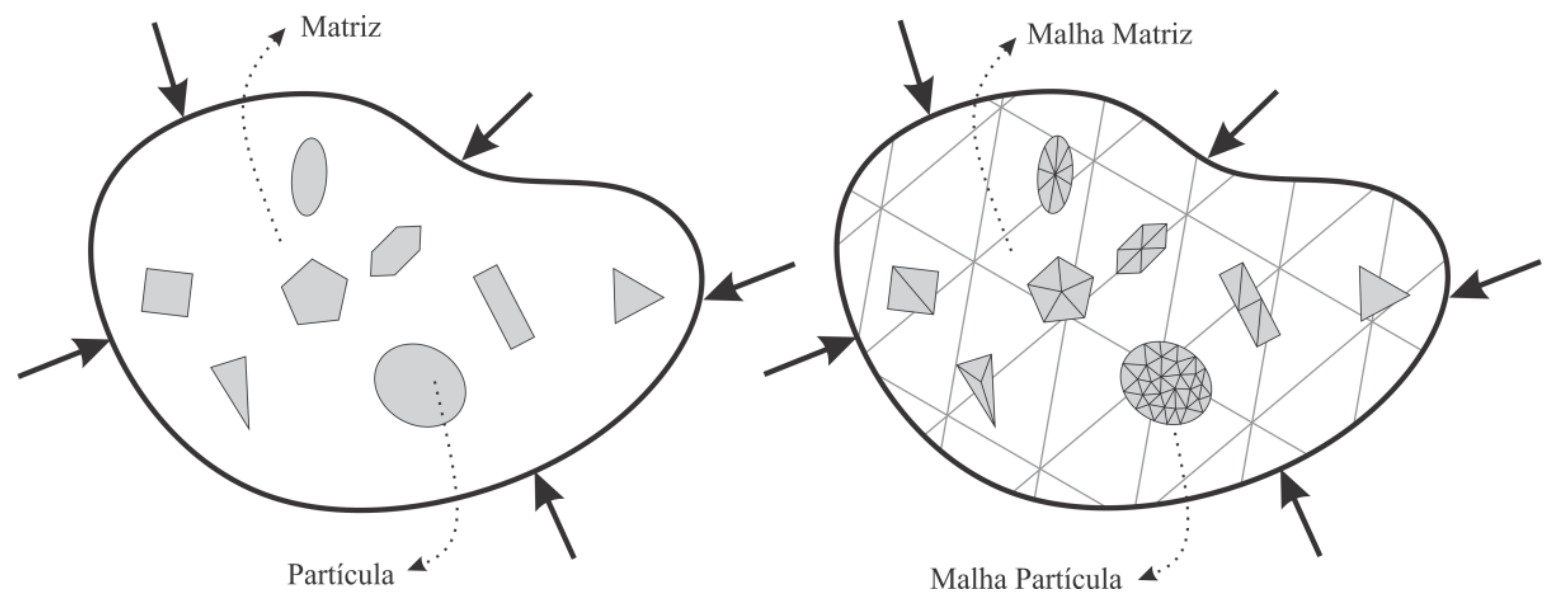

Figura 3.1. Domínio bidimensional com partículas dispersas

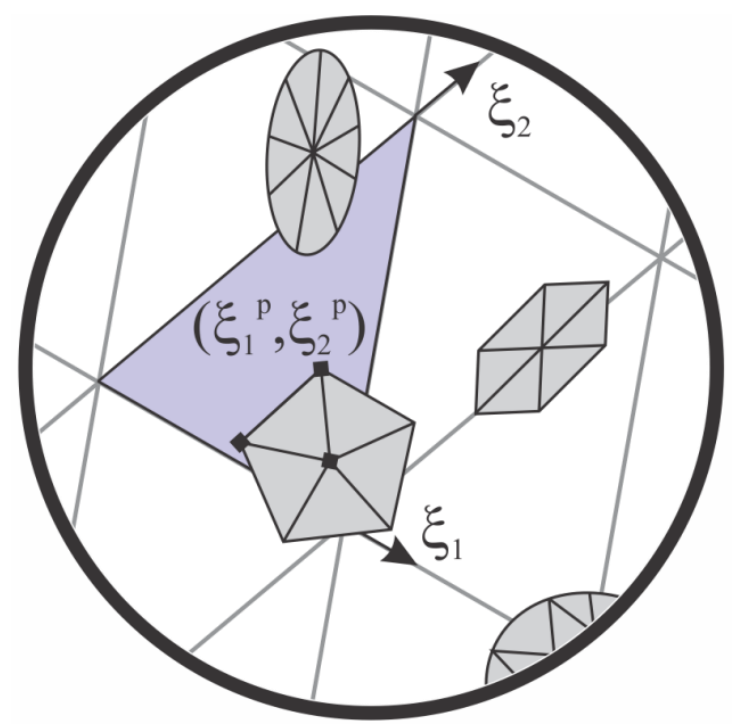

Figura 3.2. Coordenadas adimensionais dos nós das partículas

$\mathrm{Na}$ Equação 3.1 , $\phi_{l}$ são as funções de forma dos elementos triangulares, $X_{i}^{P}$ são as coordenadas dos nós das partículas na configuração inicial e $X_{i}^{l}$ são as coordenadas dos nós dos elementos triangulares utilizados para discretizar a matriz, também na configuração inicial.

Caso se obtenha um sistema de equações não lineares na Equação 3.1, procede-se com a expansão das referidas equações em Série de Taylor desprezando-se os termos de ordem superior e arbitrando-se um par de 
coordenadas adimensionais tentativa $\left(\xi_{1}^{p t}, \xi_{2}^{p t}\right)$ para iniciar o processo de solução, ou seja:

$$
\begin{aligned}
& X_{i}^{P} \cong \phi_{l}\left(\xi_{1}^{P t}, \xi_{2}^{P t}\right) X_{i}^{l}+\left.\frac{\partial \phi_{l}\left(\xi_{1}, \xi_{2}\right)}{\partial \xi_{j}}\right|_{\left(\xi_{l}^{P_{t}}, \xi_{2}^{P_{t}}\right)} \Delta \xi_{j} \\
& \text { ou } \quad X_{i}^{P}=X_{i}^{P t}+H_{i j} \Delta \xi_{j}
\end{aligned}
$$

Na Equação 3.2, $X_{i}^{P t}$ são as coordenadas tentativa dos nós das partículas calculadas com base nas coordenadas adimensionais tentativa e nas coordenadas dos elementos triangulares e $H_{i j}$ é uma matriz 2x2. A correção das coordenadas adimensionais tentativa $\Delta \xi_{i}$ é calculada resolvendo-se o seguinte sistema linear de equações:

$$
H_{i j} \Delta \xi_{j}=X_{i}^{P}-X_{i}^{P t}
$$

O procedimento descrito nada mais é do que a aplicação do Método de Newton-Raphson, uma forma simples e rápida para solução de sistemas não lineares de equações, permitindo-se encontrar o par de coordenadas adimensionais $\left(\xi_{1}^{p}, \xi_{2}^{p}\right)$ de todos os nós de partículas existentes na análise.

Pelo fato de se considerar aderência perfeita entre partículas e matriz, as posições dos nós das partículas podem ser calculadas a qualquer momento em função das posições dos nós dos elementos triangulares da matriz onde o nó da partícula é determinado, aplicando-se:

$$
Y_{i}^{P}=\phi_{l}\left(\xi_{1}^{P}, \xi_{2}^{P}\right) Y_{i}^{l}
$$

Na Equação 3.4, $Y_{i}^{l}$ são as posições dos nós utilizados na discretização do sólido bidimensional (matriz) na configuração atual, ou seja, as incógnitas do problema.

A energia de deformação do problema será computada levando-se em consideração tanto os elementos triangulares utilizados na discretização da matriz, quanto os elementos triangulares utilizados na discretização das partículas. A 
referida energia de deformação será escrita apenas em função das posições nodais dos elementos triangulares da matriz, ou seja, incógnitas da análise, uma vez que para as partículas é possível escrever as posições nodais diretamente em relação às posições dos nós dos elementos triangulares da matriz nos quais os nós da partícula se inserem. Com isso, como comentado anteriormente, nenhum acréscimo de graus de liberdade é acarretado no problema com esta abordagem utilizada para a consideração das partículas.

\subsection{Energia de Deformação}

A energia de deformação do sistema estrutural formado pelo composto partícula-matriz é obtida somando-se as parcelas da energia de deformação de cada uma das fases, partícula e matriz. Desta forma, têm-se:

$U=U_{\text {matriz }}+U_{\text {particulas }}$

$\mathrm{Na}$ Equação 3.5, $U_{\text {matriz }}$ é a parcela de energia de deformação acumulada nos elementos finitos triangulares utilizados para simular a matriz e $U_{\text {particulas }}$ é a parcela de energia de deformação acumulada nos elementos finitos bidimensionais utilizados na representação das partículas.

Para se determinar a magnitude da força interna na direção $\alpha$ de um dado nó $\beta$, pertencente aos elementos finitos triangulares da matriz, levando-se em conta a contribuição das duas fases do compósito, aplica-se o conceito de conjugado energético, resultando em:

$$
F_{\alpha}^{\beta \text { int }}=\frac{\partial\left(U_{\text {matriz }}+U_{\text {particulas }}\right)}{\partial Y_{\alpha}^{\beta}}=\frac{\partial U_{\text {matriz }}}{\partial Y_{\alpha}^{\beta}}+\frac{\partial U_{\text {particulas }}}{\partial Y_{\alpha}^{\beta}}
$$

Na Equação 3.6, $Y_{\alpha}^{\beta}$ é a posição do nó $\beta$ na direção $\alpha$ na configuração atual, lembrando-se novamente que as posições dos nós na referida configuração são os próprios graus de liberdade envolvidos na análise. 
Retomando a ideia dos desenvolvimentos, para inclusão de fibras na matriz, apresentados em Vanalli, et. al., (2004), Baiocco et. al. (2013), Nogueira et. al. (2014) e Sampaio (2014), a energia de deformação acumulada nos elementos de partículas, $U_{\text {particulas }}$, é escrita em função dos graus de liberdade das referidas partículas $Y_{i}^{P}$. Aplicando-se a regra da cadeia, com base na Equação 3.4, obtém-se:

$$
\frac{\partial Y_{i}^{P}}{\partial Y_{\alpha}^{\beta}}=\frac{\partial Y_{i}^{l}}{\partial Y_{\alpha}^{\beta}} \phi_{l}\left(\xi_{l}^{P}, \xi_{2}^{P}\right)=\delta_{\alpha i} \delta_{\beta l} \phi_{l}\left(\xi_{l}^{P}, \xi_{2}^{P}\right)=\delta_{\alpha i} \phi_{\beta}\left(\xi_{l}^{P}, \xi_{2}^{P}\right)
$$

Se o nó da partícula pertencer ao elemento triangular da matriz cuja derivada em relação à posição se realiza, e a direção $\alpha$ for igual à direção $i$ do nó da partícula, a Equação 3.7 resulta $\partial Y_{i}^{P} / \partial Y_{\alpha}^{\beta}=\phi_{\beta}\left(\xi_{1}^{P}, \xi_{2}^{P}\right)$, caso contrário resulta valor nulo. Portanto, a parcela referente à derivada da energia de deformação das partículas na Equação 3.6, caso o nó da partícula pertença ao elemento triangular de referência da matriz resulta:

$$
\frac{\partial U_{\text {particulas }}}{\partial Y_{\alpha}^{\beta}}=\frac{\partial U_{\text {particulas }}}{\partial Y_{i}^{P}} \frac{\partial Y_{i}^{P}}{\partial Y_{\alpha}^{\beta}}=\phi_{\beta}\left(\xi_{1}^{P}, \xi_{2}^{P}\right) \frac{\partial U_{\text {particulas }}}{\partial Y_{\alpha}^{P}}
$$

Usando as Equações 3.6 e 3.8 escreve-se:

$$
F_{\alpha}^{\beta \text { int }}=\frac{\partial\left(U_{\text {matriz }}+U_{\text {particulas }}\right)}{\partial Y_{\alpha}^{\beta}}=\frac{\partial U_{\text {matriz }}}{\partial Y_{\alpha}^{\beta}}+\phi_{\beta}\left(\xi_{1}^{P}, \xi_{2}^{P}\right) \frac{\partial U_{\text {particulas }}}{\partial Y_{\alpha}^{P}}
$$

A segunda derivada da energia de deformação é importante no processo de solução do problema não linear, uma vez que fornece os termos da matriz Hessiana envolvida no método de Newton Raphson. A obtenção da segunda derivada segue a ideia da aplicação da regra da cadeia apresentada no desenvolvimento da Equação 3.7.

A formulação é naturalmente não-linear geométrica, pois utiliza lei constitutiva de Saint Venant-Kirchhoff, com tensor de deformações de Green e tensor de tensões de Piola-Kirchhoff de Segunda Espécie (Ciarlet, (1993), Ogden, (1984)). 


\subsection{Equações de Equilíbrio: Método de Newton-Raphson}

As equações de equilíbrio do problema são encontradas aplicando-se o Princípio da Estacionariedade ou da Mínima Energia Potencial Total, Tauchert (1974).

A Energia Potencial Total, $\Pi$, do sistema é obtida da seguinte expressão:

$$
\Pi(Y)=U_{\text {matriz }}(Y)+U_{\text {particulas }}(Y)-\Omega(Y)
$$

Na Equação 3.11, $\Omega$ é o Potencial das forças externas aplicadas, dado por:

$$
\Omega=F_{j}^{\gamma} Y_{j}^{\gamma}
$$

$\mathrm{Na}$ Equação 3.11, $F_{j}^{\gamma}$ são as componentes do vetor das forças externas aplicadas nos nós do problema em análise, nós estes pertencentes à discretização da matriz unicamente.

O Princípio da Estacionariedade é aplicado derivando-se a energia potencial total em relação às incógnitas do problema, ou seja, em relação às posições dos nós dos elementos triangulares da matriz. Com isso, obtém-se o sistema de equações a ser resolvido:

$$
\begin{aligned}
& g_{j}^{\gamma}=\frac{\partial \Pi}{\partial Y_{j}^{\gamma}}=\frac{\partial\left(U_{\text {matriz }}+U_{\text {particulas }}\right)}{\partial Y_{j}^{\gamma}}-F_{j}=F_{j}^{\text {int }}-F_{j}=0 \\
& \operatorname{com} F_{j}^{\text {int }}=\frac{\partial\left(U_{\text {matriz }}+U_{\text {particulas }}\right)}{\partial Y_{j}^{\gamma}}
\end{aligned}
$$

$\mathrm{Na}$ Equação 3.12, $F_{j}^{\text {int }}$ é o vetor de forças internas ou gradiente da energia de deformação, calculado de acordo com a Equação. 3.6. Sendo as posições dos nós na configuração atual as incógnitas do problema, quando se adotam posições tentativas $Y^{0}$ na Equação $3.12, g_{j}^{\gamma}$ é não nulo tornando-se 0 vetor de desbalanceamento do procedimento de solução de Newton-Raphson, Luenberger (1989). 


$$
g_{j}(\boldsymbol{Y})=g_{j}\left(\boldsymbol{Y}^{0}\right)+\left.\frac{\partial g_{j}}{\partial Y_{k}}\right|_{\boldsymbol{Y}^{0}} \Delta Y_{k}+O_{j}^{2}=0
$$

A Equação 3.13 pode ser reescrita, desprezando-se termos de alta ordem como:

$$
\begin{aligned}
& \Delta Y_{k}=-\left(\left.\frac{\partial g_{j}}{\partial Y_{k}}\right|_{\mathbf{Y}^{0}}\right)^{-1} g_{j}\left(\boldsymbol{Y}^{0}\right)=-\left(\left.\frac{\partial^{2}\left(U_{\text {matriz }}+U_{\text {particulas }}\right)}{\partial Y_{k} \partial Y_{j}}\right|_{\mathbf{Y}^{0}}\right)^{-1} g_{j}\left(\boldsymbol{Y}^{0}\right) \\
& \operatorname{com}\left(\left.\frac{\partial g_{j}}{\partial Y_{k}}\right|_{\mathbf{Y}^{0}}\right)=\left(H_{k j}\right)
\end{aligned}
$$

Na Equação 3.14, $\Delta Y_{k}$ é a correção da posição nodal e $H_{k j}=\left.\frac{\partial^{2} U}{\partial Y_{k} \partial Y_{j}}\right|_{Y^{o}}$ é a matriz Hessiana ou matriz de rigidez tangente do problema.

A solução tentativa é atualizada, Equação 3.15, até que $\Delta Y_{k}$ ou $g_{j}$ tornem-se suficientemente pequenos de acordo com uma tolerância adotada na análise.

$$
Y_{k}=Y_{k}^{0}+\Delta Y_{k}
$$

A análise pode ser dividida em passos de carga, com incremento do nível de carregamento aplicado, possibilitando que se obtenha o caminho do equilíbrio para os problemas analisados.

A formulação descrita neste capítulo foi implementada, no contexto do GMEC/SET/EESC/USP, em Delphi ${ }^{\circledR}$ e encontra-se disponível para utilização no referido grupo de pesquisa. 


\section{EXEMPLOS}

Neste capítulo são apresentados quatro exemplos que foram simulados aplicando-se a formulação discutida no Capítulo 3, buscando-se analisar o comportamento, em nível macroscópico, de materiais compósitos particulados com ênfase no concreto.

Os dois primeiros exemplos tem como objetivo a verificação dos resultados aqui obtidos comparados a resultados numéricos, apresentados em Farage et. al.(2009), e experimentais, apresentados nos trabalhos de Ke et. al. ${ }^{8}$ (2006a,2006b) apud Farage et. al. (2009) e Zhou et. al. (1995).

O primeiro exemplo consiste em simulação numérica do módulo de elasticidade de concretos leves, sendo que os resultados são comparados aos obtidos tanto numericamente, considerando a técnica de Homogeneização por Expansão Assintótica (Farage et. al.(2009)), quanto experimentalmente (Ke et. al. ${ }^{8}$ (2006a,2006b) apud Farage et. al. (2009)).

O segundo exemplo segue a mesma linha do primeiro, ou seja, obtenção de módulo de elasticidade de concretos para diferentes agregados graúdos de diferentes materiais, sendo que os resultados são comparados com os obtidos no programa experimental apresentado em Zhou et. al. (1995), bem como com resultados de modelos matemáticos baseados em modelos reológicos para representação do comportamento de compósitos, apresentados também em Zhou et. al. (1995). Os modelos reológicos são os de Voigt, Reuss, Hirsch, Couto, PCouto e BNC.

O terceiro exemplo foi proposto para apresentar as potencialidades do código obtido no presente trabalho, verificando e validando a formulação em casos mais gerais que os discutidos nos dois exemplos anteriores, onde células periódicas foram consideradas nas análises. Aborda-se a simulação do comportamento global de uma chapa onde são avaliados os deslocamentos no contínuo modelado segundo duas configurações distintas: fase única com propriedades homogeneizadas para o compósito; e diferentes fases, matriz e partículas

\footnotetext{
${ }^{8}$ Ke, Y., Ortola, S., Beaucour, A.L., Cabrillac, R., Dumontet, H. Influence of aggregates on mechanical behavior of lightweight aggregate concrete: experimental characterization and modeling, In: EURO MEDITERRANEAN CONGRESS IN ADVANCES ON GEOMATERIALS AND STRUCTURES, 1. Proceedings. Hammamet, $2006 a$.

Ke, Y., Beaucour, A.L., Ortola, S., Dumontet, H., Cabrillac, R. Comportement mécanique des béton de granulats légers; étude éxperimentale et modélisation. In: RENCONTRES DU GÉNIE CIVIL ET URBAIN, COSTRUIRE, LES NOUVEAUX DÉFIS, 24. Proceedings ... Montpellier, 2006b.
} 
representadas cada uma com suas propriedades individuais. As propriedades elásticas dos materiais utilizados neste exemplo foram extraídas de Farage et. al. (2009).

Aproveitando-se a geometria e carregamentos utilizados no terceiro exemplo, fazendo-se pequenas adaptações, foram realizadas análises para o quarto exemplo proposto. Neste último caso analisado, foram testadas as potencialidades do código no que diz respeito à inclusão de vazios no contínuo. As propriedades elásticas dos materiais utilizados neste exemplo foram extraídas de Zhou et. al. (1995).

As malhas de elementos finitos utilizadas nas discretizações das matrizes e das partículas nas simulações dos quatro exemplos foram geradas no Ansys ${ }^{\circledR}$ com aproximação linear de posições e posteriormente adaptadas para aproximação cúbica de posições. A única exceção é o caso das malhas que representam as partículas no quarto exemplo, sendo que estas foram geradas com aproximação linear diretamente em código desenvolvido especificamente para geração e inclusão aleatória das referidas partículas na matriz. Os números de nós e de elementos de cada discretização estão apresentados com detalhes em cada um dos exemplos.

\subsection{Exemplo 01: Avaliação do módulo de elasticidade de concretos com agregados leves}

Este primeiro exemplo foi proposto para verificar a influência das propriedades, das geometrias e da fração volumétrica dos agregados graúdos na avaliação do módulo de elasticidade longitudinal de concretos leves, sendo que as análises foram realizadas considerando-se células periódicas, tal como na técnica de Homogeneização por Expansão Assintótica. Os resultados são comparados com resultados numéricos da referida técnica de homogeneização que foram obtidos em Farage et. al. (2009). Também são realizadas comparações com resultados experimentais obtidos em Ke et. al. ${ }^{8}$ (2006a, 2006b) apud Farage et. al. (2009). Foram realizadas análises para diferentes frações volumétricas de agregados, tal como proposto nas referências citadas. As propriedades físicas da argamassa (matriz) e dos diferentes agregados leves (partículas) utilizados são apresentadas na Tabela 4.1. 
Tabela 4.1 - Propriedades físicas dos materiais (adaptada de Farage et. al. (2009))

\begin{tabular}{|c|c|c|c|}
\hline \multicolumn{2}{|c|}{ Material } & $\mathrm{E}(\mathrm{GPa})$ & $v$ \\
\hline \multicolumn{2}{|c|}{ Argamassa $\left(\mathrm{E}_{\mathrm{m}}\right)$} & 28.58 & \multirow{6}{*}{0.2} \\
\hline \multirow{5}{*}{$\begin{array}{c}\text { Argila } \\
\text { expandida } \\
\left(E_{p}\right)\end{array}$} & 01 & 6.47 & \\
\hline & 02 & 7.50 & \\
\hline & 03 & 8.03 & \\
\hline & 04 & 10.23 & \\
\hline & 05 & 20.23 & \\
\hline
\end{tabular}

Para cada tipo de agregado apresentado na Tabela 4.1, foram realizadas análises para 4 diferentes frações volumétricas de partículas e três tipos de células periódicas, totalizando sessenta modelos numéricos analisados. As frações volumétricas de agregado utilizadas foram: $12.5 \%, 25 \%, 37.5 \%$ e $45 \%$. As células periódicas estão apresentadas nas Figuras 4.1, 4.2 e 4.3. Foram utilizados elementos finitos triangulares com aproximação cúbica para as posições nodais na discretização das duas fases, ou seja, matriz e partículas. O número de nós e elementos utilizados nas malhas de cada fase estão apresentados na Tabela 4.2.

Como pode ser observado nas referidas figuras, a malha das partículas se sobrepõe à malha da matriz, sem a necessidade de coincidência dos nós e elementos. Em todos os casos analisados, o valor utilizado no programa para o módulo de elasticidade longitudinal da matriz é o nominal, apresentado na Tabela 4.1. Porém, para as partículas, pelo fato do módulo de elasticidade dessas ser menor do que o módulo de elasticidade da matriz e para desconsiderar a sobreposição dos elementos/materiais, o valor utilizado nas modelagens é a diferença entre o valor adotado para a matriz e o valor adotado para cada caso de partícula, resultando inclusive, em alguns casos, em valores negativos para serem fornecidos ao programa.

Tabela 4.2 - Número de nós e elementos utilizados nas malhas de cada fase

\begin{tabular}{cccccc}
\hline \multirow{2}{*}{ Fase } & & \multicolumn{3}{c}{ Fração volumétrica de partículas } \\
\cline { 2 - 5 } & & $45 \%$ & $37.5 \%$ & $25 \%$ & $12.5 \%$ \\
\hline \hline Partícula & Nós & \multicolumn{4}{c}{6193} \\
Tipo A & Elementos & \multicolumn{4}{c}{1334} \\
\hline Partícula & Nós & 3349 & 2992 & 2029 & 1060 \\
\cline { 2 - 5 } Tipo B & Elementos & 720 & 642 & 432 & 222 \\
\hline Partícula & Nós & \multicolumn{4}{c}{2003} \\
Tipo C & Elementos & \multicolumn{4}{c}{164} \\
\hline \multirow{2}{*}{ Matriz } & Nós & \multicolumn{4}{c}{3632} \\
\cline { 2 - 5 } & Elementos &
\end{tabular}


(a)
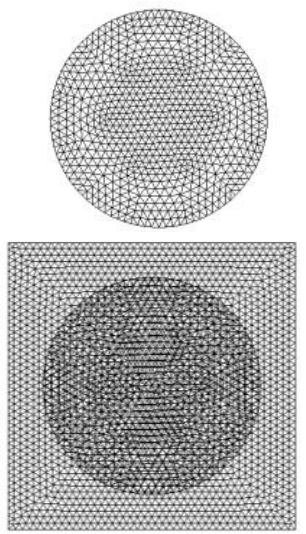

(c)

$45 \%$
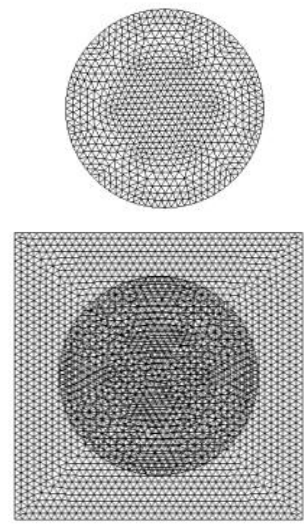

$37.5 \%$
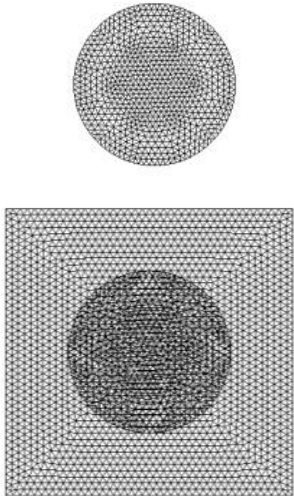

$25 \%$
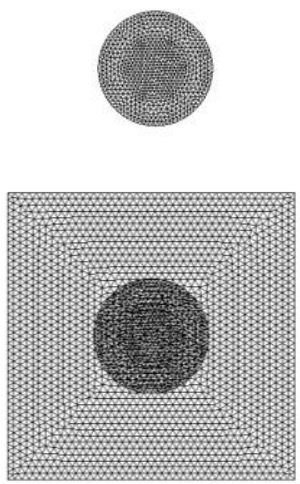

$12.5 \%$

Figura 4.1 - Célula periódica $A$

(a) discretização das partículas; (b) célula periódica; (c) fração volumétrica

(a)
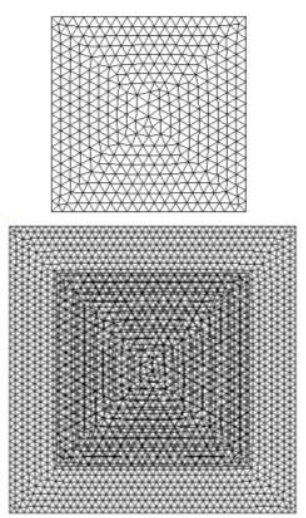

$45 \%$

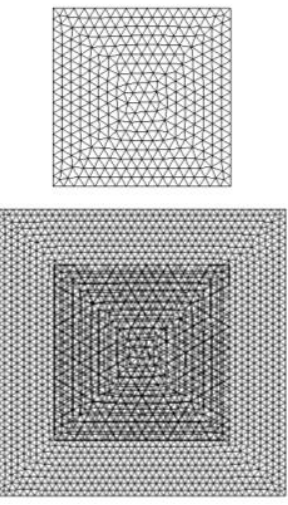

$37.5 \%$
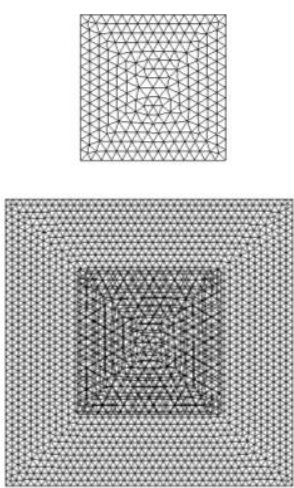

$25 \%$
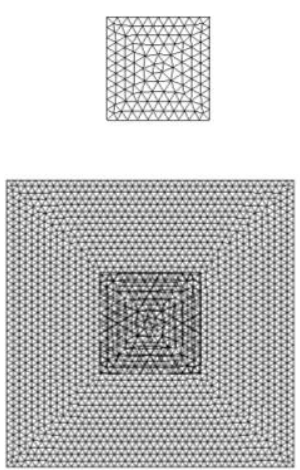

$12.5 \%$

Figura 4.2 - Célula periódica $B$

(a) discretização das partículas; (b) célula periódica; (c) fração volumétrica

(a)
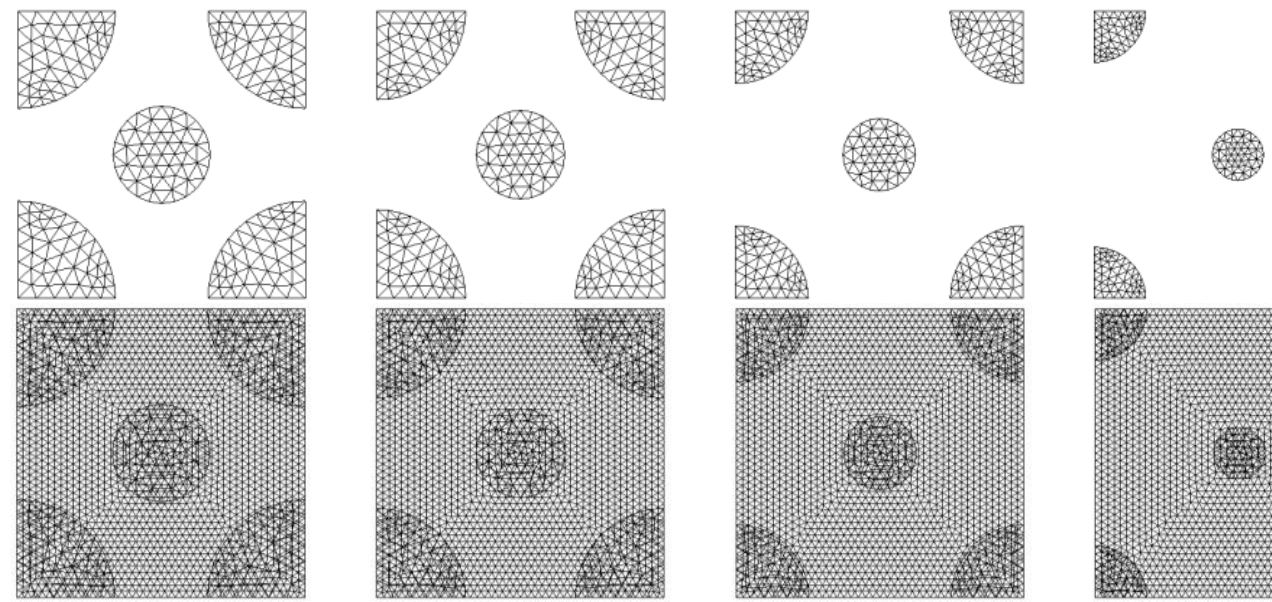

$37.5 \%$

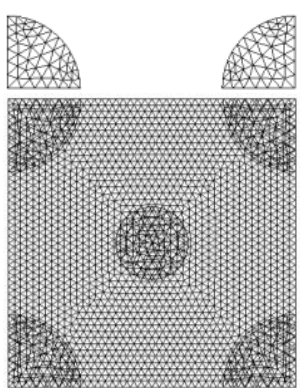

$25 \%$

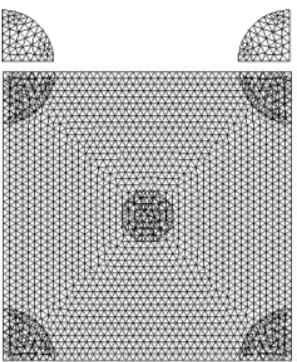

$12.5 \%$

Figura 4.3 - Célula periódica C

(a) discretização das partículas; (b) célula periódica; (c) fração volumétrica 
Para obtenção dos valores de módulo de elasticidade longitudinal do concreto $\left(E_{c}\right)$ equivalente ao meio homogeneizado, em cada caso, as simulações numéricas foram realizadas com controle de deslocamento em uma das faces e vinculação, na mesma direção do carregamento, na face paralela oposta. Com os valores conhecidos do deslocamento, das dimensões da célula periódica e das reações na face vinculada, foi possível determinar o valor do referido módulo de elasticidade homogeneizado para comparação com os resultados numéricos e experimentais. Os valores de deslocamentos prescritos foram adotados de tal forma que as análises fossem realizadas em regime de pequenos deslocamentos e pequenas deformações, permitindo assim a aplicação direta da Lei de Hooke para determinação dos parâmetros elásticos desejados.

Os resultados obtidos para os sessenta modelos analisados estão compilados na Tabela 4.3, sendo também apresentados os erros relativos entre os valores obtidos no presente trabalho e os valores obtidos experimentalmente em Ke et. al. ${ }^{8}$ (2006a, 2006b) apud Farage et. al. (2009), além dos valores numéricos fornecidos em Farage et. al. (2009).

Tabela 4.3 - Resultados das análises (adaptada de Farage et. al. (2009))

\begin{tabular}{|c|c|c|c|c|c|c|c|c|c|c|c|c|c|c|c|}
\hline \multirow{3}{*}{ № } & \multirow{3}{*}{$\begin{array}{l}{ }^{*} \mathrm{E}_{\mathrm{p}} \\
(\mathrm{Gpa})\end{array}$} & \multirow{3}{*}{$\begin{array}{c}\text { Fração } \\
\text { vol. } \\
\%\end{array}$} & \multirow{3}{*}{$\begin{array}{l}* * \mathrm{E}_{\mathrm{c}} \\
(\mathrm{Gpa})\end{array}$} & \multicolumn{4}{|c|}{ Célula periódica $\mathrm{A}$} & \multicolumn{4}{|c|}{ Célula periódica $\mathrm{B}$} & \multicolumn{4}{|c|}{ Célula periódica $\mathrm{C}$} \\
\hline & & & & \multicolumn{2}{|c|}{$\begin{array}{l}\text { Presente } \\
\text { Trabalho }\end{array}$} & \multicolumn{2}{|c|}{$\begin{array}{c}\text { Farage et.al. } \\
(2009)\end{array}$} & \multicolumn{2}{|c|}{$\begin{array}{l}\text { Presente } \\
\text { Trabalho } \\
\end{array}$} & \multicolumn{2}{|c|}{$\begin{array}{c}\text { Farage et.al. } \\
(2009)\end{array}$} & \multicolumn{2}{|c|}{$\begin{array}{l}\text { Presente } \\
\text { Trabalho } \\
\end{array}$} & \multicolumn{2}{|c|}{$\begin{array}{c}\text { Farage et.al. } \\
(2009)\end{array}$} \\
\hline & & & & $\begin{array}{c}E_{c} \\
(G p a)\end{array}$ & $\begin{array}{c}\text { |erro| } \\
(\%)\end{array}$ & $\begin{array}{c}E_{c} \\
(G p a)\end{array}$ & $\begin{array}{c}\mid \text { erro| } \\
(\%)\end{array}$ & $\begin{array}{c}E_{c} \\
(G p a)\end{array}$ & $\begin{array}{c}\text { |erro| } \\
(\%)\end{array}$ & $\begin{array}{c}E_{c} \\
(G p a)\end{array}$ & $\begin{array}{c}\text { |erro| } \\
(\%)\end{array}$ & $\begin{array}{c}E_{c} \\
(G p a)\end{array}$ & $\begin{array}{c}\mid \text { erro| } \\
(\%)\end{array}$ & $\begin{array}{c}E_{c} \\
\text { (Gpa) }\end{array}$ & $\begin{array}{c}\text { |erro| } \\
(\%)\end{array}$ \\
\hline 1 & \multirow{4}{*}{6.47} & 12.5 & 23.54 & 23.66 & 0.51 & 23.79 & 1.06 & 23.71 & 0.72 & 23.81 & 1.15 & 23.46 & 0.34 & 23.49 & 0.21 \\
\hline 2 & & 25.0 & 20.67 & 19.88 & 3.82 & 20.16 & 2.47 & 20.08 & 2.85 & 20.18 & 2.37 & 19.34 & 6.43 & 19.34 & 6.43 \\
\hline 3 & & 37.5 & 16.74 & 16.82 & 0.48 & 16.93 & 1.14 & 17.04 & 1.79 & 17.20 & 2.75 & 16.01 & 4.36 & 15.96 & 4.66 \\
\hline 4 & & 45.0 & 15.67 & 15.17 & 3.19 & 15.45 & 1.40 & 15.65 & 0.13 & 15.61 & 0.38 & 14.28 & 8.87 & 14.24 & 9.13 \\
\hline 5 & \multirow{4}{*}{7.50} & 12.5 & 24.90 & 24.06 & 3.39 & 24.17 & 2.93 & 24.10 & 3.19 & 24.19 & 2.85 & 23.86 & 4.17 & 23.92 & 3.94 \\
\hline 6 & & 25.0 & 21.39 & 20.50 & 4.16 & 20.74 & 3.04 & 20.81 & 2.70 & 20.78 & 2.85 & 20.00 & 6.51 & 20.05 & 6.26 \\
\hline 7 & & 37.5 & 17.29 & 17.56 & 1.56 & 17.67 & 2.20 & 17.76 & 2.74 & 17.92 & 3.64 & 16.86 & 2.47 & 16.86 & 2.49 \\
\hline 8 & & 45.0 & 15.70 & 16.07 & 2.37 & 16.25 & 3.50 & 16.28 & 3.71 & 16.39 & 4.39 & 15.33 & 2.34 & 15.21 & 3.12 \\
\hline 9 & \multirow{4}{*}{8.03} & 12.5 & 26.16 & 24.25 & 7.28 & 24.35 & 6.92 & 24.28 & 7.17 & 24.38 & 6.80 & 24.10 & 7.89 & 24.12 & 7.80 \\
\hline 10 & & 25.0 & 21.68 & 20.81 & 4.01 & 21.03 & 3.00 & 20.94 & 3.42 & 21.07 & 2.81 & 19.16 & 11.63 & 20.40 & 5.90 \\
\hline 11 & & 37.5 & 17.90 & 17.95 & 0.29 & 18.03 & 0.73 & 18.13 & 1.28 & 18.29 & 2.18 & 17.30 & 3.35 & 17.30 & 3.35 \\
\hline 12 & & 45.0 & 16.61 & 16.45 & 0.95 & 16.65 & 0.24 & 16.65 & 0.26 & 16.79 & 1.08 & 15.69 & 5.56 & 15.69 & 5.54 \\
\hline 13 & \multirow{4}{*}{10.23} & 12.5 & 25.14 & 24.98 & 0.62 & 25.08 & 0.24 & 25.02 & 0.49 & 24.90 & 0.95 & 24.87 & 1.06 & 22.17 & 11.81 \\
\hline 14 & & 25.0 & 22.42 & 22.01 & 1.82 & 22.17 & 1.12 & 22.11 & 1.40 & 22.20 & 0.98 & 21.80 & 2.77 & 21.73 & 3.08 \\
\hline 15 & & 37.5 & 19.43 & 19.49 & 0.30 & 19.49 & 0.31 & 19.60 & 0.89 & 19.72 & 1.49 & 19.02 & 2.12 & 19.01 & 2.16 \\
\hline 16 & & 45.0 & 18.29 & 18.12 & 0.90 & 18.24 & 0.27 & 18.27 & 0.08 & 18.37 & 0.44 & 17.60 & 3.77 & 17.57 & 3.94 \\
\hline
\end{tabular}




\begin{tabular}{|c|c|c|c|c|c|c|c|c|c|c|c|c|c|c|c|}
\hline \multicolumn{16}{|c|}{... conclusão } \\
\hline \multirow{3}{*}{ № } & \multirow{3}{*}{$\begin{array}{l}{ }^{*} \mathrm{E}_{\mathrm{p}} \\
\text { (Gpa) }\end{array}$} & \multirow{3}{*}{$\begin{array}{c}\text { Fração } \\
\text { vol. } \\
\%\end{array}$} & \multirow{3}{*}{$\begin{array}{l}{ }^{* *} \mathrm{E}_{\mathrm{c}} \\
\text { (Gpa) }\end{array}$} & \multicolumn{4}{|c|}{ Célula periódica $\mathrm{A}$} & \multicolumn{4}{|c|}{ Célula periódica B } & \multicolumn{4}{|c|}{ Célula periódica C } \\
\hline & & & & \multicolumn{2}{|c|}{$\begin{array}{l}\text { Presente } \\
\text { Trabalho }\end{array}$} & \multicolumn{2}{|c|}{$\begin{array}{c}\text { Farage et.al. } \\
(2009)\end{array}$} & \multicolumn{2}{|c|}{$\begin{array}{l}\text { Presente } \\
\text { Trabalho }\end{array}$} & \multicolumn{2}{|c|}{$\begin{array}{c}\text { Farage et.al. } \\
(2009)\end{array}$} & \multicolumn{2}{|c|}{$\begin{array}{l}\text { Presente } \\
\text { Trabalho }\end{array}$} & \multicolumn{2}{|c|}{$\begin{array}{c}\text { Farage et.al. } \\
(2009)\end{array}$} \\
\hline & & & & $\begin{array}{c}E_{c} \\
(G p a)\end{array}$ & $\begin{array}{c}\text { |erro| } \\
(\%)\end{array}$ & $\begin{array}{c}E_{c} \\
(G \mathrm{gpa})\end{array}$ & $\begin{array}{c}\text { |erro| } \\
(\%)\end{array}$ & $\begin{array}{c}E_{c} \\
(G \mathrm{gpa})\end{array}$ & $\begin{array}{c}\text { |erro| } \\
(\%)\end{array}$ & $\begin{array}{c}E_{c} \\
(G \mathrm{pa})\end{array}$ & $\begin{array}{c}\text { |erro| } \\
(\%)\end{array}$ & $\begin{array}{c}E_{c} \\
(G p a)\end{array}$ & $\begin{array}{c}\text { |erro| } \\
(\%)\end{array}$ & $\begin{array}{c}E_{c} \\
(G p a)\end{array}$ & $\begin{array}{c}\text { |erro| } \\
(\%)\end{array}$ \\
\hline 17 & \multirow{4}{*}{20.23} & 12.5 & 27.37 & 27.33 & 0.15 & 27.35 & 0.07 & 27.34 & 0.11 & 27.35 & 0.07 & 27.32 & 0.18 & 27.33 & 0.15 \\
\hline 18 & & 25.0 & 26.26 & 26.16 & 0.38 & 26.19 & 0.27 & 26.18 & 0.30 & 26.20 & 0.23 & 26.14 & 0.46 & 26.13 & 0.50 \\
\hline 19 & & 37.5 & 25.28 & 25.07 & 0.83 & 25.01 & 1.07 & 25.08 & 0.79 & 25.11 & 0.67 & 25.01 & 1.07 & 25.00 & 1.11 \\
\hline 20 & & 45.0 & 24.32 & 24.43 & 0.45 & 24.43 & 0.45 & 24.45 & 0.53 & 24.47 & 0.62 & 24.37 & 0.21 & 24.36 & 0.16 \\
\hline \multicolumn{16}{|c|}{${ }^{*} E_{p}$ Módulo de elasticidade longitudinal do agregado - Ke et. al. ${ }^{8}$ (2006a, 2006b) apud Farage et. al. (2009) } \\
\hline
\end{tabular}

A variação dos valores de módulo de elasticidade obtidos, para um mesmo concreto, considerando-se diferentes tipos de células periódicas indica que a geometria e a distribuição das inclusões nas referidas células afetam significativamente as análises numéricas.

De maneira geral, os resultados obtidos para os três tipos de células periódicas são satisfatórios para a grande maioria dos sessenta casos analisados, Figura 4.4 (a,b,c). As maiores diferenças existentes podem ser atribuídas às malhas utilizadas nas discretizações, tanto da matriz quanto das partículas, onde se acredita que refinamentos nos modelos poderão levar a melhores resultados.

(a)

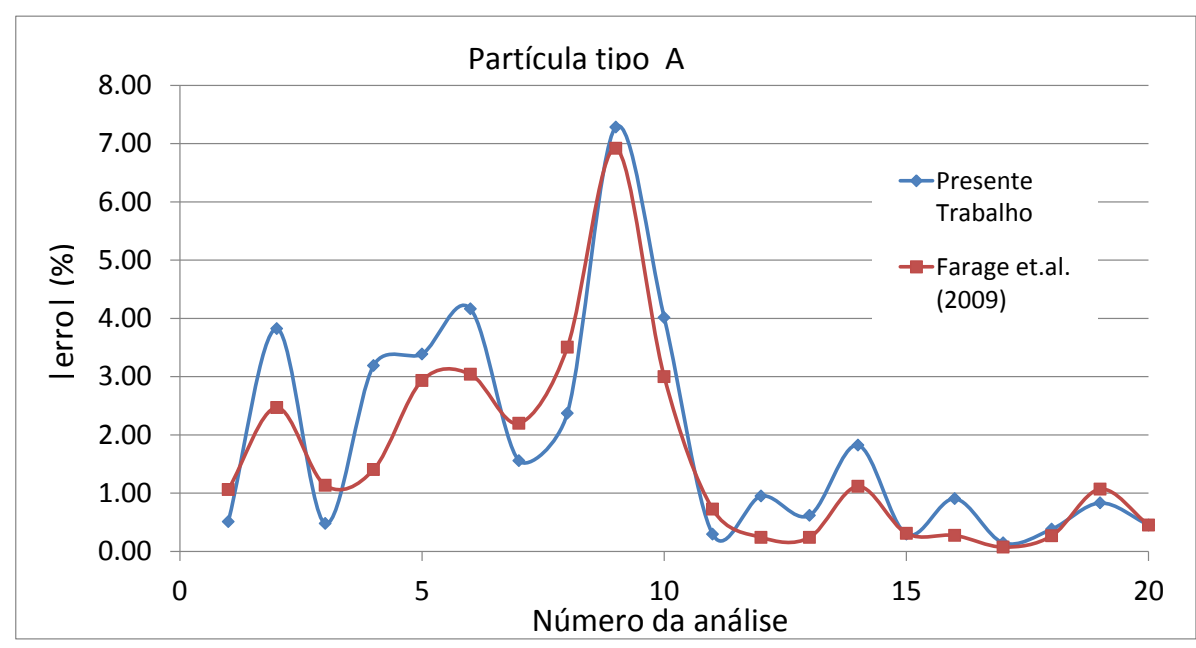


(b)

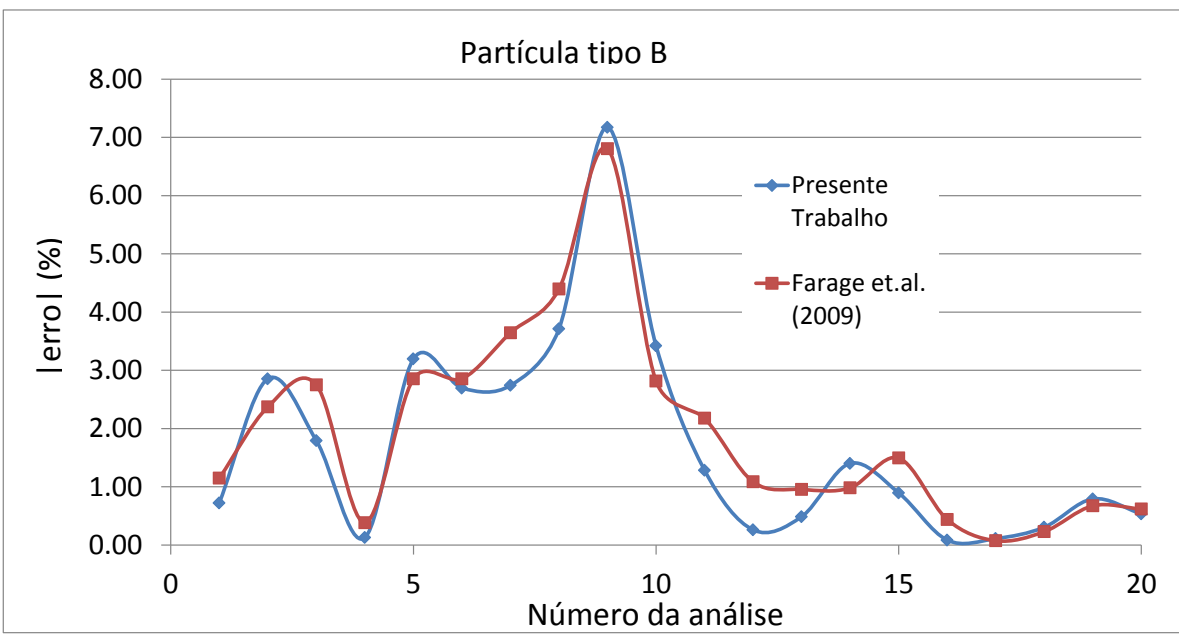

(c)

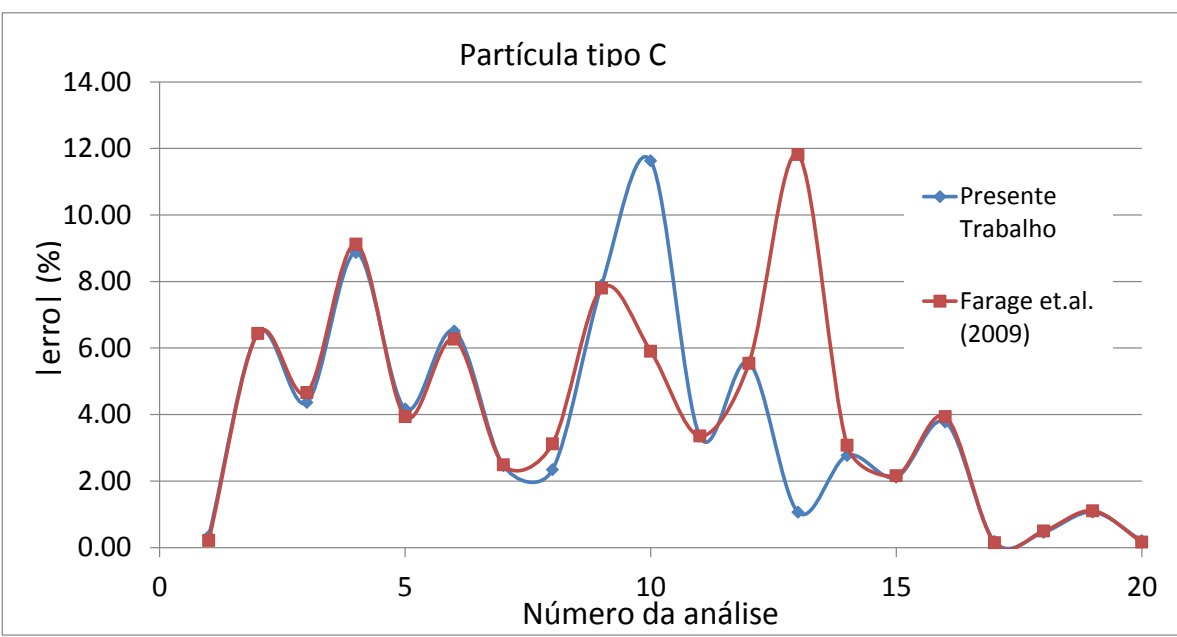

(d)

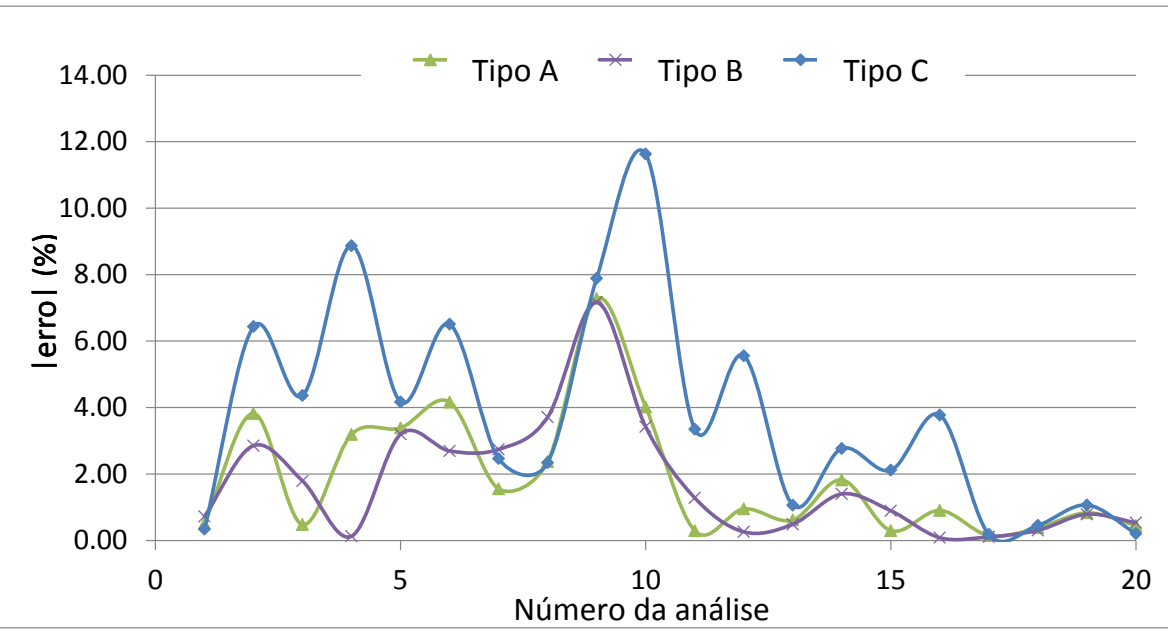

Figura 4.4 - Erros relativos aos valores experimentais para célula periódica (a) tipo A; (b) tipo B e (c) tipo C; (d) comparação entre os erros relativos e valores experimentais para os diferentes tipos de células periódicas

Os resultados obtidos permitem avaliar que as células periódicas tipo $\mathrm{A}$ e $\mathrm{B}$ forneceram melhores resultados quando comparadas aos valores fornecidos para as células do tipo C, como pode ser verificado na Figura 4.4 (d). 


\subsection{Exemplo 02: Módulo de elasticidade de concretos de alto desempenho}

Seguindo a mesma ideia do exemplo anterior, pretende-se com este exemplo verificar a influência das propriedades e geometrias dos agregados graúdos na avaliação do módulo de elasticidade longitudinal de concretos de alto desempenho, sendo que, novamente, as análises foram realizadas considerando-se células periódicas, tal como na técnica de Homogeneização por Expansão Assintótica.

São analisados compósitos de matriz cimentícia com inclusões de agregados de diferentes materiais. Os resultados são comparados com os obtidos no programa experimental apresentado em Zhou et. al. (1995), bem como com resultados de modelos reológicos fornecidos pelos referidos autores.

No programa experimental apresentado em Zhou et. al. (1995), são avaliados, experimentalmente, os valores de módulo de elasticidade longitudinal dos compósitos (matriz cimentícia + agregados) para 7, 28 e 91 dias. Os autores observaram que os resultados obtidos aos 28 dias preveem adequadamente 0 comportamento dos concretos ensaiados, uma vez que os resultados obtidos aos 7 dias correspondiam a aproximadamente $94 \%$ dos valores obtidos aos 28 dias, não apresentando acréscimos significativos após este período. Os modelos matemáticos, utilizados em Zhou et. al. (1995) para a obtenção dos valores homogeneizados de módulo de elasticidade para os casos ensaiados experimentalmente, foram extraídos desta referência e são reproduzidos a seguir:

a) Modelo de Voigt:

$$
\frac{\mathrm{E}_{\mathrm{c}}}{\mathrm{E}_{\mathrm{m}}}=1+\left(\frac{\mathrm{E}_{\mathrm{a}}}{\mathrm{E}_{\mathrm{m}}}-1\right) \mathrm{V}_{\mathrm{a}}
$$

com: $E_{c}=$ Módulo de elasticidade do concreto, $E_{m}=$ Módulo de elasticidade da matriz cimentícia (ou argamassa) e $E_{p}=$ Módulo de elasticidade do agregado (ou partículas), válidos para todos os modelos apresentados.

b) Modelo de Reuss:

$$
\frac{\mathrm{E}_{\mathrm{m}}}{\mathrm{E}_{\mathrm{c}}}=1+\left(\frac{\mathrm{E}_{\mathrm{m}}}{\mathrm{E}_{\mathrm{a}}}-1\right) \mathrm{V}_{\mathrm{a}}
$$


c) Modelo de Hirsch:

$\frac{\mathrm{E}_{\mathrm{m}}}{\mathrm{E}_{\mathrm{c}}}=\frac{1}{2}\left[\frac{1}{1+\left(\frac{\mathrm{E}_{\mathrm{a}}}{\mathrm{E}_{\mathrm{m}}}-1\right) \mathrm{V}_{\mathrm{a}}}+\left(1+\left(\frac{\mathrm{E}_{\mathrm{m}}}{\mathrm{E}_{\mathrm{a}}}-1\right) \mathrm{V}_{\mathrm{a}}\right)\right]$

d) Modelo de Couto:

$$
\frac{\mathrm{E}_{\mathrm{c}}}{\mathrm{E}_{\mathrm{m}}}=1+\frac{\mathrm{V}_{\mathrm{a}}}{\sqrt{\mathrm{V}_{\mathrm{a}}}-\mathrm{V}_{\mathrm{a}}+\frac{\mathrm{E}_{\mathrm{m}}}{\mathrm{E}_{\mathrm{a}}-\mathrm{E}_{\mathrm{m}}}}
$$

e) Modelo de PCouto:

$$
\frac{E_{c}}{E_{m}}=1+\frac{V_{a}}{\frac{E_{a}}{E_{a}-E_{m}}-\sqrt{V_{a}}}
$$

f) Modelo de BNC:

$$
\frac{\mathrm{E}_{\mathrm{c}}}{\mathrm{E}_{\mathrm{m}}}=\left(\frac{\mathrm{E}_{\mathrm{a}}}{\mathrm{E}_{\mathrm{m}}}\right)^{\mathrm{V}_{\mathrm{a}}}
$$

No presente trabalho foram realizadas análises para as diferentes geometrias e materiais adotados para os agregados, porém com uma única fração volumétrica de agregados, $42.5 \%$. As propriedades físicas da argamassa (matriz) e dos diferentes materiais utilizados como agregados graúdos (partículas) são

\begin{tabular}{|c|c|c|c|}
\hline Material & & $\mathrm{E}(\mathrm{GPa})$ & $v$ \\
\hline Argamassa & $\left(E_{m}\right)$ & 40.8 & \multirow{7}{*}{0.2} \\
\hline Argila expandida & \multirow{6}{*}{$\left(E_{p}\right)$} & 5.2 & \\
\hline Cinza volante & & 18.2 & \\
\hline Calcário & & 56.0 & \\
\hline Cascalho & & 54.0 & \\
\hline Vidro & & 72.0 & \\
\hline Aço & & 210.0 & \\
\hline
\end{tabular}
apresentadas na Tabela 4.4.

Tabela 4.4 - Propriedades físicas dos materiais (adaptada de Zhou et. al. (1995)) 
Para cada tipo de agregado apresentado na Tabela 4.4, foram realizadas análises para cinco tipos de células periódicas, variando a geometria das inclusões, totalizando trinta modelos numéricos analisados. A fração volumétrica de agregado, como dito anteriormente, foi a mesma para todos os casos, ou seja, $42.5 \%$. As malhas utilizadas na discretização da argamassa e das cinco diferentes geometrias de inclusão adotadas são apresentadas na Figura 4.5. Novamente, foram utilizados elementos finitos triangulares com aproximação cúbica de posições na discretização das duas fases. O número de nós e elementos utilizados nas malhas de cada fase estão apresentados na Tabela 4.5.

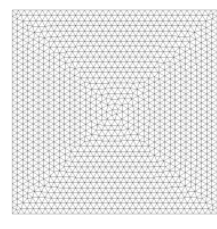

Matriz

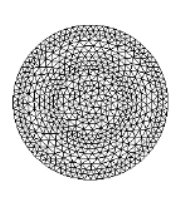

Tipo 1

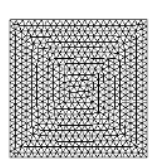

Tipo 2

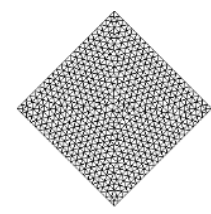

Tipo 3

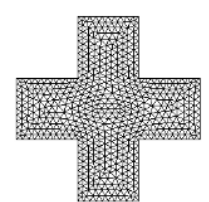

Tipo 4

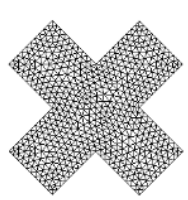

Tipo 5

Inclusões

Figura 4.5 - Discretizações da matriz e inclusões

Tabela 4.5 - Número de nós e elementos utilizados nas malhas de cada fase

\begin{tabular}{ccc}
\hline Fase & Nós & Elementos \\
\hline \hline Partícula Tipo 1 & 5116 & 1110 \\
\hline Partícula Tipo 2 & 5020 & 1086 \\
\hline Partícula Tipo 3 & 5020 & 1086 \\
\hline Partícula Tipo 4 & 5059 & 1084 \\
\hline Partícula Tipo 5 & 5059 & 1084 \\
\hline Matriz & 11968 & 2614 \\
\hline
\end{tabular}

Considerando a combinação da matriz com cada geometria apresentada na Figura 4.5, tem-se como resultado as configurações de células periódicas apresentadas na Figura 4.6, utilizadas nas análises de cada um dos diferentes materiais adotados para o agregado.

Novamente, como pode ser observado na Figura 4.6, a malha das partículas se sobrepõe à malha da matriz, sem a necessidade de coincidência dos nós e elementos. Da mesma forma que para o exemplo anterior, em todos os casos 
analisados, o valor utilizado para o módulo de elasticidade longitudinal da matriz é o nominal, apresentado na Tabela 4.4. Já para as partículas, o valor utilizado nas modelagens é a diferença entre o valor adotado para a matriz e o valor adotado para cada tipo de material utilizado para os agregados, para desconsiderar a sobreposição dos elementos/materiais, resultando inclusive, para alguns materiais, em valores negativos para serem fornecidos ao programa.

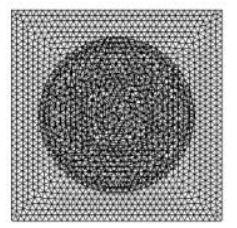

Tipo 1

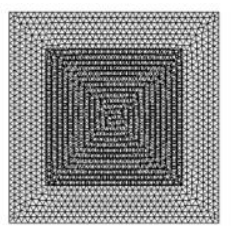

Tipo 2

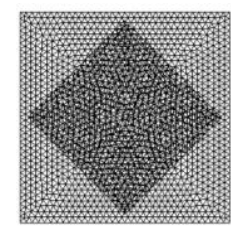

Tipo 3

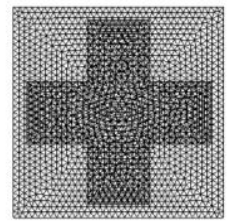

Tipo 4

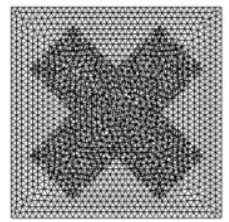

Tipo 5

Figura 4.6 - Células periódicas

Os valores de módulo de elasticidade longitudinal $\left(E_{c}\right)$ equivalente ao meio homogeneizado foram obtidos da mesma forma que para o exemplo anterior, ou seja, as simulações numéricas, em regime de pequenos deslocamentos e pequenas deformações (Lei de Hooke), foram realizadas com controle de deslocamento em uma das faces e vinculação, na mesma direção do carregamento, na face paralela oposta. Com os valores conhecidos do deslocamento, das dimensões da célula periódica e das reações na face vinculada, foi possível determinar o valor do referido módulo de elasticidade longitudinal homogeneizado para comparação com os resultados numéricos e experimentais da referência.

Os resultados para os trinta modelos analisados no presente trabalho são apresentados na Tabela 4.6, e são comparados aos valores experimentais e teóricos fornecidos em Zhou et. al. (1995), sendo ainda incluídos na referida tabela os erros relativos entre os valores obtidos e os valores experimentais de Zhou et. al. (1995).

Novamente, percebe-se a sensibilidade nos resultados de módulo de elasticidade longitudinal obtidos numericamente em relação às diferentes geometrias adotadas para as inclusões dos cinco tipos de células periódicas simuladas para os 6 diferentes materiais de agregado graúdo. Essa sensibilidade é menor para os agregados de cascalho e calcário, onde os erros relativos aos valores experimentais são praticamente iguais para todas as células periódicas, sendo que os valores dos módulos de elasticidade das fases são mais próximos para estes casos. 
Tabela 4.6 - Resultados das análises (adaptada de Zhou et. al. (1995))

\begin{tabular}{|c|c|c|c|c|c|c|c|}
\hline & & \multicolumn{6}{|c|}{ Concreto: $57.5 \%$ Argamassa + 42.5\% Agregado graúdo } \\
\hline & & $\begin{array}{c}\text { Argila } \\
\text { Expandida }\end{array}$ & $\begin{array}{c}\text { Cinza } \\
\text { volante }\end{array}$ & Calcário & Cascalho & Vidro & Aço \\
\hline \multirow{7}{*}{$\begin{array}{c}E_{c}(\mathrm{GPa}) \\
\text { Zhou et. al. } \\
\quad(1995)\end{array}$} & Experimental & 18.6 & 30.2 & 49.5 & 51.3 & 52.8 & 69.9 \\
\hline & Voigt & 26.1 & 31.3 & 47.2 & 46.4 & 54.0 & 112.8 \\
\hline & Reuss & 12.0 & 26.9 & 46.1 & 45.5 & 50.0 & 62.0 \\
\hline & Hirsch & 16.4 & 28.9 & 46.6 & 45.9 & 51.9 & 80.0 \\
\hline & Couto & 21.9 & 29.8 & 46.8 & 46.0 & 52.1 & 77.8 \\
\hline & PCouto & 19.1 & 28.9 & 46.5 & 45.8 & 51.3 & 70.2 \\
\hline & BNC & 17.0 & 29.0 & 46.5 & 46 & 51.9 & 81.5 \\
\hline \multirow{5}{*}{$\begin{array}{c}\mathrm{E}_{\mathrm{c}}(\mathrm{GPa}) \\
\text { Célula } \\
\text { periódica }\end{array}$} & Tipo 1 & 19.0 & 29.0 & 46.5 & 45.9 & 51.4 & 71.3 \\
\hline & Tipo 2 & 19.5 & 29.1 & 46.6 & 45.9 & 51.5 & 72.4 \\
\hline & Tipo 3 & 15.7 & 28.6 & 46.6 & 45.9 & 51.5 & 74.3 \\
\hline & Tipo 4 & 16.6 & 28.7 & 46.6 & 45.9 & 51.8 & 79.3 \\
\hline & Tipo 5 & 17.0 & 28.6 & 46.5 & 45.8 & 51.3 & 72.6 \\
\hline \multirow{5}{*}{$\begin{array}{l}\text { |erro| (\%) } \\
\text { Célula } \\
\text { periódica }\end{array}$} & Tipo 1 & 2.2 & 4.1 & 6.0 & 10.6 & 2.7 & 2.1 \\
\hline & Tipo 2 & 4.9 & 3.7 & 5.9 & 10.6 & 2.5 & 3.6 \\
\hline & Tipo 3 & 15.7 & 5.4 & 6.0 & 10.6 & 2.5 & 6.3 \\
\hline & Tipo 4 & 10.6 & 4.9 & 5.8 & 10.5 & 1.9 & 13.4 \\
\hline & Tipo 5 & 8.4 & 5.3 & 6.0 & 10.6 & 2.8 & 3.8 \\
\hline
\end{tabular}

Os resultados obtidos para concretos utilizando-se agregados com módulo de elasticidade inferior ao da matriz cimentícia são, como esperado, inferiores aos valores de módulo de elasticidade da referida matriz, valendo a mesma análise para a situação inversa.

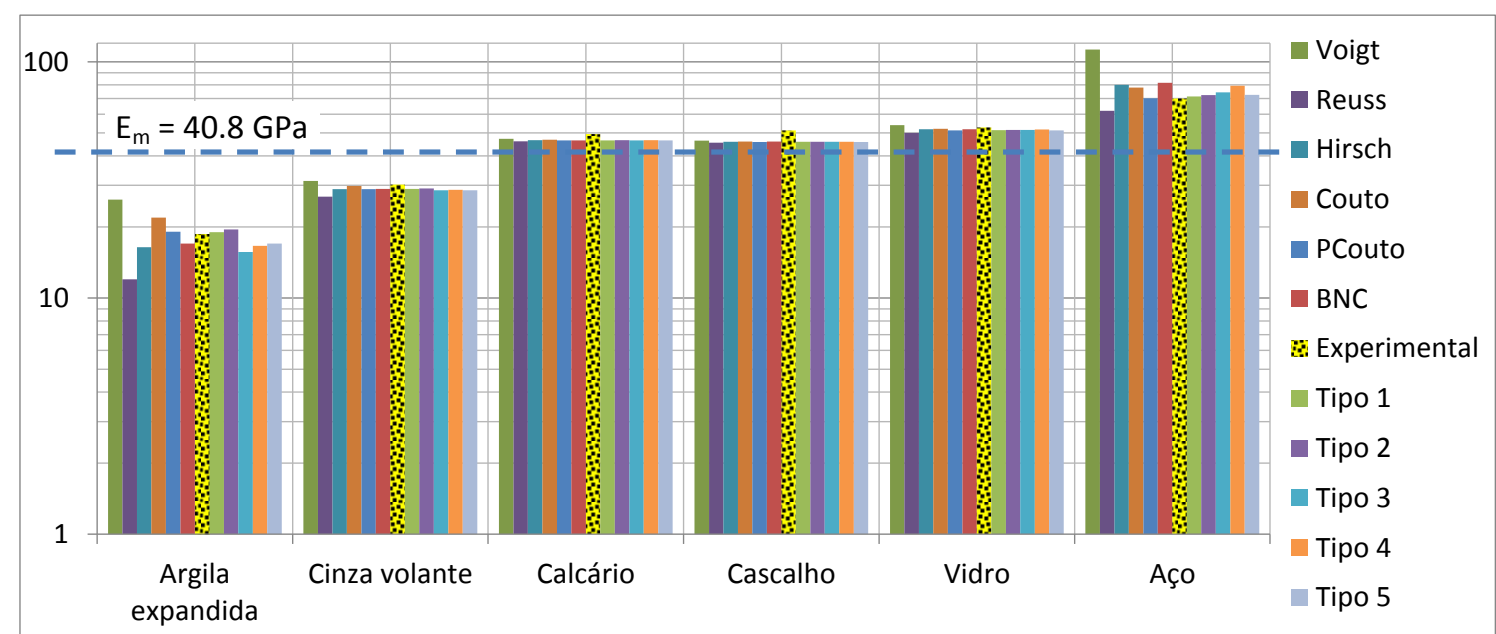

Figura 4.7 - Comparação entre os valores teóricos e experimentais fornecidos em Zhou et. al. (1995) e os valores obtidos no presente trabalho para diferentes materiais e tipos de células periódicas 
Tal como no exemplo anterior, as diferenças existentes podem ser, em parte, atribuídas às malhas utilizadas nas discretizações, tanto da matriz quanto das partículas, onde se acredita que refinamentos nos modelos poderão levar a melhores resultados.

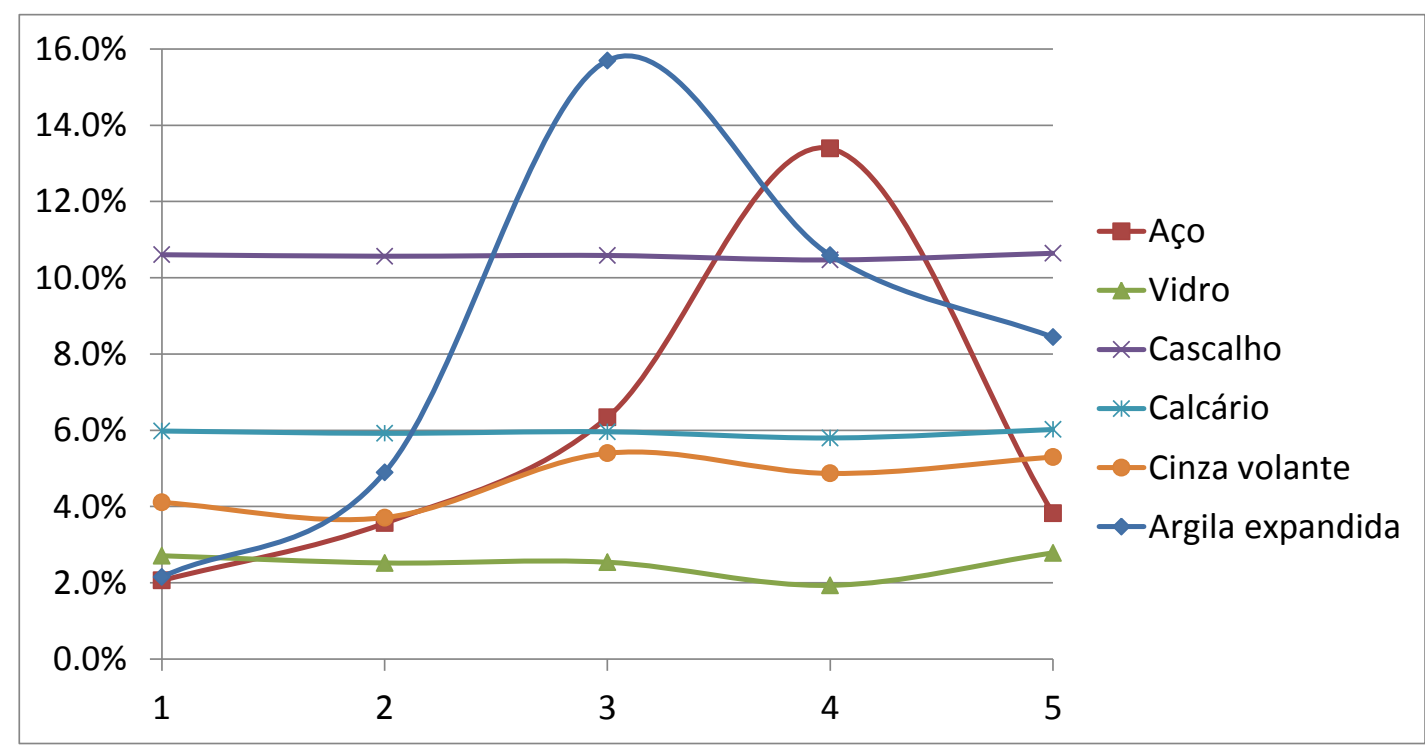

Figura 4.8 - Erros relativos aos valores experimentais de Zhou et. al. (1995) para diferentes agregados e tipos de célula periódica

Pode-se afirmar que, para as análises realizadas nos dois primeiros exemplos, as contribuições provenientes das variações de tamanho das partículas, bem como do efeito do empacotamento que por ventura venha a ocorrer devido a esta variação de tamanho, não são levados em consideração no comportamento desses modelos baseados em células periódicas.

\subsection{Exemplo 03: Sólido bidimensional com geometria trapezoidal}

Este exemplo trata da simulação do comportamento global de uma chapa com geometria trapezoidal, similar à geometria de uma barragem, onde são avaliados os deslocamentos no contínuo modelado segundo duas configurações distintas. $\mathrm{Na}$ primeira adotam-se as propriedades homogeneizadas para $\mathrm{o}$ compósito, ou seja, fase única, e em seguida repete-se a simulação considerandose as diferentes fases que constituem o material, matriz e partículas, comparando-se 
os resultados para verificação do desempenho da formulação na análise de casos mais gerais que os discutidos nos dois primeiros exemplos, onde células periódicas foram utilizadas. A geometria e condições de contorno do problema estão apresentadas na Figura 4.9.
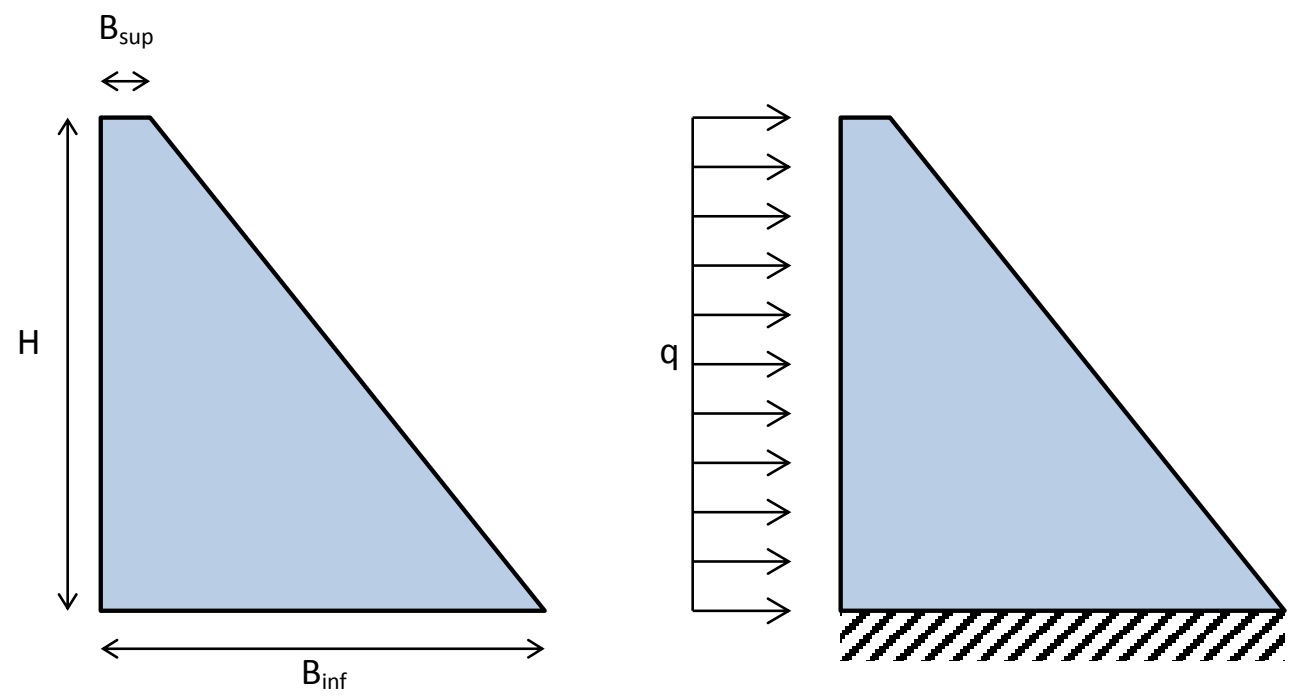

Figura 4.9 - Geometria e condições de contorno

$\left(q=5 \mathrm{kN} / \mathrm{cm} ; \mathrm{H}=100 \mathrm{~cm} ; B_{\text {sup }}=10 \mathrm{~cm}\right.$ e $\left.B_{\text {inf }}=90 \mathrm{~cm}\right)$

No caso de fase única, foram analisados dois compósitos diferentes, considerando as propriedades homogeneizadas nas simulações. Para os modelos com duas fases foram analisadas 6 situações, combinando os casos dos dois materiais utilizados na fase única com 3 geometrias diferentes de partículas distribuídas aleatoriamente, sendo: partículas circulares (tipo 1), quadradas (tipo 2) e com geometria aleatória (tipo 3). As propriedades elásticas dos materiais utilizados neste exemplo, bem como as frações volumétricas de cada fase, foram extraídas de Farage et. al. (2009) e estão apresentadas na Tabela 4.7.

Tabela 4.7 - Propriedades físicas dos materiais

\begin{tabular}{|c|c|c|c|c|c|}
\hline \multirow{2}{*}{ Material } & \multicolumn{2}{|c|}{$\begin{array}{c}\text { Matriz } \\
\text { (argamassa cimentícia) }\end{array}$} & \multicolumn{2}{|c|}{$\begin{array}{c}\text { Partículas } \\
\text { (argila expandida) }\end{array}$} & \multirow{2}{*}{$\begin{array}{c}\text { Concreto } \\
\text { (matriz + partículas) } \\
{ }^{*} \mathrm{E}_{\mathrm{c}}(\mathrm{GPa})\end{array}$} \\
\hline & ${ }^{*} \mathrm{E}_{\mathrm{m}}(\mathrm{GPa})$ & $\begin{array}{l}\text { Fração vol. } \\
(\%)\end{array}$ & ${ }^{*} \mathrm{E}_{\mathrm{a}}(\mathrm{GPa})$ & $\begin{array}{l}\text { Fração vol. } \\
\text { (\%) }\end{array}$ & \\
\hline Concreto 1 & \multirow{2}{*}{28.58} & \multirow{2}{*}{87.5} & 6.47 & \multirow{2}{*}{12.5} & 23.54 \\
\hline \multirow{2}{*}{\multicolumn{6}{|c|}{$=0.0$ para todos os materiais }} \\
\hline & & & & & \\
\hline $\begin{array}{l}{ }^{*} E_{a} \text { Módulo de } \\
{ }^{* *} E_{c} \text { Módulo de }\end{array}$ & $\begin{array}{l}\text { sticidade long } \\
\text { asticidade lon }\end{array}$ & dinal do conc & $\begin{array}{l}- \text { Ke et. al. }{ }^{8} \\
\text { - Ke et. al. }\end{array}$ & 2006b; a & $\begin{array}{l}\text { age et. al. (2009)) } \\
\text { rage et. al. (2009)) }\end{array}$ \\
\hline
\end{tabular}


Foram utilizados elementos finitos triangulares com aproximação cúbica de deslocamentos na discretização da matriz e elementos finitos com aproximação linear de deslocamentos na discretização das partículas. As malhas de elementos finitos utilizadas nas simulações são apresentadas na Figura 4.10. O número de nós e elementos utilizados nas malhas de cada fase estão apresentados na Tabela 4.8.

(a)

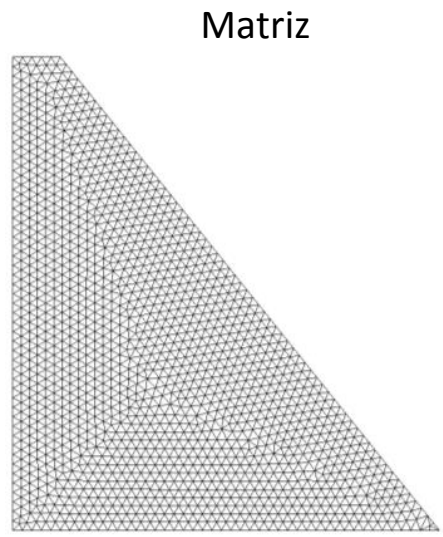

Partículas
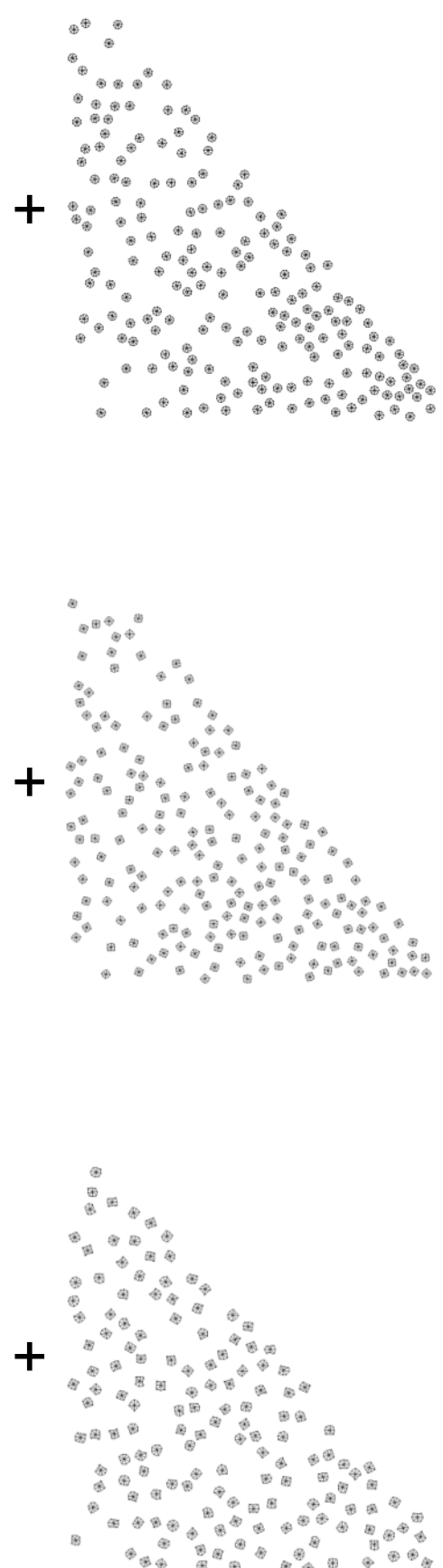

Compósito
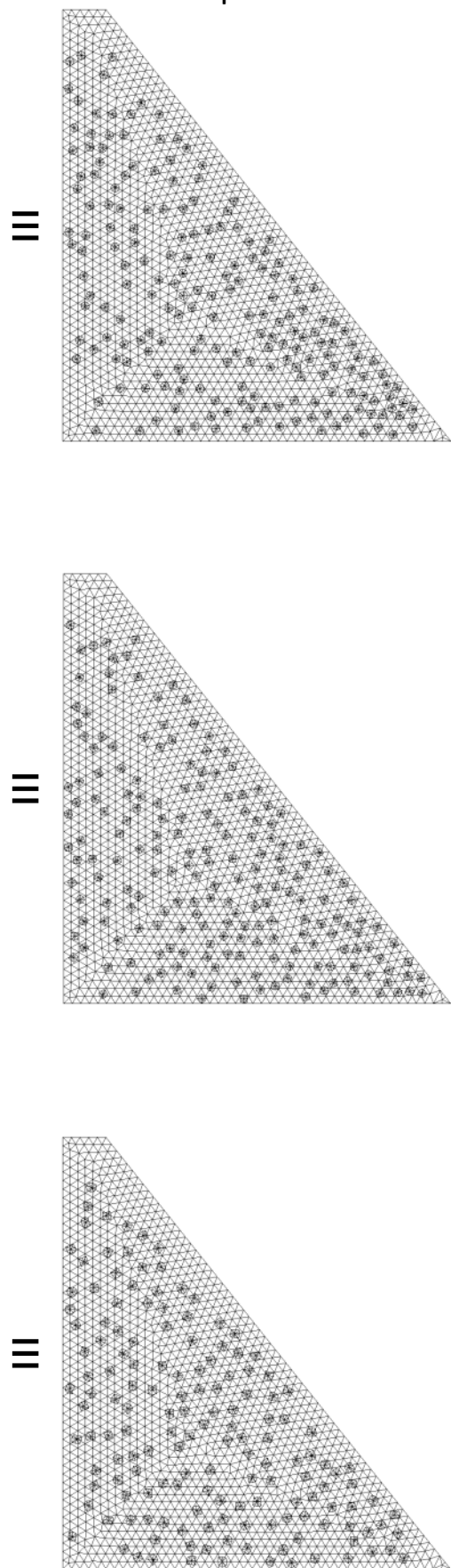

Figura 4.10 - Malhas matriz e partículas

Geometria: (a) circular; (b) quadrada; (c) aleatória 
Tabela 4.8 - Número de nós e elementos utilizados nas malhas de cada fase

\begin{tabular}{ccc}
\hline Fase & Nós & Elementos \\
\hline \hline Partícula Tipo 1 & 1755 & 1560 \\
\hline Partícula Tipo 2 & 1773 & 1576 \\
\hline Partícula Tipo 3 & 1395 & 1240 \\
\hline Matriz & 13105 & 2857
\end{tabular}

Os resultados obtidos para os materiais concreto 1 e concreto 2 (Tabela 4.7) são apresentados, respectivamente nas Figuras 4.11 e 4.12, tanto para 0 caso homogeneizado quanto para o caso de fases distintas, ou seja, matriz e partículas modeladas separadamente. A Tabela 4.9 apresenta comparação dos máximos deslocamentos horizontais e verticais obtidos nas simulações para o topo do modelo.

Concreto 1

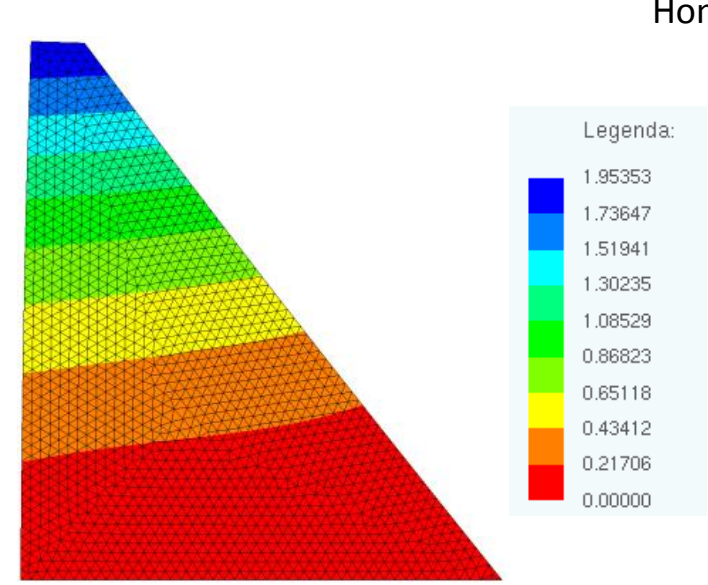

(a)

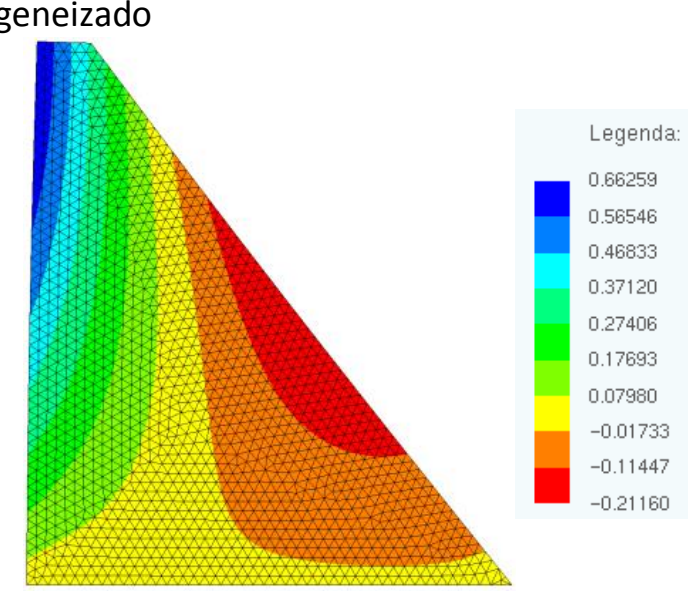

(b)

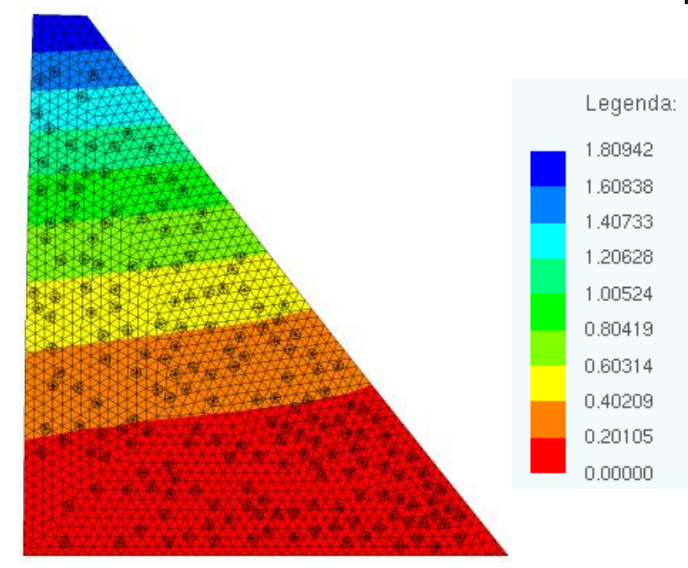

(a)

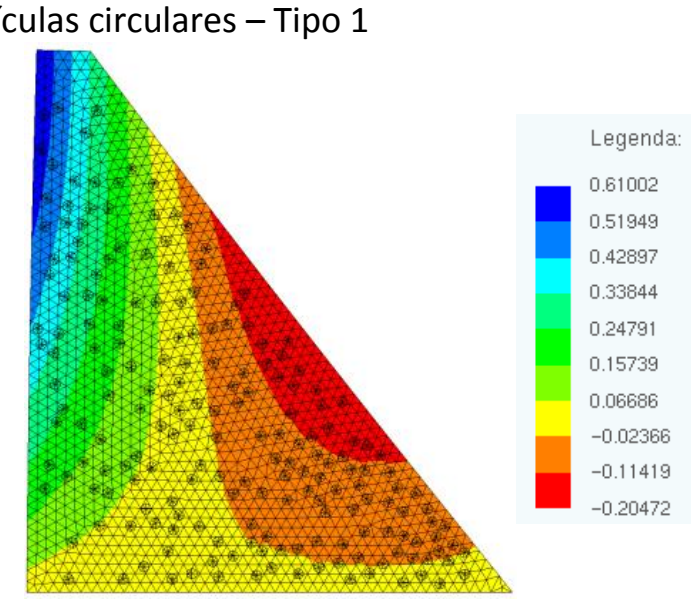

(b)

Fases distintas: partículas quadradas - Tipo 2 


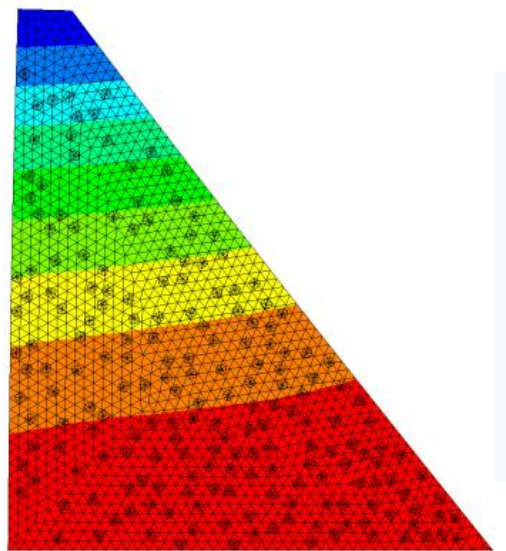

(a)

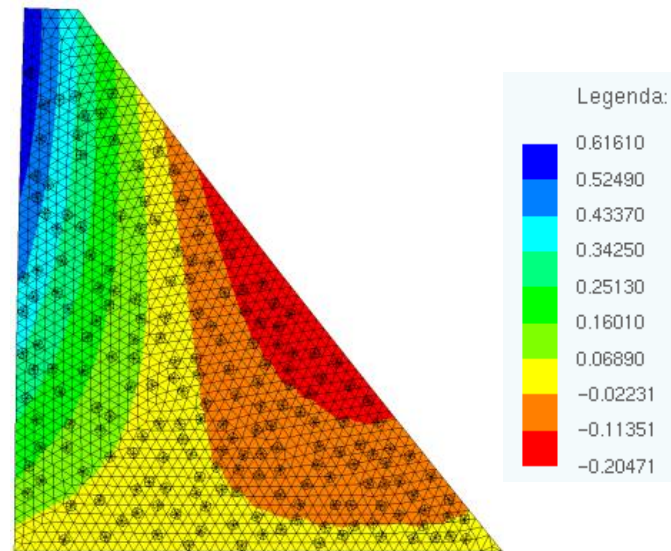

(b)

Fases distintas: partículas aleatórias - Tipo 3

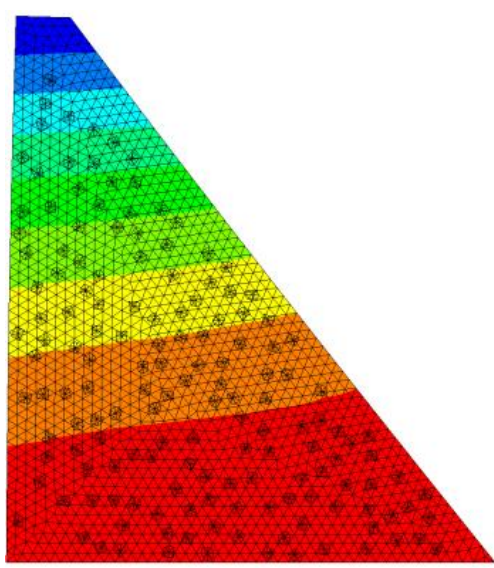

(a)

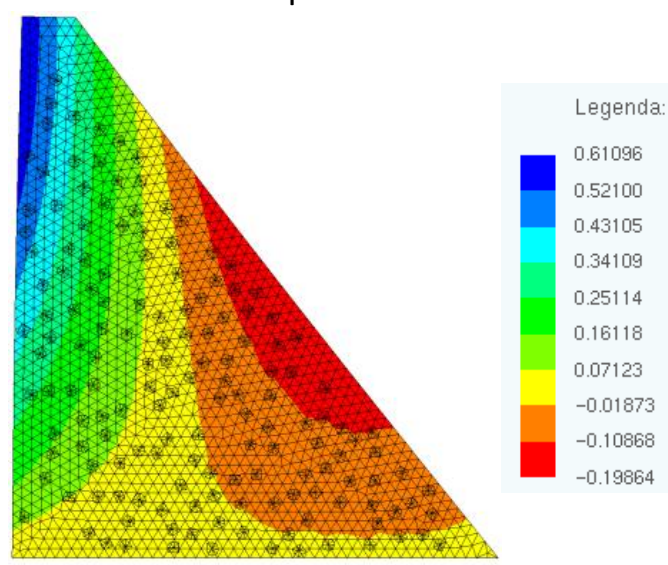

(b)

Figura 4.11 - Concreto 1: deslocamentos (a) horizontais e (b) verticais

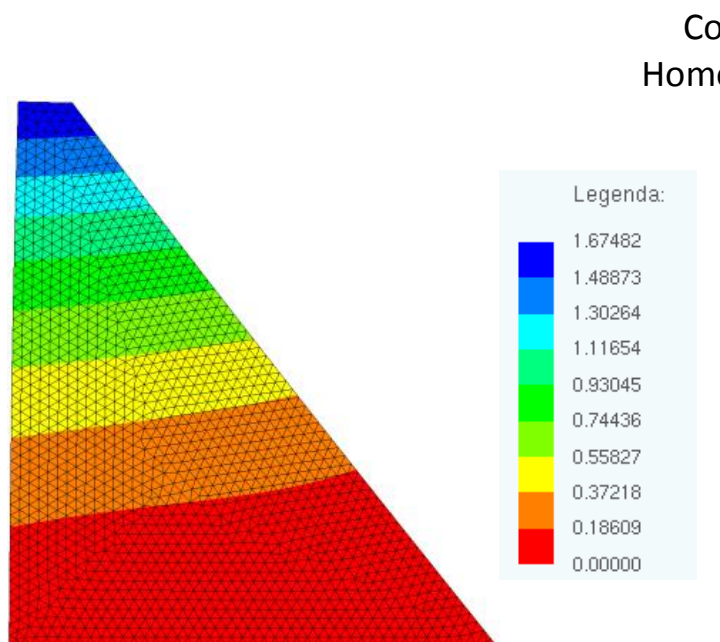

(a)

Concreto 2

Homogeneizado

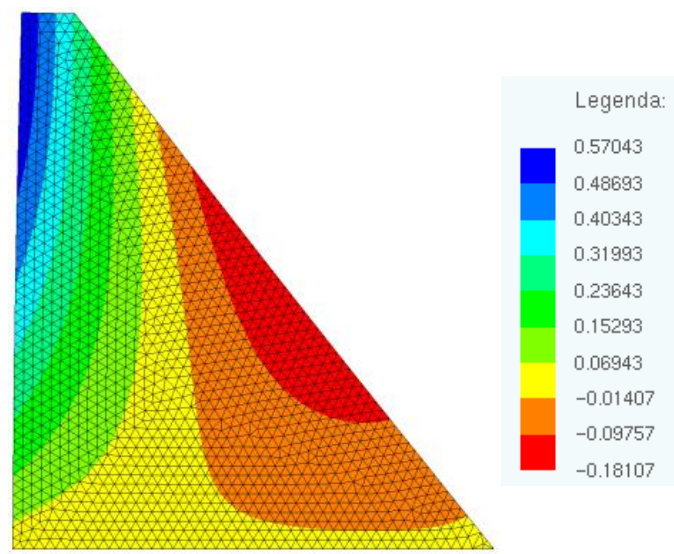

(b)

Fases distintas: partículas circulares - Tipo 1 


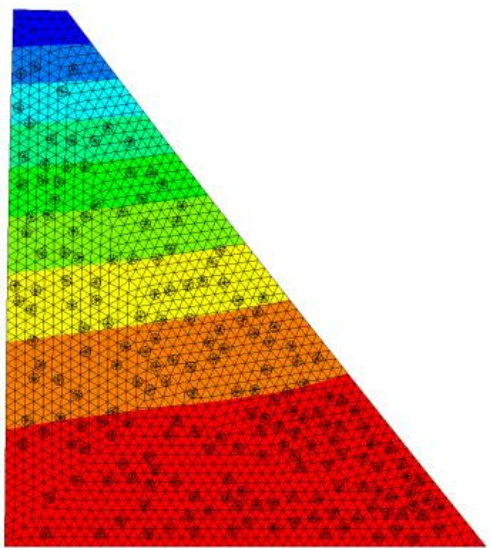

(a)

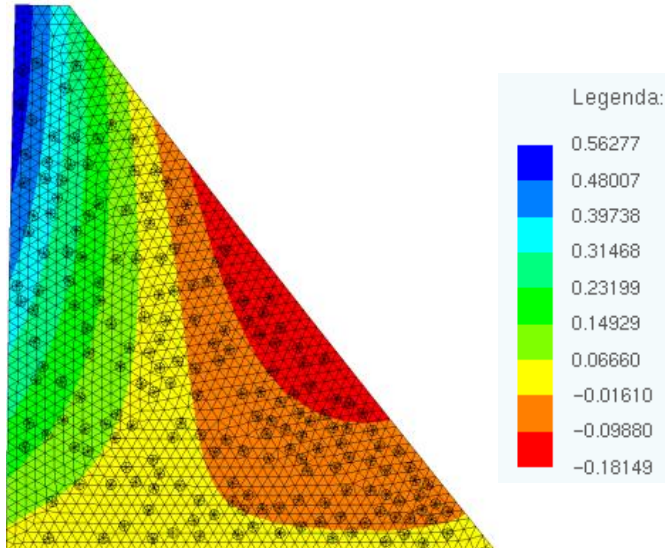

(b)

Fases distintas: partículas quadradas - Tipo 2

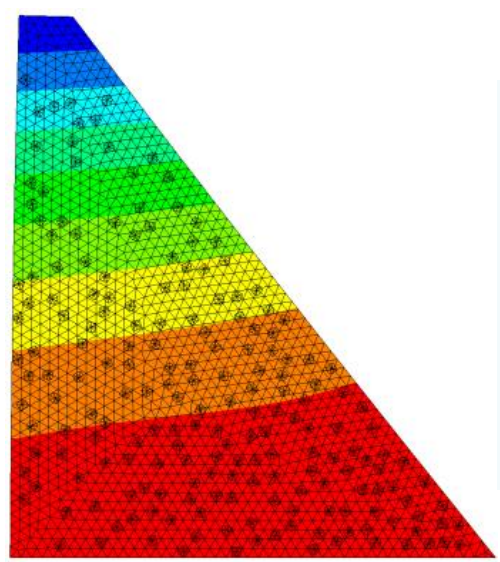

(a)

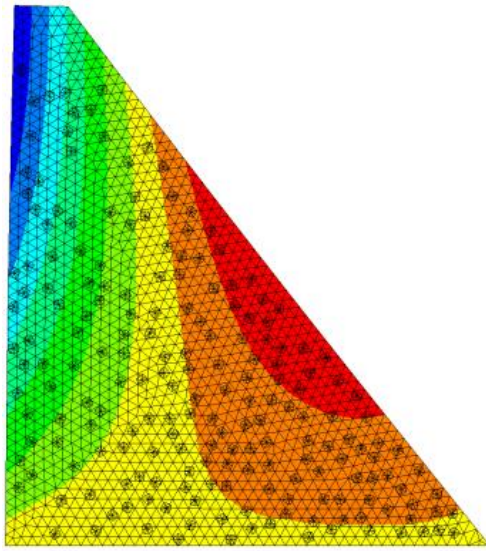

(b)

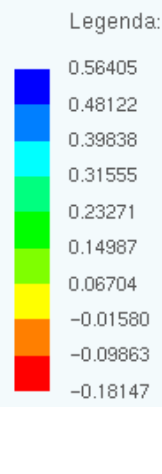

Fases distintas: partículas aleatórias - Tipo 3

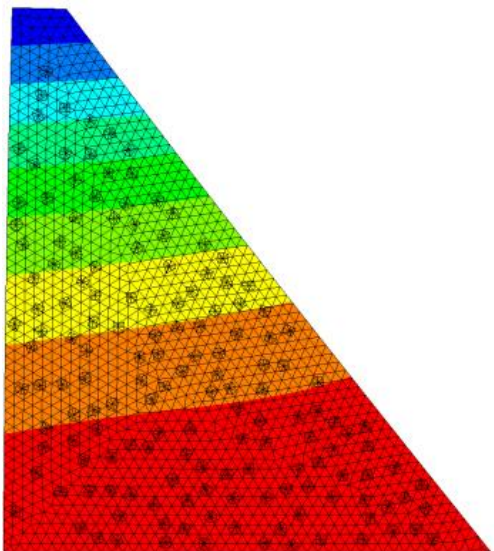

(a)

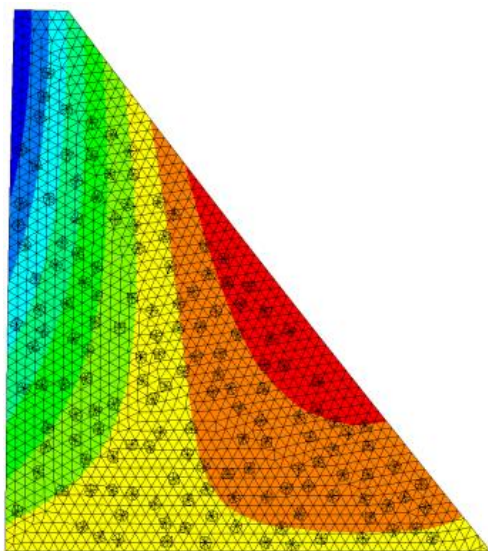

(b)

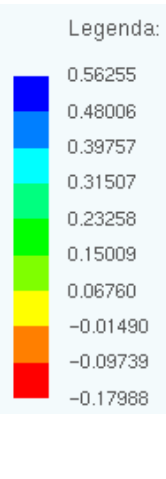

0.56255

0.48006

.15009

.06760

17988

Figura 4.12 - Concreto 2: deslocamentos (a) horizontais e (b) verticais

Tabela 4.9 - Comparação dos máximos deslocamentos horizontais e verticais

\begin{tabular}{ccccccccc}
\hline & \multicolumn{2}{c}{ Homogeneizado } & \multicolumn{5}{c}{ Fases distintas } \\
\cline { 2 - 8 } Material & $\begin{array}{c}\text { Horizontal } \\
(\mathrm{cm})\end{array}$ & $\begin{array}{c}\text { Vertical } \\
(\mathrm{cm})\end{array}$ & $\begin{array}{c}\text { Corizontal } \\
(\mathrm{cm})\end{array}$ & $\begin{array}{c}\text { Vertical } \\
(\mathrm{cm})\end{array}$ & $\begin{array}{c}\text { Horizontal } \\
(\mathrm{cm})\end{array}$ & $\begin{array}{c}\text { Vertical } \\
(\mathrm{cm})\end{array}$ & $\begin{array}{c}\text { Horizontal } \\
(\mathrm{cm})\end{array}$ & $\begin{array}{c}\text { Vertical } \\
(\mathrm{cm})\end{array}$ \\
\hline \hline Concreto 1 & 1.9535 & 0.6626 & 1.8094 & 0.6100 & 1.8245 & 0.6161 & 1.8057 & 0.6109 \\
\hline Concreto 2 & 1.6748 & 0.5704 & 1.6559 & 0.5628 & 1.6590 & 0.5641 & 1.6537 & 0.5626 \\
\hline
\end{tabular}


É possível verificar que tanto a geometria quanto as propriedades físicas das partículas influenciaram nos resultados de deslocamento horizontais e verticais obtidos. Os erros relativos entre os valores obtidos para o caso de fases distintas e para o caso homogeneizado, considerando tanto deslocamentos horizontais quanto verticais, ficaram entre $6.6 \%$ e $7.94 \%$ para o Concreto 1 e entre $0.94 \%$ e $1.37 \%$ para - Concreto 2, sendo possível verificar que para maiores relações entre as propriedades adotadas para a matriz e para as partículas os erros relativos foram maiores (Concreto 1).

\subsection{Exemplo 04: Sólido bidimensional com inclusão de vazio}

Aproveitando-se a geometria e carregamentos utilizados no terceiro exemplo, fazendo-se pequenas adaptações, foram realizadas análises para o quarto exemplo proposto com caráter geral e discussão qualitativa dos resultados. Neste último caso analisado, foram testadas as potencialidades do código utilizado no que diz respeito à inclusão de vazios no contínuo, um caso extremo da relação entre as propriedades físicas da matriz e das partículas. A geometria e condições de contorno estão apresentadas na Figura 4.13.
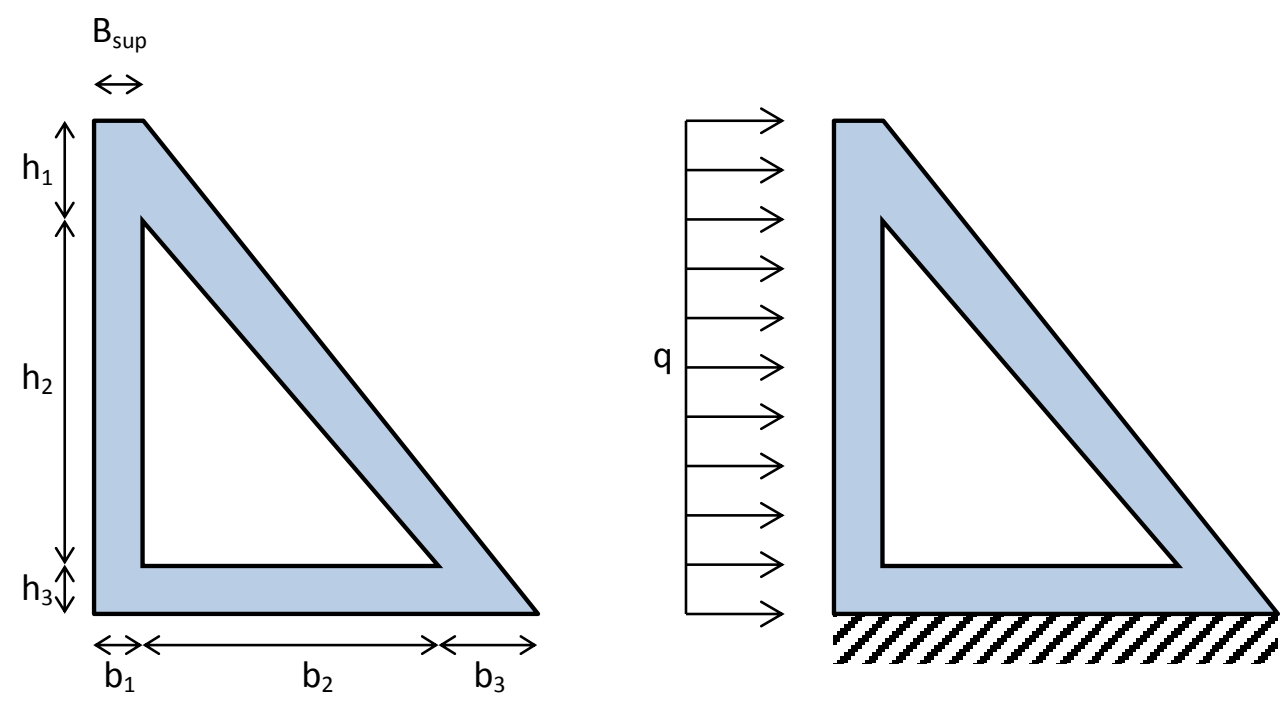

Figura 4.13 - Geometria e condições de contorno

$\left(\mathrm{q}=5 \mathrm{kN} / \mathrm{cm} ; \mathrm{h}_{1}=20 \mathrm{~cm} ; \mathrm{h}_{2}=70 \mathrm{~cm} ; \mathrm{h}_{3}=10 \mathrm{~cm}\right.$;

$\left.b_{1}=10 \mathrm{~cm} ; b_{2}=60 \mathrm{~cm} ; b_{3}=20 \mathrm{~cm} ; B_{\text {sup }}=10 \mathrm{~cm}\right)$ 
Neste exemplo as partículas são utilizadas para descontar a contribuição do material no vazio com geometria triangular apresentado na Figura 4.13. As propriedades elásticas do material utilizado neste exemplo foram: $E=40.8 \mathrm{GPa}$ e $v$ $=0.0$, correspondentes aos valores adotados no segundo exemplo para a argamassa, Tabela 4.3. Portanto, matriz e partículas tem praticamente as mesmas propriedades físicas, uma vez que não se é possível adotar os valores idênticos em virtudes dos problemas numéricos que surgem devido ao desacoplamento das malhas. Neste sentido, a relação adotada para $E_{p} / E_{m}$ é de 0.995 . Para efeito de comparação, analisa-se também a chapa apresentada na Figura 4.13 já com o vazio triangular existente, ou seja, sem a consideração das partículas para tal inclusão.

Foram utilizados elementos finitos triangulares com aproximação cúbica de deslocamentos na discretização tanto da matriz quando das partículas (vazio), bem como no caso da chapa gerada já com a consideração do vazio. As malhas de elementos finitos utilizadas nas simulações são apresentadas na Figura 4.14. O número de nós e elementos utilizados nas malhas estão apresentados na Tabela 4.10 .

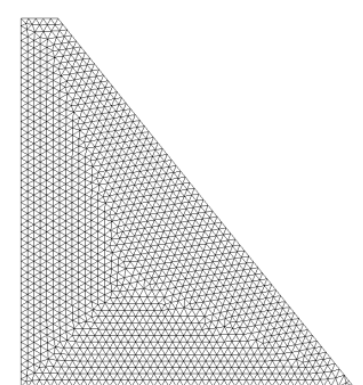

Matriz
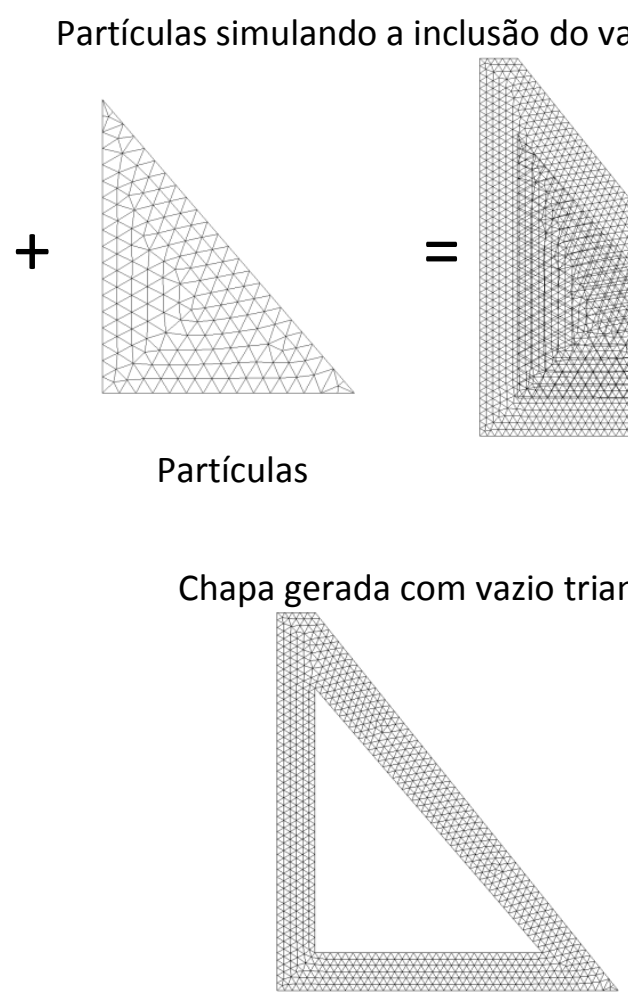

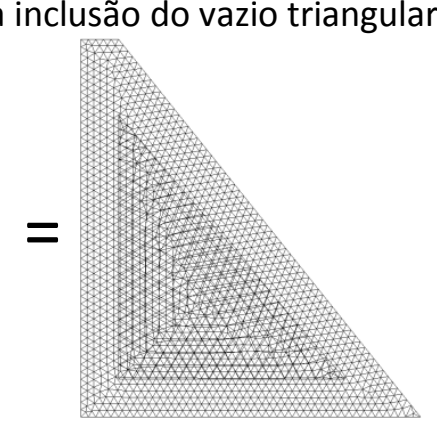

Chapa equivalente

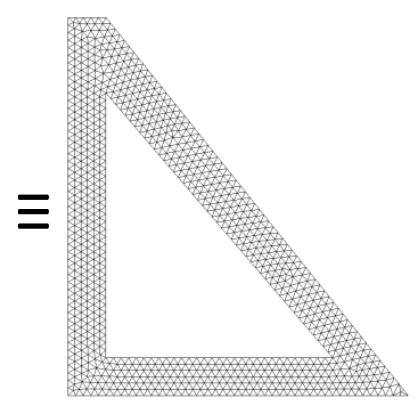


Tabela 4.10 - Número de nós e elementos utilizados nas malhas

\begin{tabular}{ccc}
\hline Fase & Nós & Elementos \\
\hline Matriz & 13105 & 2857 \\
\hline Partículas & 1441 & 301 \\
\hline Chapa triangular com vazio & 7926 & 1669 \\
\hline
\end{tabular}

Os resultados de deslocamentos horizontais e verticais obtidos para os 2 casos analisados são apresentados, na forma de mapa de cores, na Figura 4.15. Os valores limites das legendas dos dois casos analisados foram mantidos iguais para melhor comparação dos resultados e correspondem aos valores obtidos para o caso da chapa já gerada com o vazio. Os máximos deslocamentos obtidos para os dois casos analisados foram ligeiramente diferentes, justificando-se tal resultado tanto pela posição das partículas no contínuo, onde a influência dessa parcela descontando rigidez do conjunto afeta todos os elementos onde ocorre a sobreposição das malhas, produzindo uma sombra de vazio além das dimensões reais do triângulo a ser descontado, quanto pelo fato de não ser possível considerar a rigidez das partículas com valor igual em módulo ao da matriz devido aos já mencionados problemas numéricos.

De maneira geral, os resultados obtidos permitem concluir que a formulação utilizada para modelagem de meios contínuos com inclusões, mais ou menos rígidas que o meio, fornece bons resultados. Acredita-se ainda que um refinamento das malhas utilizadas no problema podem gerar resultados melhores para os casos analisados. Vale lembrar que o refinamento das discretizações das partículas não acarreta em acréscimo do número de graus de liberdade global do problema, considerada uma das características positivas da formulação utilizada.

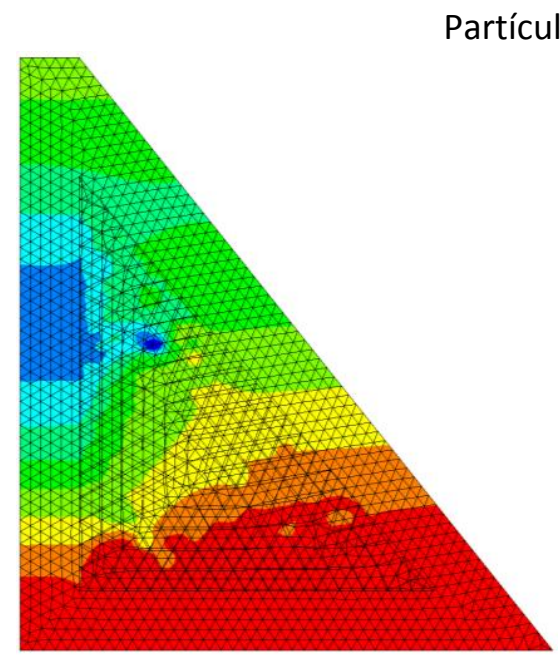

(a)

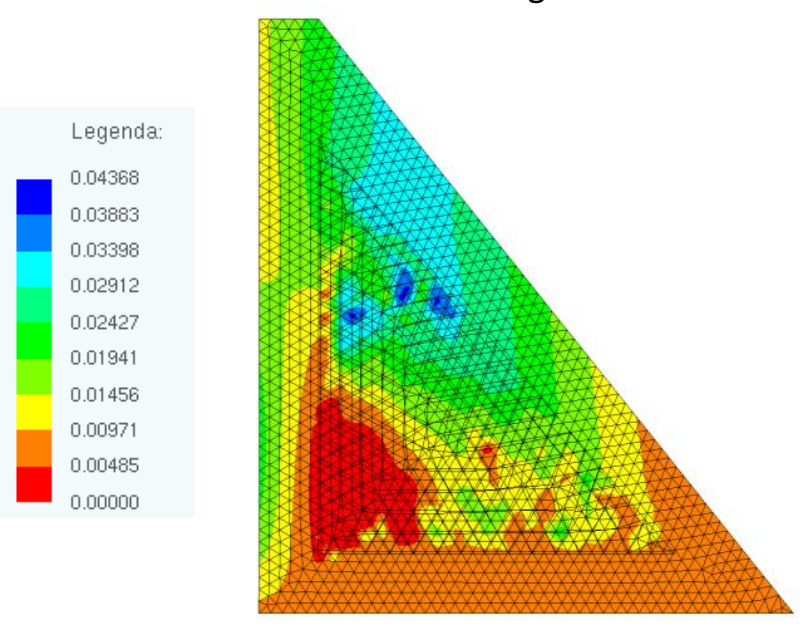

(b) 


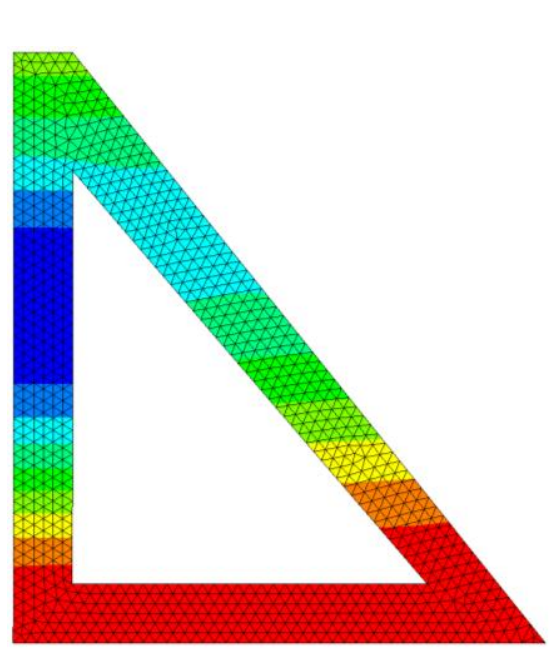

(a)

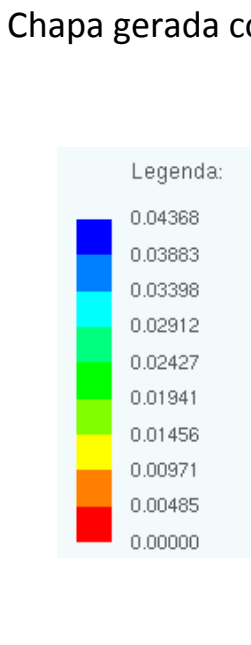

Figura 4.15 - Deslocamentos (a) horizontais e (b) verticais

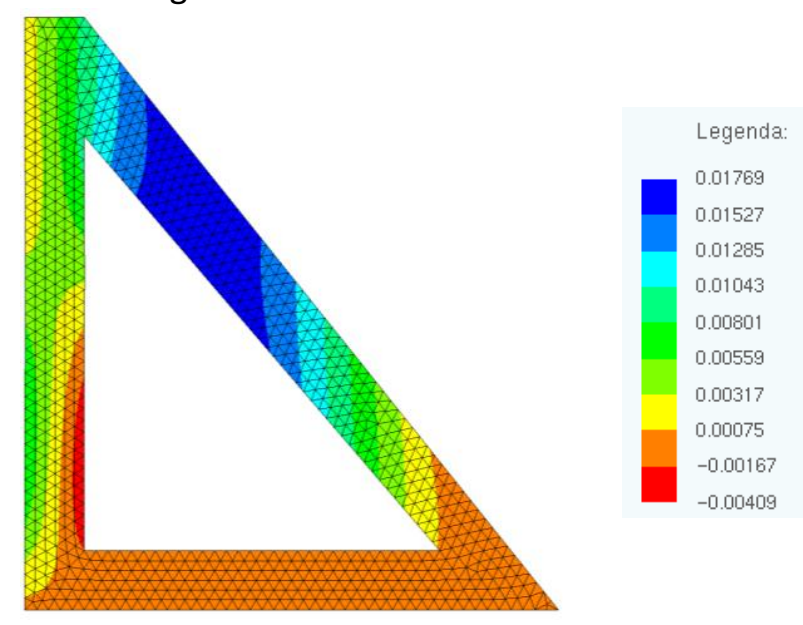

(b) 


\section{CONSIDERAÇÕES FINAIS}

A proposta de aplicação de formulação não linear geométrica baseada no Método dos Elementos Finitos Posicional para análise bidimensional elástica de compósitos particulados sem o aumento dos graus de liberdade do problema foi realizada com sucesso no presente trabalho.

Os resultados obtidos apresentaram boa concordância quando comparados aos obtidos tanto em ensaios experimentais quanto utilizando modelos teóricos e modelos numéricos baseados na técnica de homogeneização por expansão assintótica.

O compósito mais usual na construção civil, o concreto, foi discutido neste estudo e os resultados apresentaram conformidade tanto para concretos leves quanto para concretos de alto desempenho. Modelos considerando células periódicas e estruturas com dimensões e geometrias mais gerais foram simulados com sucesso. No que se refere às células periódicas, a formulação aqui utilizada surge como estratégia alternativa para obtenção de propriedades homogeneizadas de compósitos em vista dos bons resultados obtidos.

A influência que as partículas geram no comportamento macroscópico do conjunto foi discutida, considerando-se para tanto nas análises diferentes geometrias, dimensões, frações volumétricas e propriedades físicas dessas partículas.

As variações nos valores de módulo de elasticidade obtidos nos primeiro e segundo exemplos, para um mesmo concreto, considerando-se diferentes tipos de células periódicas, indicam que tanto a geometria quanto a posição das inclusões nas referidas células podem afetar significativamente os resultados das análises numéricas. Também se deve lembrar que, para as análises realizadas nesses dois exemplos, as contribuições provenientes das variações de tamanho das partículas, bem como do efeito do empacotamento que por ventura venha a ocorrer devido a esta variação de tamanho, não são consideradas no comportamento de modelos baseados em células periódicas.

Mesmo para modelos mais gerais, com geometria e distribuição aleatória para as partículas, os resultados em deslocamentos, obtidos para os modelos, foram satisfatórios, inclusive para consideração da inclusão de vazio no contínuo, caso extremo da relação entre as propriedades físicas da matriz e das partículas. 
De maneira geral, os resultados obtidos com a aplicação da formulação para modelagem de meios contínuos com inclusões de partículas foram todos satisfatórios. Acredita-se também que este trabalho abre possibilidades para novas análises e discussões que venham a se desenvolver nestes temas.

\subsection{Propostas de Trabalhos Futuros}

Como propostas para desenvolvimentos futuros podem ser citados os seguintes temas:

- Tratamento mais adequado para a interface ou zona de transição entre matriz e partículas, fase esta desconsiderada na formulação utilizada na presente pesquisa;

- Análise da distribuição de tensões nas fases do compósito;

- Consideração da não linearidade física das fases que compõem o compósito na formulação;

- Consideração de inclusão de fibras simultaneamente às inclusões de partículas;

- Consideração de compósitos com matrizes diferentes das cimentícias abordadas neste trabalho;

- Verificação do comportamento desses materiais diante da variação de tamanho das partículas em um mesmo modelo, inclusive com análise da influência do empacotamento de partículas nos resultados de propriedades físicas dos compósitos;

- Desenvolvimento de modelo tridimensional para inclusão de partículas; 


\section{REFERÊNCIAS BIBLIOGRÁFICAS}

ABDELGADER, H.S. Stress-Strain Relations and Modulus of Elasticity of Two-Stage Concrete. Journal of Materials in Civil Engineering, v 15, n 4, p 329-334, 2003.

ACADMESH2D: Software Acadêmico para geração de malhas não-estruturadas 2D para modelos de elementos finitos. Versão beta. São Carlos: Departamento de Engenharia de Estruturas, Escola de Engenharia de São Carlos, Universidade de São Paulo, 2012. Disponível em: <http://www.set.eesc.usp.br>

ACADVIEW: Software para pós-processamento em elementos finitos 2D e 3D. Versão 1.0. São Carlos: Departamento de Engenharia de Estruturas, Escola de Engenharia de São Carlos, Universidade de São Paulo, 2005. Disponível em: $<$ http://www.set.eesc.usp.br>

ALLAIRE, G. Homogenization and two-scale convergence. SIAM Journal on Mathematical Analysis, v.23, n.6, p. 1482-1518, 1992.

ALLEN, D.H. Homogenization principles and their application to continuum damage mechanics. Composites Science and Technology, v. 61, p. 2223-2230, 2001.

ANSYS ${ }^{\circledR}$ Multiphysics, Version 12.0.1 [S.1]: ANSYS, Inc, 2009.

ASSAN, A.E. Método dos elementos finitos: primeiros passos. $2^{2}$ edição. Campinas: UNICAMP, 2003. 304 p.

BAALBAKI, W., BENMOKRANE, B., CHAALLAL, O.. Influence of coarse aggregate on elastic properties of high-performance concrete. ACI Materials Journal, v.88, n.5, p. 499-503, 1991.

BAIOCCO, M.H., CODA, H.B., PACCOLA, R.R. A simple way to introduce skeletal muscles by fem. In: 22nd International Congress of Mechanical Engineering COBEM 2013, 2013, Ribeirão Preto - SP. Proceedings of COBEM 2013, 2013.

BARBERO, E.J. Finite element analysis of composite materials. New York: Ed.Taylor \& Francis Group, 2008. 
BARBERO, E.J.; REDDY, J.N. Nonlinear Analysis of composite laminates using a generalized laminated plate theory. AIAA JOURNAL, v.28, n.11, p. 1987-1994, 1990.

BARBOSA, J.I., LOJA, M.A.R., SOARES, C.M.M. A study on the modeling of sandwich functionally graded particulate composites. Composite Structures, v. 94, n. 7, p. 2209-2217, 2012.

BEER, G., WATSON, J.O. Introduction to finite and boundary element methods for engineers. New York: Wiley, 2002.

BESHR, H., ALMUSALLAM, A.A, MASLEHUDDIN, M. Effect of coarse aggregate quality on the mechanical properties of high strength concrete. Construction and Building Materials, v 17, n 2, p 97-103, 2003.

BONET, J., WOOD, R.D. Nonlinear continuum mechanics for finite element analysis. Cambridge University Press, 1997.

BREBBIA C.A., GEORGIOU, P. Combination of boundary and finite elements for elastostatics. Journal Applied Mathematical Modelling, v.3, p. 212-220, 1979.

CALLISTER, W.D. Fundamentals of Materials: Science and Engineering. John Wiley \& Sons, inc., 2001.

CHEN, C.R., QIN, S.Y., LI, S.X., WEN, J.L. Finite element analysis about effects of particle morphology on mechanical response of composites. Materials Science and Engineering A, China, v 278, n 1, p 96-105, 2000.

CIARLET, P.G. Mathematical Elasticity. North-Holland, 1993.

CODA, H.B. Análise da vibração livre de meios elásticos bidimensionais pelo método dos elementos de contorno. Dissertação de Mestrado, SET, Universidade São Paulo, São Carlos, Brasil, 1990.

CODA, H.B. An exact FEM geometric non-linear analysis of frames based on position description. In: XVIII Congresso Brasileiro de Engenharia Mecânica, São Paulo, 2003. 
CODA, H.B. Mecânica dos Materiais e das Estruturas - Notas de Aula. Escola de Engenharia de São Carlos. São Paulo. 2008.

CODA, H.B., GRECO, M. A simple FEM formulation for large deflection 2D frame analysis based on position description. Comput. Methods Appl. Mech. Engrg., v. 193, p. $35413557,2004$.

CODA, H.B., PACCOLA, R.R. A positional FEM formulation for geometrical nonlinear analysis of shells. Latin American Journal of Solids and Structures. 5, p. 205223, 2008.

COOK, R.D., MALKUS, D.S., PLESHA, M.E. Concepts and Applications of Finite Element Analysis. 3.ed. Ed. Jonh Wiley \& Sons, Inc., 1989.

CRISFIELD, M.A. Non-Linear finite element analysis of solids and structures. v.1. England: John Wiley \& Sons, 2000.

CROUCH, L.K., PITT, J., RYAN, H. Aggregate Effects on Pervious Portland Cement Concrete Static Modulus of Elasticity. Journal of Materials in Civil Engineering, v 19, n 7, p 561-568, 2007

CUI, H.Z., LO, T.Y., MEMON, S.A., XU, W. Effect of lightweight aggregates on the mechanical properties and brittleness of lightweight aggregate concrete. Construction and Building Materials, v 35, p 149-158, 2012.

ESHELBY, J.D. The determination of the elastic field of an ellipsoidal inclusion, and related problems. Proceedings of the Royal Society of London Series AMathematical and Physical Sciences, v. 241, n. 1226, p. 376-396, 1957.

ESHELBY, J.D. The determination of the elastic field of an ellipsoidal inclusion, and related problems. Proceedings of the Royal Society of London Series AMathematical and Physical Sciences, v. 252, n. 1271, p. 561-569, 1959.

FARAGE, M.C.R., BEAUCOUR, A.L., BARRA, L.P.S., KE,Y., SANÁBIO, D.F.S., FERREIRA, A.P.G. Multiscale modeling of the elastic moduli of lightweight aggregate concretes: numerical estimation and experimental validation. REM: Revista Escola de Minas, Ouro Preto, v. 62, n. 4, p. 455-462, 2009. 
GUIMARÃES, G.P. Uma formulação de elementos finitos axissimétricos para análise de tubos laminados em materiais compósitos 2006. 120p Dissertação (Mestrado em Mecânica)-Pontifícia Universidade Católica do Rio de Janeiro, Departamento de Engenharia Mecãnica, 2006.

HAN, S.C., TABIEI, A., PARK, W.T. Geometrically nonlinear analysis of laminated composite thin shells using a modified first-order shear deformable element-based Lagrangian shell element. Composite Structures, v.82, n.3, p. 465-474, 2008.

HASHIN, Z. Analysis of composite materials - A survey. Journal of Applied Mechanics, v. 50, n. xxv, xxvii, 7, 16, p. 481-505, 1983.

HASHIN, Z., SHTRIKMAN, S.A. variational approach to the theory of the elastic behaviour of multiphase materials. Journal of the Mechanics and Physics of Solids, v.11, n.2, p. 127-140, 1963.

HERAKOVICH, C.T. Mechanics of composites: A historical review. Mechanics Research Communication, v.41, p 1-20, 2012.

HERAKOVICH, C.T. (1998). Mechanics of fibrous composites. John Wiley \& Sons, Inc., 1998.

HILL, R.A. self-consistent mechanics of composite materials. Journal of the Mechanics and Physics of Solids, v. 13, n.4, p.213-222, 1965.

HOLZAPFEL, G.A. Nonlinear Solid Mechanics: A Continuum Approach for Engineering. Ed. John Wiley \& Sons Ltd, 2004.

KE, Y., BEAUCOUR, A.L., ORTOLA, S., DUMONTET, H., CABRILLAC, R. Influence of volume fraction and characteristics of lightweight aggregates on the mechanical properties of concrete. Construction and Building Materials, v 23, n 8, p 2821-2828, 2009.

KLISZCZEWICZ, A., AJDUKIEWICZ, A. Differences in instantaneous deformability of HS/HPC according to the kind of coarse aggregate. Cement and Concrete Composites, v 24, n 2, p 263-267, 2002. 
LI, S., LIU, W.K. Meshfree and particle methods and their applications. Applied Mechanics Reviews- ASME DC, v. 55, n. 1, p. 1-34, 2002.

LUENBERGER, D. G. Linear and nonlinear programming. Addison-Wesley Publishing Company, 1989

MACIEL, D.N. Análise de problemas elásticos não lineares geométricos

empregando o método dos elementos finitos posicional. Tese de doutorado - Escola de Engenharia de São Carlos, Universidade de São Paulo, São Carlos, 2008.

MARQUES, G.C.S.C. Estudo e desenvolvimento de código computacional baseado no MEF para análise dinâmica não linear geométrica de sólidos bidimensionais. Dissertação de mestrado - Escola de Engenharia de São Carlos, Universidade de São Paulo, São Carlos, 2006.

MENDONÇA, P. de T.R. Materiais compostos e estruturas-sanduíche: projeto e análise, Ed. Manole, Barueri, SP, 2005.

MEHTA, P. K., MONTEIRO, P.J.M. Concreto: estrutura, propriedades e materiais. 1 ed. São Paulo: Pini, 573 p, 2008.

MICHEL, J.; MOULINEC, H.; SUQUET, P. Effective properties of composite materials with periodic microstructure: a computational approach. Comput. Methods Appl. Mech. Engrg, v. 172, p. 109-143, 1999.

MILTON, G. W. The Theory of Composites. Cambridge: Cambridge University Press (Cambridge Monographs on Applied and Computational Mathematics), 2004.

MORI, T., TANAKA, K. Average Stress in matrix and average elastic energy of materials with misfitting inclusions. ACTA Metallurgia, v.21, n.5, p. 571-574, 1973

NAKASONE, Y., NISHIYAMA, H., NOJIRI, T. Numerical equivalent inclusion method: a new computational method for analyzing stress fields in and around inclusions of various shapes. Materials Science and Engineering A, Japan, v 285, n 1, p 229-238, 2000. 
NOGUEIRA, G.V., SAMPAIO, M, do S.M., PACCOLA, R.R. ; CODA, H.B. Consideração do deslizamento na análise de sólidos elásticos bidimensionais reforçados por fibras através do método dos elementos finitos posicional. In: XXXV Ibero-Latin American Congress on Computational Methods in Engineering CILAMCE 2014, 2014, Fortaleza - CE - Brasil. Proceedings of CILAMCE 2014, 2014.

OGDEN, R.W. Non-linear Elastic Deformations. Chichester, England: Ellis Horwood Ltda., 1984.

PACCOLA, R.R., CODA, H.B., VANALLI, L. A simple way to introduce fibers into FEM models. Comunications in Numerical Methods in Engineering, v.24, n.7, p. 585603, 2008.

PAIVA, J.B.D. Introdução ao método dos elementos finitos. Capítulo 4 (Método dos elementos finitos - placas) São Carlos, SP: Notas de Aula, 2012.

PALMQUIST, S.M., JANSEN, D.C., SWAN, C.W. Compressive behavior of concrete with vitrified soil aggregate. Journal of Materials in Civil Engineering, v 13, n 5, p 389394, 2001.

PASCON, J.P. Modelos constitutivos para materiais hiperelásticos: estudo e implementação computacional. Dissertação (Mestrado) - Departamento de Engenharia de Estruturas, Escola de Engenharia de São Carlos, Universidade de São Paulo, São Carlos, 2008.

PETYT, M., HAN, W.M., HSIAO, K.M. An investigation into geometrically NonlinearAnalysis of Rectangular Laminated Plate using the hierarchical finite element method. In: INTERNATIONAL CONFERENCE ON COMPUTATIONALMETHODS IN ENGINEERING (ICCME), 93, 1992, Singapore.Anais, p. 273-288, 1994.

PRADO, E.B.T. Utilização de métodos computacional e de homogeneização na investigação do comportamento elástico não linear de laminados. 2013. Tese (Doutorado em engenharia de Estruturas) - Escola de Engenharia de São Carlos, Universidade de São Paulo, São Carlos, 2013. 
RADTKE, F.K.F., SIMONE, A., SLUYS, L.J. A partition of unity finite element method for simulating non-linear debonding and matrix failure in thin fiber composites. International Journal for Numerical Methods in Engineering, p. 86:453-476, 2011.

REDDY, J.N. Mechanics of laminated composite plates and shells: theory and analysis. Second edition. [S.I.]: CRC (CRC Mechanical Engineering Series Press), 2004.

ROSLER, J., HARDERS H., BAKER, M. Mechanical Behaviour of Engineering Materials: Metals, Ceramics, Polymers, and Composites. Berlin: Ed. Springer-Verlag, Heidelberg, 2007.

SAMPAIO, M.S.M. Análise não linear geométrica de cascas laminadas reforçadas com fibras. 2014. Tese (Doutorado em engenharia de Estruturas) - Escola de Engenharia de São Carlos, Universidade de São Paulo, São Carlos, 2014.

SAMPAIO, M.S.M., CODA, H.B., PACCOLA, R.R. Análise não linear geométrica de sólidos elásticos bidimensionais reforçados com fibras via MEF. Cadernos de Engenharia de Estruturas, v. 13, n. 59, p. 59-62, 2011. Edição Especial ENDOSET 2011. ISSN: 1809-5860.

SORIANO, H.L. Método dos elementos finitos em análise de estruturas. São Paulo: EDUSP, 2003.

TAUCHERT, T.R. Energy principles in structural mechanics. McGraw Hill, 1974.

TOULEMONDE, C., MASSON, R., GHARIB, J.E. Modeling the effective elastic behavior of composites: a mixed finite element and homogenisation approach. $\mathrm{C}$. R. Mecanique, v. 336, p. 275-282, 2008.

TU, Z, LU, Y. Mesoscale modelling of concrete for static and dynamic response analysis - Part 1: model development and implementation. Structural Engineering and Mechanics, v 37, n 2, p 197-213, 2011 .

TU, Z, LU, Y. Mesoscale modelling of concrete for static and dynamic response analysis - Part 2: numerical investigation. Structural Engineering and Mechanics, $v$ 37, n 2, p 215-231, 2011b. 
VAN MIER, J.G.M. Fracture processes of concretes: assessment of material parameters for facture models, v.1. NW: CRC Press, 1997.

VANALLI, L. O MEC e o MEF aplicados à análise de problemas viscoplásticos em meios anisotrópicos e compostos. Tese (Doutorado) - Escola de Engenharia de São Carlos, Universidade de São Paulo. São Carlos. 2004.

VASILIEV, V.V., MOROZOV, E.V. Mechanics and Analysis of Composite Materials. Elsevier Science Ltd. UK. 2001.

VENTURINI, W.S., LEITE, L.G.S. Boundary element formulation for 2D solids with stiff and soft thin inclusions. Engineering analysis with boundary elements, v. 29, n.3, p. $257-267,2005$

WANG, Z.M., KWAN, A.K.H., CHAN, H.C. Mesoscopic study of concrete I: generation of random aggregate structure and finite element mesh. Computers \& Structures, v.70, n.5, p. 533-544, 1999a.

WANG, Z.M., KWAN, A.K.H., CHAN, H.C. Mesoscopic study of concrete II: nonlinear finite element analysis. Computers \& Structures, v.70, n.5, p. 545-556, 1999b.

WU, K., CHEN, B., YAO, W., ZHANG, D. Effect of coarse aggregate type on mechanical properties of high-performance concrete. Cement and Concrete Research, v 31, n 10, p 1421-1425, 2001.

YANG, C.C., HUANG, R., YEIH, W., SUE, I.C. Aggregate effect on elastic moduli of cement-based composite materials. Journal of Marine Science and Technology, v. 3, n.1, p. 5-10, 1995.

YANG, C.C., HUANG, R. Double inclusion model for approximate elastic moduli of concrete material. Cement and Concrete Research, v.26, n.1, p. 83-91, 1996.

ZAITSEV, Y.B., WITTMANN, F.H. Simulation of crack propagation and failure of concrete. Matériaux et Construction, v.14, n.5, p. 357-365, 1981.

ZHANG, Y.X., YANG, C.H. A family of simple and robust finite elements for linearand geometrically nonlinear analysis of laminated composite plates. In: International 
Conference on Composite Structures, 13, 2005. Australia. Anais, v.75, n.1-4, p. 545552, 2006.

ZHOU, F.P., LYDON, F.D., BARR, B.I.G. Effect of coarse aggregate on elastic Modulus and Compressive Strength of High Performance Concrete. Cement and Concrete Research, v 25, n.1, p. 177-186, 1995.

ZIENKIEWICZ, O.C., KELLY, D.M., BETTESS, P. The coupling of the finite element method and boundary solution procedures. International Journal for Numerical Methods in Engineering, v.11, p. 355-376, 1977.

ZIENKIEWICZ, O.C., TAYLOR, R.L., ZHU, J.Z. The finite element method: its basis \& fundamentals. Ed. Butterworth-Heinemann, Massachusetts, 2013. 